Technical and Economic

Parameters Affecting Fast

Breeder Reactor Deployment

F. A. O'Hara

September 13, 1971

AEC Research and Development Report

Monsanto

\section{MOUND LABORATORY}

Miamisburg, Ohio

operated by

MONSANTO RESEARCH CORPORATION a subsidiary of Monsanto Company

for the

U. S. ATOMIC ENERGY COMMISSION

U. S. Government Contract No. AT-33-1-GEN-53 


\section{DISCLAIMER}

This report was prepared as an account of work sponsored by an agency of the United States Government. Neither the United States Government nor any agency Thereof, nor any of their employees, makes any warranty, express or implied, or assumes any legal liability or responsibility for the accuracy, completeness, or usefulness of any information, apparatus, product, or process disclosed, or represents that its use would not infringe privately owned rights. Reference herein to any specific commercial product, process, or service by trade name, trademark, manufacturer, or otherwise does not necessarily constitute or imply its endorsement, recommendation, or favoring by the United States Government or any agency thereof. The views and opinions of authors expressed herein do not necessarily state or reflect those of the United States Government or any agency thereof. 


\section{DISCLAIMER}

Portions of this document may be illegible in electronic image products. Images are produced from the best available original document. 
$\bullet$
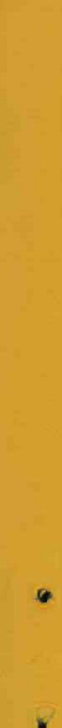


\title{
Technical and Economic Parameters Affecting Fast Breeder Reactor Deployment
}

\author{
F. A. O'Hara
}

Issued: September 13, 1971

A thesis subritted to the college

of Engineering of the University

of Cincinnati, Cincinnati, Ohio,

in partial fulfillment of the re-

quirements for the degree of

Doctor of Philosophy.

\section{TNOTICE}

This report was prepared as an account of work sponsored by the Unved States Government Neither the United States nor the United States Atormic Energy Com

mission, nor any of their employees, nor any of their contractors, subcontractors,

or their employees, makes any worranty, express or implied, or assumes any lega

liability or responsibility for the accuracy, completeness or usefulness of any

information, apporatus, product or process disclosed, or represents that its use

would not infringe privotely owned rights

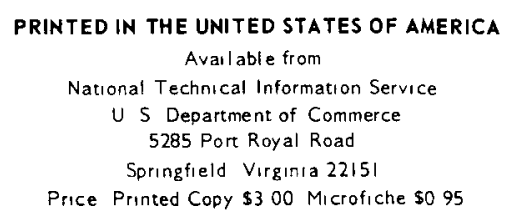

MONSANTO RESEARCH CORPORATION

A Subsidiary of Monsanto Company

MOUND LABORATORY

Miamisburg, Ohio

45342

operated for

\section{UNITED STATES ATOMIC ENERGY COMMISSION}

U S Government Contract No AT-33-1-GEN 53 
TECHNICAL AND ECONOMIC PARAMETERS AFFECTING

FAST BREEDER REACTOR DEPLOYMENT

\section{ABSTRACT}

The effects of various technical and economic parameters on LMFBR deployment plans have been studied to assess the best future "mix" of light water reactors and fast breeder reactors which will result in minimum cumulative nuclear generating costs discounted to the year 1985. Projected growth in domestic nuclear generating capacity was taken from various predictions $[19,20,21]$, and the future domestic nuclear generating capacity was assumed to consist only of light water reactors and liquid metal cooled fast breeder reactors. Technical characteristics representing the two reactor types were taken as fixed, typical values for this study. The 1 ight water reactor characteristics represent a composite between PWRs and BWRs, whereas the most recent follow-on design was used as the reference for LMFBRs. Annual domestic power generation costs are calculated as a function of the installed capacity of both light water and fast breeder reactors in each particular year, the unit costs of each reactor type, the load factor, plutonium requirements, plutonium price 
and discount rate, and other factors. The cumulative nuclear generating costs are then computed as the sum of the discounted annual costs.

Future variations in plant capital costs and incremental changes in fuel cycle costs for the two respective reactor types govern the ideal time scale for introduction of LMFBRs. Using published predictions concerning future variations in these unit charges $[41,42,43]$ and assuming unlimited supplies of plutonium, the economically desirable, most rapid growth rate of breeder capacity can be determined. When other economic factors are held constant, the price of plutonium then dominates both the economically ideal introduction date for breeders and the rate growth of installed FBR capacity.

It may not be possible to achieve this economically ideal FBR deployment plan for various practical reasons including a scarcity of plutonium. This necessitates formulation of workable strategies so that the breeder deployment may approach, as nearly as possible, the ideal minimum cumulative nuclear generating costs. 
TABLE OF CONTENTS

ABSTRACT . . . . . . . . . . . . . . . . . $i i$

ACKNOWLEDGMENTS . . . . . . . . . . . . . . . . vi

TABLE OF CONTENTS . . . . . . . . . . . . . . . viii

LIST OF FIGURES. . . . . . . . . . . . . . . . . . xi

LIST OF TABLES . . . . . . . . . . . . . . . . . xiv

INTRODUCTION . . . . . . . . . . . . . . . . . . 1

The Problem . . . . . . . . . . . . . . . 1

Background and Previous Work . . . . . . . 4 Nuclear Growth Rate . . . . . . . . . 7

Plutonium . . . . . . . . . . . . . . . . 11

Fast Breeder Reactors and Plutonium . . . 12

Light water Reactors and Plutonium . . . 18

Choice Purely on the Basis of Economics . . . . . 20

Technological Limitations to the Economic Choice. 22

Objective . . . . . . . . . . . . . . . 23

MODEL OF THE NUCLEAR GENERATING INDUSTRY . . . . . . 26

Typica1 Light Water Reactor . . . . . . . 27

Typical Fast Breeder Reactor . . . . . . . 31 
Assumptions for Economic Analysis . . . . . . . .39

Determination of Plutonium Requirement . . . .42

Determination of Energy Costs . . . . . . . .44

Determination of Economic Ideal . . . . . .48

DISCUSSION OF VARIABLES AFFECTING MINIMUM GENERATING COSTS. . . . . . . . . . . . . . . . . . . . 51

Nuclear Parameters Affecting Generating Costs . . .52

Fast Breeder Reactor Plutonium Requirement . .52

Fast Breeder Reactor Plutonium Production . .53

Light Water Reactor Plutonium Production . . .56

Light Water Reactor Plutonium Requirement . .58

Plutonium Value. . . . . . . . . . .59

Non-Nuclear Factors Affecting Nuclear Generating

Costs... . . . . . . . . . . . . . .67

Capital Costs . . . . . . . . . . . .68

Operating, Maintenance, and Insurance Costs .69

Bases for Fuel Cycle Cost . . . . . . . .71

Discount Rate. . . . . . . . . . . 75

RESULTS . . . . . . . . . . . . . . . . 85

Effect of Nuclear Generating Capacity and

Capital Case . . . . . . . . . . . . . 87

Effect of Plutonium Price . . . . . . . . . . . .93

Effect of Plutonium Utilization . . . . . . . . .99 
Effects of Reactor Variables and Losses . . . . . . 103 Effect of Ex-core Inventory . . . . . . . . . .110 Effect of Discount Rate . . . . . . . . . . . 112 Recapitulation. . . . . . . . . . . . . . . 114

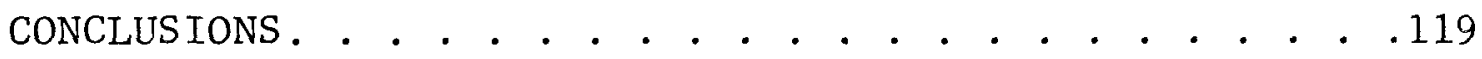
IMPLICATIONS OF CONCLUSIONS . . . . • • • • . . . . . 124 FUTURE WORK . . . . . . . . . . . . . . . . . . . 127 REFERENCES . • . . . . . . . . . . . . • . . . . . . 129 APPENDIX I: FURTHER DESCRIPTION OF LIGHT WATER REACTOR.137 APPENDIX II: FURTHER DESCRIPTION OF FAST BREEDER REACTOR . . . . . . . . . . . . . . . . . . . . . . APPENDIX III: LISTING OF COMPUTER PROGRAM MIN-E-COST. . 160 


\section{LIST OF FIGURES}

Number

Title

$\underline{\text { Page }}$

1 Projection of Domestic Electrical

8

Generating Demand and Capacity

2

Estimated Installed Nuclear Capacity

9

3

Light Water Reactor Feed and Discharge

30

Uranium Enrichment Versus Fuel Exposure

4

Plutonium Concentration in Light Water

Reactor Discharged Fuel as a Function

of Discharge Fue1 Exposure

5

Flow Diagram of Annual Calculations to

Determine Preferred Achievable Breeder Mix and Costs

6

Annual Plutonium Production, Requirements, and Balance for Fastest Breeder Growth Rate Following 1985 Introduction

7 Contradistinctive Prognoses of Future Plutonium Worth

8 Potential Range of Future Capital Costs

for Light Water and Fast Breeder Reactors

Estimated Future Operating, Maintenance, and Insurance Costs for Light Water and Fast Breeder Reactors

An Appraisal of Future Unit Energy Costs

of Light Water and Fast Breeder Reactors at a Plutonium Price of $\$ 0 / \mathrm{g}$

11 Variation in Light water and Fast Breeder

Reactor Fuel Cycle and Unit Energy Costs for Particular Plutonium Prices 


\section{LIST OF FIGURES (CONTINUED)}

Number

12

13

14

18
Title

Page

iloo on Discount Rate for Years in the Future

Cumulative Idea 1 Generating Costs in

Future Years as Affected by Generating Capacity Estimates and Capital Case

Fraction Versus Time for Two Nuclear Capacity Estimates

Unit Energy and Annual Generating Costs

in the Year 1985 as a Function of

Plutonium Price for Various LWR-FBR

Mixes of Capital Case C

Dependence of Introduction Date and

Ideal Breeder Reactor Fraction on

Plutonium Price for Capital Case D

Added Nuclear Generating Costs (to the

Year 2010) as a Function of Plutonium

Price for the Various Capital Cases

Added Nuclear Generating Costs (to the Year 2010) for Extreme Plutonium Utilization Schemes and Representative Plutonium Prices

Added Nuclear Generating Costs (to the year 2010) as a Function of Discharge Plutonium Concentration for Various Plutonium Prices

Changes in Added Nuclear Generating from Losses with Plutonium Price as a Parameter 
LIST OF FIGURES (CONTINUED)

Number

21

22

23

24

25

26

27
Tit $1 \mathrm{e}$

Page

109 Generating Costs and the Fast Breeder Reactor Fraction due to FBR Specific Inventory

Effect of Discount Rate on the Added Nuclear Generating Costs (to the Year 2010) with Plutonium Price as a Parameter

Forecast of Future Plutonium Price Limited by Supply-Demand and Market Constraints

Horizonta1 Cross-Sectional Diagram of LWR Fuel Assembly and CruciformShaped Control Rod (after ORNL-3686)

Horizontal Cross-Sectional Diagram of LMFBR Core and Blankets (after AI-12792)

Typical LMFBR Fuel $P$ in and Element Design (after AI-68-Memo-37, Vol. I)

Vertica1 Cross Section of LMFBR Core Showing Fuel Regions and Dimensions 


\section{LIST OF TABLES}

Number

Title

Page

I Neutronic Properties of Mixed Oxide

13

Fue1s

II

Partial Description of Typical Light

Water Reactor

III Partial Description of Assumed First Generation LMFBR

IV FBR Isotopic Mass Balance for Equi-

librium Cycle

V Conditions for Competitive LWR-FBR

90

Unit Energy Costs

VI Effect of Ex-core Inventory on Capital

Case II-D

VII Interdependence of Plutonium Price and

Other Important Parameters on Cumulative Generating Costs

VIII Description of Typical Light Water Reactor

IX

Description of Assumed First Generation LMFBR 


\section{INTRODUCTION}

The Problem

The advent of the fast breeder reactor has long been heralded as the potential salvation for the ills that plague mankind in its attempt to find adequate energy resources. In fact, the fast breeder reactor appears to be precisely what man has been forever seeking - something for nothing. It has been suggested that in a fast breeder reactor man will use "cheap" and plentiful potential fue 1 in the form of natural uranium, along with some plutonium, to produce energy while at the same time increasing the quantity of valuable plutonium. All this might be accomplished in an economic structure such that the net fuel cycle costs could be negative, and the overall energy generation costs would be so low that abundant power would be affordable by a11. Not only may it be possible to produce enough electrical power to satisfy contemporary needs; but because of the unique "breeding" characteristic of this form of power generation, the amount of plutonium will increase ultimately doubling at a faster rate than the demand for electricity and, thereby, assuring sufficient supplies of energy for all man's needs. 
This optimistic expectation is contingent upon only two factors: the development, introduction and use of nuclear reactions which will operate in such a manner; and the availability of sufficient plutonium in order to initially charge these reactors and to refuel them. The development of such reactors is being pursued through the United States Atomic Energy Commission's Liquid Metal Fast Breeder Reactor (LMFBR) Program. The second factor, assurance of sufficient plutonium to fuel these reactors, is examined in this dissertation. Plutonium availability is affected by the technological (non-nuclear as well as nuclear) and the economic climate, both of which contribute certain parameters which influence the availability of this relatively new element.

The object of this work is to determine, for a nuclear electrical generating system consisting solely of light water reactors and fast breeder reactors, the discounted minimum nuclear generating costs over the next several decades. In order to determine this, it will be necessary to identify the parameters which influence these costs, as we11 as the values which these parameters must assume, in order to combine to produce a minimum. The method that has 
been employed to define this minimum involved the development of a model of the domestic nuclear generating system in order to ascertain the total nuclear generating costs. The costs for each combination of parameters were calculated and compared to one another by determining the additional costs incurred above an ideal. The ideal is defined solely on the basis of parameters which give the minimum costs each year even though the parameters may not be compatible from year to year (i.e., ideal capacity may switch from all light water reactors one year to all breeders the next) and, therefore, would not be realistic. Once the most desirable parameter combination (having attainable costs nearest the ideal) has been identified, policies may be formulated which contribute to the development of this parameter combination and ultimately to the achievement of minimum generating costs.

Some may regard it as premature to consider potential problems which may not arise for 15-25 years. One must realize, however, that: (1) Experience has shown that approximately 20 years is required for new nuclear reactor concepts to become commercially viable; (2) The anticipated lives of present and foreseen nuclear systems is 
thirty years or more; (3) Utility planning must be forecast long in advance (For utility planning, it is already the year 1978); and (4) The interval between the present and the LMFBR introduction date provides sufficient time to implement any schemes that may be required to approach the desirable minimum nuclear generating cost. Therefore, it is not on $1 \mathrm{y}$ reasonable to conduct such a study at the present time, it is necessary to do so.

Background and Previous Work

Breeder reactors are of fundamental importance because they will utilize precious natural resources much more efficiently than presently installed burner (or consumer) reactors. The raw material which is required as feed for a breeder reactor consists of plentiful natura 1 or depleted uranium as opposed to the costly enriched uranium required in today's reactors. The use of fast breeder reactors makes possible energy production per unit weight of mined uranium about 50 times greater than that achievable in present types of reactors [1]. 
The real key to low cost power and sufficient power lies not in the extent of our fuel deposits, but rather in how we11 the resources are utilized. The reserves of coal, oil, and gas in this country will be more precious in the long term as sources of organic molecules than as sources of heat [2]. As for nuclear energy sources, as long as the fission process is utilized, ultimate depletion of our uranium deposits is inevitable without the breeder [3].

There has been, in the past, considerable interest in the analysis of a nuclear power program consisting of a variety of reactor types $[4,5,6]$. Iliffe [7] and others [8] have even made analyses of reactors as portions of a total electrical generating system. Many of these investigations have considered the effect of economics but have been primarily oriented toward a specific task such as Eschbach's determination of the value of plutonium in specific reactors [9] or to project the future value which it might assume under different circumstances $[10,11]$. 
In this country, when considerations of different reactor types have been appraised, any savings have generally been expressed in terms of energy or resources such as less uranium ore consumed or fewer units of separative work required $[12,13,14]$. This type of expression is understandable and, for a comparison of similar technologies, good in that a better physical description can be obtained. However, expressing savings in such terms is useless when comparisons to dissimilar technologies or even different fields of endeavor (social priorities, for instance) are desired.

Two domestic studies which have considered the economics of breeder reactors have done so on the basis of costbenefit analysis $[15,16]$. While cost-benefit analyses are useful for deciding between projects which have the same end, this type of treatment will not produce results which can be compared to other unrelated topics. It, therefore, seems imperative that an analysis be made of a mixed reactor program that yields results in terms of net dollars saved and, by so doing, is able to determine the time-dependence of the parameters necessary to approach, as nearly as possible, the most desirable economic consequence. 


\section{Nuclear Growth Rate}

Since 1900 , the demand for electrical energy has increased by a factor of two every ten years (ten year doubling time) in the United States [17]. This same rate of increase is projected for the near future, at least (cf. Figure 1). This requires the installation of new electrical generation capacity sufficient to satisfy the projected demand plus provisions for some degree of reserve power. The kinds and amounts of generating capabilities that satisfy the electrical demand are also shown in Figure 1. Today nuclear power has become an accepted means of power generation. As the most prominent fuel of the near future, it will capture an increasing $1 \mathrm{y}$ greater proportion of the installed electric generating capacity for economic reasons.

The extent to which nuclear power will be utilized was projected by the AEC in its 1962 Report to the President [18] (see Curve A of Figure 2). This estimate was updated in the 1967 Supplement of this report [19] as shown in Curve B of Figure 2. Since that date, more optimistic predictions of the fraction of installed generating capacity that will be nuclear have appeared based on the burgeoning number of nuclear generating 


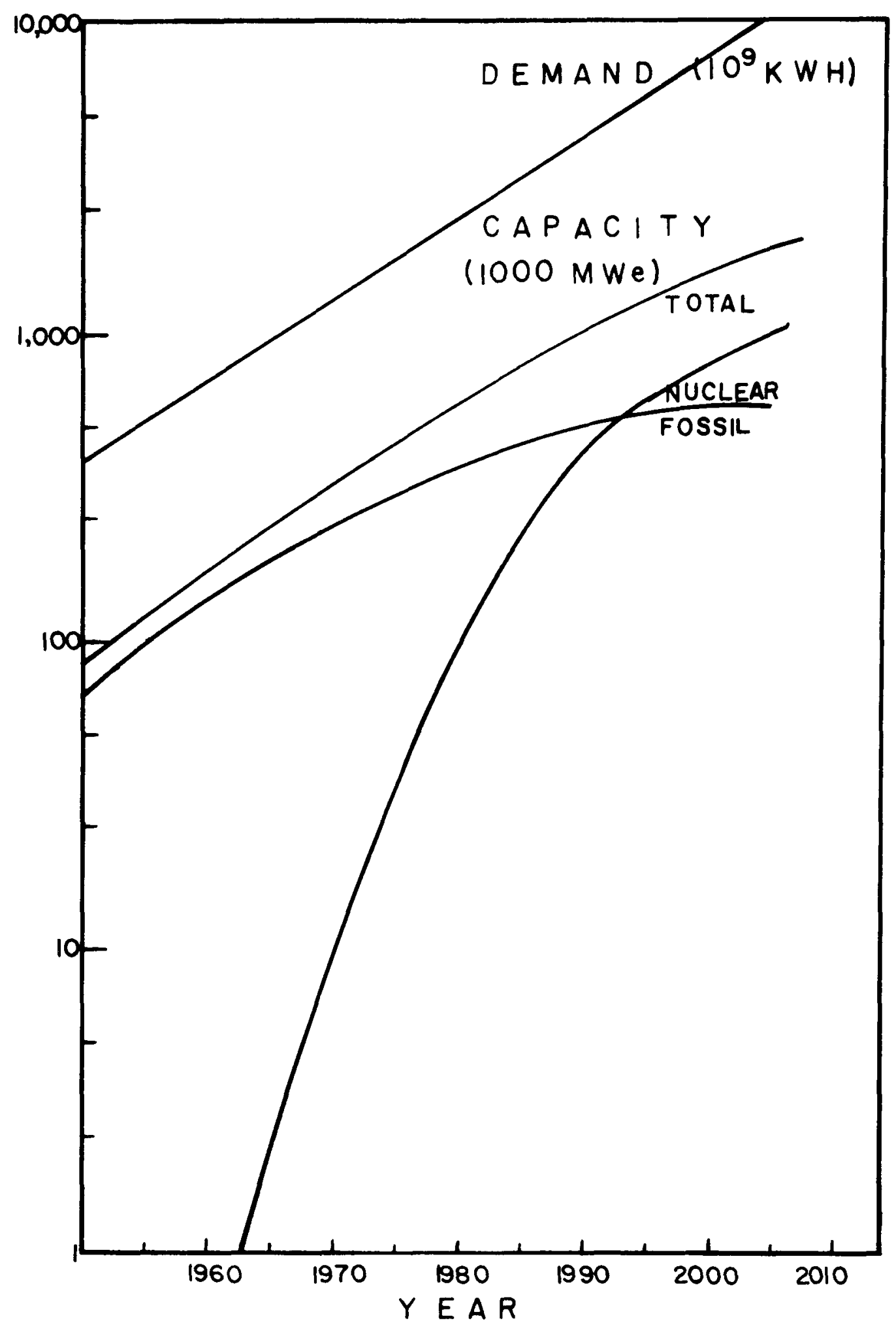

Figure 1: Projection of Domestic Electrical Generating Demand and Capacity 


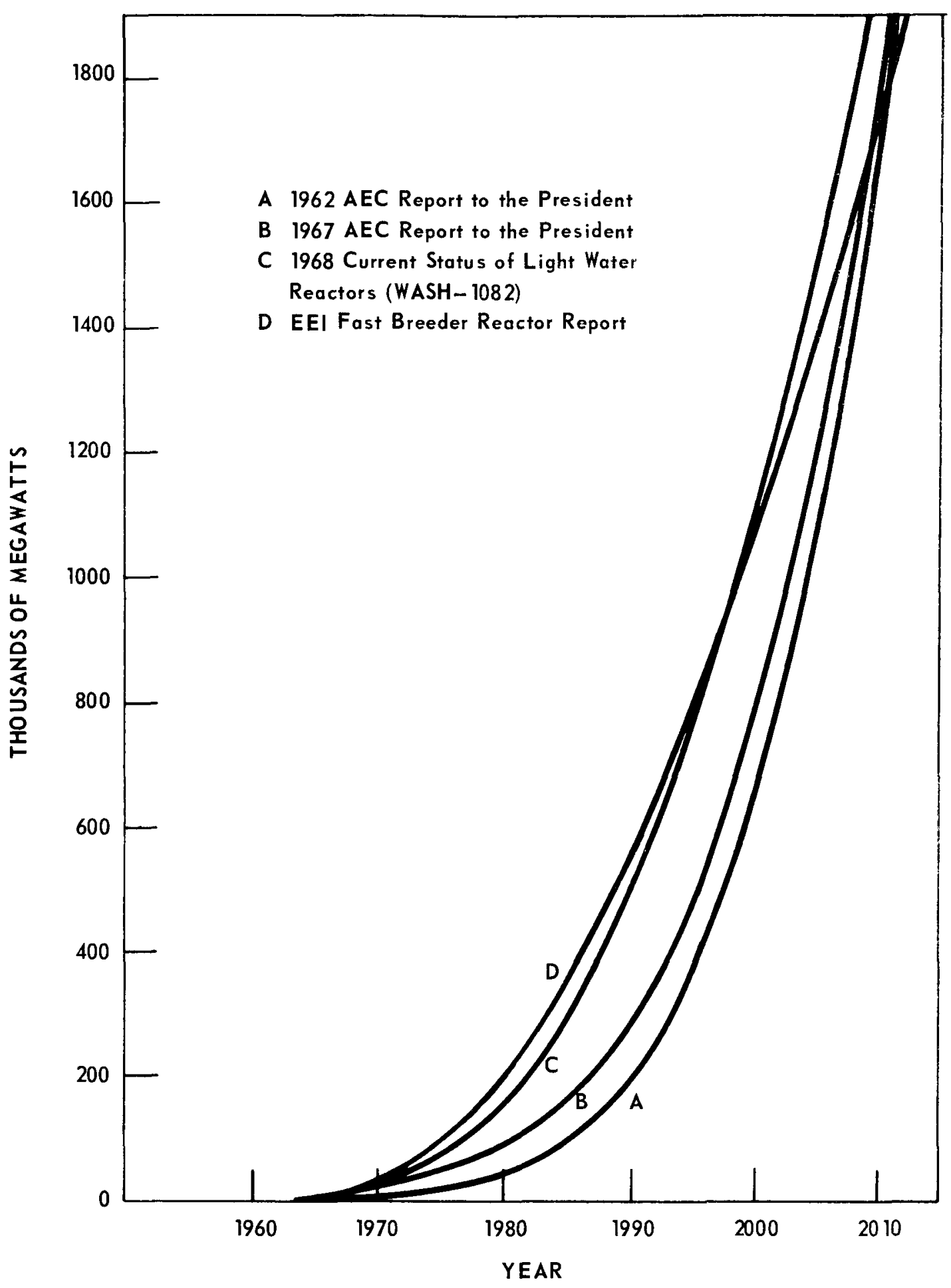

Figure 2: Estimated Installed Nuclear Capacity 
plants that were ordered during the years 1967 and $1968[20,21]$. The rate of increase of these estimates indicates an installed nuclear capacity of 150,000 Mw(e) in 1980 and suggests the nuclear capacity will approach 2,000,000 Mw(e) by the year 2010 (see Curves C, D of Figure 2). The rate of nuclear plant sales in the intervening three years have not borne out such optimistic estimates due mainly to increasing nuclear plant costs, a veritable saturation of the manufacturers' facilities, nuclear plant licensing delays and frequent and more heightened attacks on nuclear power by environmentalists urging a slowdown in power production in general, and nuclear plant construction in particular. Nevertheless, some industry sources, arguing on the basis of pure economics, hold fast to the 1980 projection [22] while others take a more conservative viewpoint based on the factors mentioned which tend to support the earlier estimates [23]. In light of these factors, it appears reasonable to assume that the installed nuclear capacity until 1985 will be in the region' bounded by the 1967 AEC Report and later projections. Should the economic, technical, and political factors combine to achieve the more recent 1980 projections, the current estimates for 
the year 2000 could certainly be considered reasonable.

For the purposes of this study, it will be assumed that the nuclear generating capacity is composed solely of light water reactors and fast breeder reactors. Although there is presently minor support for other reactor concepts, the bulk of the commercial and AEC funding and interest seems to lie with these two reactor types.

\section{$\underline{\text { Plutonium }}$}

Whenever a quantity of natural or slightly enriched uranium is fissioned, some plutonium is produced by neutron absorption in ${ }^{238} \mathrm{U}$. The net amount of plutonium produced is dependent upon a great many factors. The most fundamental factor is the average energy of the neutron energy distribution (spectrum) in the reactor which governs the relative magnitude of the rates of production and consumption of plutonium. Since most materials have a lower cross section (probability of interaction) at higher neutron energies (a "fast" neutron energy distribution) than at "thermal" energies (neutrons in thermal equilibrium with surrounding media), the absorption tends to be a smaller portion of the total neutron interactions in a fast breeder. Also the number of neutrons produced per neutron absorbed ( $\eta$ ) tends to be higher at higher energies. A higher energy 
neutron spectrum, as well as the degree of fuel burnup, tends to produce a more desirable isotopic composition of the product plutonium. These factors all contribute to the fast reactor being preferred for the production and utilization of plutonium. Table I indicates some of the important parameters associated with plutonium production and consumption for various average neutron energies.

The plutonium produced may be utilized or "burned" in the reactor in which it has been produced or in some other reactor. If in the same reactor, the plutonium may be burned in situ which has the economic benefit of not requiring reprocessing. However, the amount of material that can be efficiently burned in situ is limited, so that it may be preferable to recycle the plutonium in new fuel elements. If the recycled plutonium is to be used in a different reactor, this may be or may not be of the same type as the original.

\section{Fast Breeder Reactors and Plutonium}

Fast reactors are fueled with plutonium mixed with natural uranium in the ratio $1: 3$ or $1: 4$. Since they produce more plutonium than they consume, such reactors are known as "breeders". A useful figure of merit of a breeder is the amount of time required for a given reactor 
TABLE I

NEUTRONIC PROPERTIES OF MIXED OXIDE FUEL

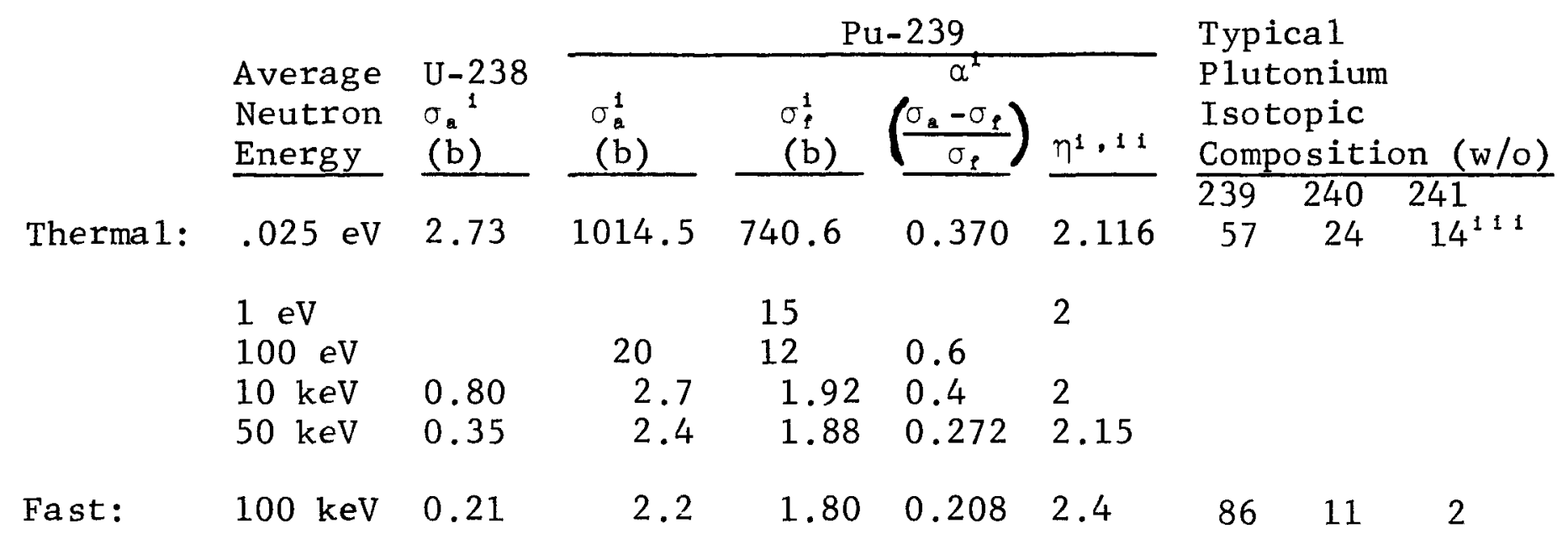

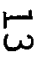

i BNL-325 (1965)

ii J. Lamarsh, Nuclear Reactor Theory, p. 112 (1966)

iii J. B. Rol1, "Commercial Plutonium Recycle", Power Engineering, p. 34, (November, 1970) 
to produce sufficient plutonium to yield excess plutonium in an amount equal to its initial plutonium inventory, thus permitting a doubling of the installed capacity. The "doubling time" is directly proportional to the specific inventory requirements of the reactor and inversely a function of the breeding ratio.

Specific inventory (the reciprocal of specific power) is defined as the ratio: Quantity of fissile inventory per unit electrical or thermal power ( $\mathrm{kg} / \mathrm{Mw}$ or $\mathrm{g} / \mathrm{kW}$ ). The specific inventory, although usually considered as a whole, can be divided into in-core specific inventory (amount in the reactor at any time) and ex-core specific inventory (amount cooling, in reprocessing, fabrication, shipment or storage at any time). Generally, ex-core inventories can increase the total specific inventory by $50 \%$ or greater [24]. The decrease in cross section with neutron energy requires that in order to produce a given amount of power, the fissile specific inventory be much greater in a fast reactor than in a thermal reactor. This also makes the inventory charges a greater component of the total power cost in a fast reactor. 
There are a variety of ways to define breeding ratio [25]. The only one which is strictly correct for a "closed" fuel cycle is the ratio of fuel atoms extracted from the reactor to fuel atoms inserted into the reactor, if these are of the same kind $[3,25]$.

$$
\mathrm{BR}=\frac{\text { Fissile atoms extracted }}{\text { Fissile atoms inserted }}
$$

This quantity may be computed over the total life of the entire reactor (fissile core plus blankets of fertile uranium), the life of each core (quantity of plutonium discharged from core and blanket during one complete irradiation cycle), or taken on an instantaneous basis for a continuous feed reactor at equilibrium.

Breeding ratios for fast reactors can be in excess of 1.6 (a so-called high-gain breeder), but normally for LMFBRs the value is in the range 1.2 to 1.4 . A high breeding ratio is not necessarily conducive to conservation of fuel resources, particularly not if it is obtained at the expense of a high specific inventory [26]. 
Simple or straight-line doubling time (SDT), which is applicable to a single reactor operating alone, is given by

$$
\mathrm{SDT}=\mathrm{k} \frac{\mathrm{SI_{T0 }}}{\mathrm{BR}-1}
$$

where $k$ is a constant whose value depends on load factor, $\alpha$ (the neutron capture-to-fission ratio for plutonium) and frequency of refueling. The simple doubling time gives some indication of the potential rate of growth of breeder capacity starting from zero.

Compound doubling time, on the other hand, reflects the gain that occurs if the plutonium "dividends" are immediate1y reinvested in other breeders that have the same rate of return as the original reactor [27].

$$
\mathrm{CDT}=\frac{\ln 2}{\ln \left(1+\frac{1}{S D T}\right)}
$$

This expression can actually be meaning ful only when a large number of similar reactors are operating simultaneously. Then the term "doubling time" can be thought of as the time required for a generation of breeders to provide sufficient plutonium inventory for a doubled population of reactors. 
Typica1 doubling times of first generation LMFBRs range from 7 to 19 years [28]. In order to satisfy the requirements of a power industry doubling time of approximately ten years, the most desirable breeder would have a doubling time somewhat less than this. Since short doubling times result from high breeding ratios and low specific inventories for a given breeding ratio, a reactor with a shorter doubling time has an additiona 1 economic attraction as the inventory charges amount to a very large investment of capital and a large percentage of the fuel cycle costs.

Even though breeders produce more plutonium than they consume, changes in plutonium price can affect the fuel costs of fast reactors adversely (i.e., fuel cycle costs increase with plutonium price) for the range of breeding ratios mentioned above for LMFBRs [29]. At a breeding ratio of approximately 1.5 , this trend reverses. Even for a breeding ratio of 1.6 , a reduction of $0.1 \mathrm{mils} / \mathrm{KWH}$ requires an increase in plutonium cost of $\$ 10-\$ 11 / g$. 


\section{Light Water Reactors and P1utonium}

Plutonium is also produced in light water reactors. The quantity of plutonium generated in this instance is considerably less per unit power than that produced in a fast breeder reactor. This can be seen from Table I. In order that the power level $\left(\phi \mathrm{N}_{f} \sigma_{f}\right)$ is the same in both reactors, the flux in the fast reactor must be some hundreds of times that of the thermal reactor. Although the ${ }^{238} \mathrm{U}$ thermal absorption cross section is a factor of 10 greater, the larger fast neutron flux results in a higher plutonium conversion ratio. Typical light water reactor conversion ratios are only $0.4-0.6$. The higher $\alpha$ value at thermal energies (cf. Table I) results in plutonium produced in light water reactor being composed of the higher plutonium isotopes. Consequently, this means that the fissile plutonium ratio is lower in this kind of material. With a greater quantity of the ${ }^{241} \mathrm{Pu}$ isotope, there exists the additional problem of decay when the material is stored for long periods of time. All these factors contribute to the preference for plutonium produced in a fast spectrum. 
There are some differences in the amounts of plutonium produced in various types of light water reactors. Under optimum fuel cycle management, pressurized water reactors generally produce about a $20 \%$ greater yield of plutonium than do boiling water reactors [30]. If desired, the quantity of plutonium produced in a light water reactor may be increased by adjusting the hydrogen-to-metal ratio [31]. However, such changes are accomplished at the expense of fuel cycle economy.

As well as producing the plutonium, light water reactors may also be fueled with it. This concept is presentIy being advocated throughout the nuclear industry through the program known as "1ight water recycle". There are many reasons for the current interest in the recycle of plutonium in light water reactors. Primarily, these stem from a desire to ease the tension on uranium ore and enrichment requirements as well as to utilize fissile material which is on hand. However, as can be seen again from Table I, light water reactors do not employ plutonium as efficiently as do fast breeder reactors.

It is undoubtedly true that plutonium will and should eventually be burned in light water reactors. It will be 
shown later that this course is not advisable in the near future if the goal of minimizing long-term nuclear power costs is to be achieved.

Choice Purely on the Basis of Economics

Other studies $[15,16]$ have clearly shown that the benefits to be realized by breeder reactors outweigh the costs which will be incurred in their development. These analyses have been based on detailed estimates of the required development costs as well as on overall appraisals of the savings breeders will provide as energy sources. Such analyses assume that once breeders have been developed, all the elements are attendant to their full-scale utilization. All of the absolute costs in these analyses are synchronized around some specific year of breeder introduction. In this study, costs of producing energy are all considered to be relative to the date of commercial introduction of breeder reactors by the technique of 
present-worth accounting or discounting*. The present study will not be concerned with justifying the costs expended for breeder reactor research, but will assume that the technology for both light water reactors and fast breeders is available after the "introduction date".

Whether additional nuclear generating capacity for future installation should be of the light water reactor type or the fast breeder type would be an elementary decision if only economic considerations were involved. The correct choice would be that for which the discounted generating costs for the quantity of capacity being added is least when considered over the desired period of time. If it is assumed that the useful plant lives of the two type reactors are the same, the present worth

*Discounting, or present-worth accounting, involves the assignment of a present value to some future expense or revenue. The vehicle for such a consideration is referred to as the present-worth factor. This expression is a function both of the length of time between the future transaction and the present as well as the discount rate which the evaluator deems appropriate. (More will be said concerning the "appropriate" discount rate later.) The selected discount rate, $i$, (genera11y in percent) is applied to the time span, $n$, (generally in years) in a compounded manner to determine the present-worth factor:

$$
\mathrm{PWF}=\frac{1}{(1+i)^{\mathrm{n}}}
$$

Past costs may be considered in the same manner; however in this case, the sign on the time span, $n$, is negative. 
factors in the future would be identical since the addition in either case is planned for the same point in time. Thus the proper decision purely on an economic basis could be made by comparing the annual generating costs of the two systems. Further, if the average load factors over the lives of the two types of plants could be assumed identical, then the unit generating costs (mil/KWH) would be a valid basis of comparison. Since the more general case enables one to permit different or even time-varying load factors for the two plant types in this study, the basis for the economic decision has been the annual generating costs.

\section{Technological Limitations to Economic Choice}

The economic choice of nuclear capacity addition that is preferred may not be realizable due to limitations imposed by technological considerations. It will be assumed that there will be reactor manufacturers who will always be capable of furnishing sufficient plants to satisfy the nuclear demand. Further, it will be assumed that the possibility always exists of commissioning light water reactors to meet the nuclear demand since this type plant is currently being built. 
The two most important constraints on fast breeder reactor additions are the date of commercial introduction of the breeder and a sufficient quantity of plutonium to initially fuel new breeders as well as to refuel those already producing power. Target date of the LMFBR Program for a commercially acceptable plant is 1985 [32].

A method has been devised to assure that only those fast reactors that can be fueled may be built. This entails keeping a running total of the quantity of plutonium available for use through a plutonium "profit-and-loss" account. This statement includes entries for production and the possible use of plutonium in light water reactors in addition to the plutonium production and requirements of the fast breeders. The sum of all these is accumulated on an annual basis in a "plutonium balance". The permissible new additions to fast breeder reactor capacity are then determined from this balance.

\section{Objective}

The primary objective of this study is to determine that combination of 1 ight water reactors and fast breeder reactors which, while satisfying the nuclear generating demand, will result in minimum nuclear generating costs 
discounted to the year 1985 .

The annual discounted costs are a function of (among others) the installed capacity of both the light water reactors and the fast breeder reactors in that year, the load factors and unit costs of each, the quantity of plutonium held in stockpile, the plutonium price and the discount rate.

$$
\begin{aligned}
& \mathrm{DNGC}=\mathrm{f}\left(\mathrm{CAP}_{L_{W R}}, \mathrm{CAP}_{F_{\mathrm{B} R}}, \mathrm{LF}_{L_{W R},}, \mathrm{LF}_{F_{\mathrm{B}} R}, \mathrm{UC}_{L_{W R}}, \mathrm{UC}_{F_{\mathrm{B}} R},\right. \\
& \text { PuBa1, PuPr, Disrat) }
\end{aligned}
$$

The total generating costs are the sum of the annual discounted costs. The objective function is therefore:

$$
\text { TNGC }=\sum_{1=1}^{n} \text { DNGC }_{1}
$$

In this study, the variables which influence this objective function are adjusted until that realizable combination of parameters is established which yields accumulated generating costs as close to the economically ideal generating costs as possible. The measure of this proximity is the added cost (ADCOST) above the economic ideal associated with each particular case. 
From the rate of change of the additional costs with respect to each variable, the extent of cost dependence can be determined. This determination enables an identification of the more important variables to be controlled. Thereafter, formulation of policies to achieve minimum future generating costs of a mixed fast breeder-1ight water reactor economy will be possible.

It is recognized that the extent of future generating costs depends on the rate of growth of nuclear capacity. For this reason different growth rates, including those projections that have been widely proclaimed, have been considered. It is also acknowledged that the development of fusion or other innovative energy sources is a definite possibility. However, the fusion eventuality presently appears sufficiently uncertain that no allowance has been made for it in this investigation. This has been justified on the assumption that, should a controlled thermonuclear reaction be achieved in the laboratory within 10 years, an additional 20 years would be required to transform laboratory curiosity into commercial realization. Such intervals of time approach the horizon used in this study. Other unforseen or inestimable breakthroughs have similarly been neglected. In any analysis of this sort, projections into the future are fraught with such unpredictabilities. 
MODEL OF THE NUCLEAR GENERATING INDUSTRY

The model which has been formulated to represent the future nuclear power generation system consists of various potential mixes of 1 ight water reactors and fast breeder reactors. The light water reactors are represented by a pressurized water reactor whose design has been initiated by Westinghouse and modified by Oak Ridge National Laboratory [32]. The first-generation liquid metal cooled fast breeder reactor is that designed by Atomics Internationa 1 [33].

A11 future additions to the nuclear capacity are assumed to be $1000 \mathrm{MW}(\mathrm{e})$ in size. There does appear to be some, though not appreciable, motivation for single plants of greater capacity than this. Although the unit costs $(\$ / \mathrm{KWe})$ are somewhat less for larger sized plants, the forced-outage rates are considerably greater (as much as 20-30\%) as well [34]. Such a forced-outage rate has the effect of reducing overall system reliability. Secondly, thousand megawatt plants are a convenient number with which to make additions to the nuclear capacity. This is especially true since most estimated projections of future generating capacity are rounded to the nearest thousand megawatts. Fina11y, 
1000 MWe is the size of the specific reactor designs which are being utilized here. This makes possible the direct application of the relevant design parameters.

\section{TYPICAL LIGHT WATER REACTOR*}

The typical light water reactor is fueled with slightly enriched $\mathrm{UO}_{2}$ and both moderated and cooled by means of pressurized $\mathrm{H}_{2} \mathrm{O}$. Pertinent design characteristics are presented in Table II. A more complete description of the light water reactor may be found in Appendix I. The active core is 11 feet high and 12.8 feet in diameter. The reactor contains 264 fuel assemblies and 109 contro1 rods. Chemical poison control in the form of a boric acid solution is used for shim control to reduce the control rod requirements [35].

*The basic design of the LWR is taken from a Westinghouse Study: $1000 \mathrm{MW}(\mathrm{e})$ Closed Cycle Water Reactor Study, Report WCAP 2385, March, 1963. 
PARTIAL DESCRIPTION OF TYPICAL

LIGHT WATER REACTOR

Reactor Power

Core nuclear power, MW(th)

Net electrical power, MW(e)

1002

Net thermodynamic efficiency, \%

31.1

Core and Fuel

Moderator and coolant material

Fuel material

Fuel fabrication

Cladding materia 1

Ful1 life, yr

Equivalent diameter of core, ft

$\mathrm{H}_{2} \mathrm{O}$

$\mathrm{UO}_{2}$

pelletized Zirca $10 y-4$

Active height of core, ft

3

12.8

11.0

Number of fuel assemblies

264

Peak-to-average power ratio

Average core power density, KW/liter

3.3

Average specific power, $\mathrm{KW} / \mathrm{kg}$ of

80.7

fertile material

31.7

Fuel Cycle

Fuel management scheme

In-core residence time, yr

(at 0.8 load factor)

Average fuel exposure, MWD/MT

Average exposure in maximum rod, MWD/MT

Three batches, scatter reloading 2.3

25,000

30,000 
The typical light water reactor has a maximum-to-average heat flux ratio of 3.3 , a core power density of $80.7 \frac{\mathrm{KW}}{\text { 1iter }}$, and a coolant outlet temperature of $598^{\circ} \mathrm{F}$. Short control rod followers that extend 3.7 feet into the 11 foot core and other mixing devices force the interchange of coolant between and within assemblies [36].

The fuel elements are designed to operate for three years at a linear heat rating of $16 \frac{\mathrm{KW}}{\mathrm{ft}}$ and a maximum heat flux of $544,000 \mathrm{BTU} / \mathrm{hr} \cdot \mathrm{ft}^{2}$ to a maximum burnup of $30,000 \mathrm{MWD} / \mathrm{MT}$ of uranium. The peak cladding temperature is $640^{\circ} \mathrm{F}$; coolant pressure is 2050 psi [37].

Physics calculations of the $1000 \mathrm{MW}(\mathrm{e})$ pressurized water reactor were performed by Oak Ridge National Laboratory [38]. Initial excess reactivity (i.e., feed fuel enrichment) was treated as a parameter in these calculations in order to optimize fuel costs. The feed and discharge enrichment for the equilibrium cycle are shown in Figure 3 as a function of average exposure of discharged fuel. Also shown is the feed enrichment that would be required if the neutron leakage were $1 \%$ smaller (i.e., a larger core size). 


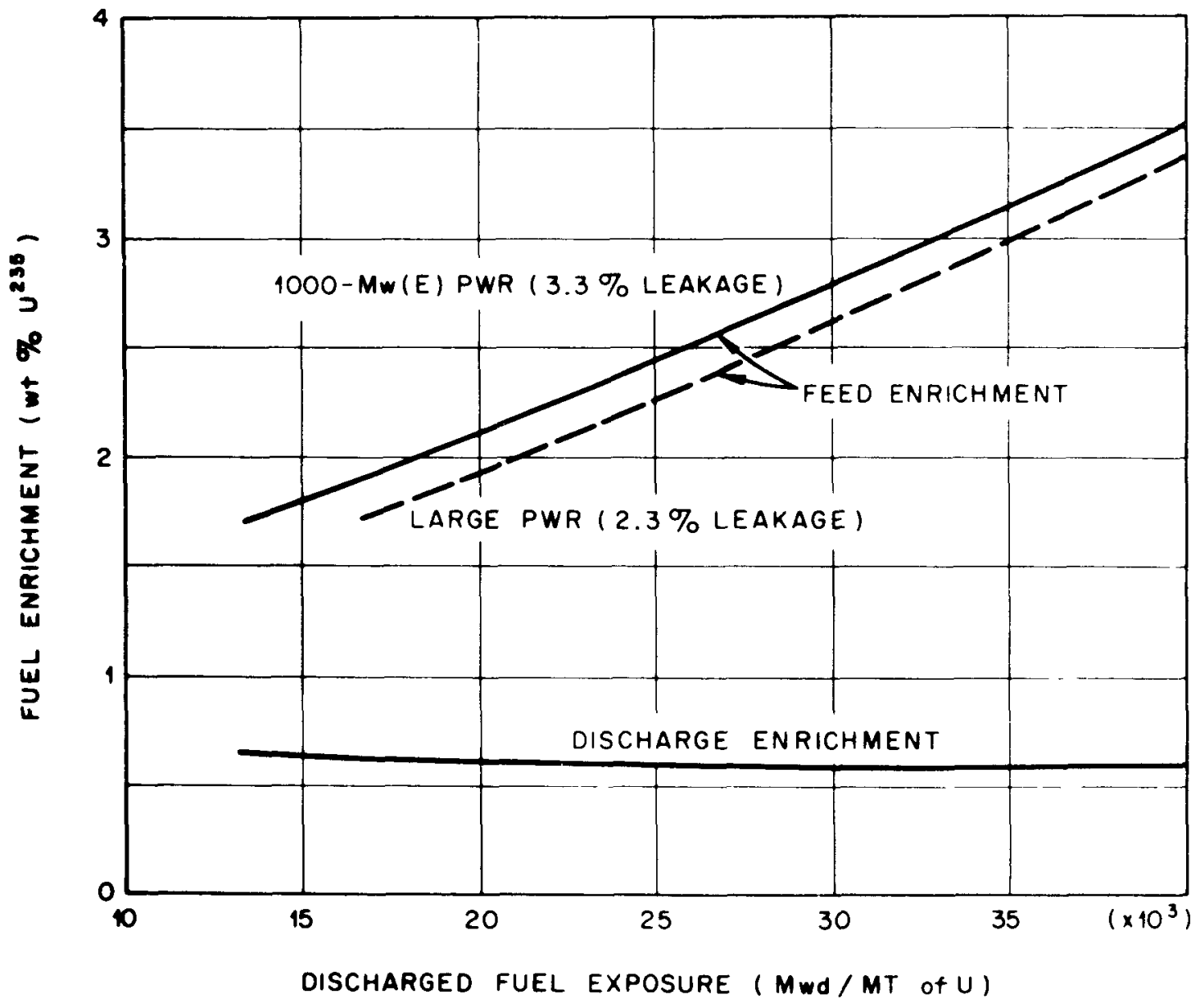

Figure 3: Light Water Reactor Feed and Discharge Uranium Enrichment Versus Fuel Exposure (after ORNL-3686) 
The reference fuel management scheme is the "3-batch roundelay" or "scatter-reload" program in which one-third of the core loading is discharged at each annual shutdown. Discharge plutonium concentrations are shown in Figure 4.

In the present analysis, the initial enrichment was allowed to vary from $1.70 \%$ to $3.66 \%$ which yielded corresponding burnups that ranged from 10,000 to $40,000 \mathrm{MWD} / \mathrm{MTU}$.

\section{TYPICAL FAST BREEDER REACTOR}

The typical first generation LMFBR consists of a core of mixed (uranium and plutonium) oxide fuel, suitably contained and subdivided to assure adequate heat removed by the circulating liquid-sodium coolant. At full load, sodium enters the vessel at the lower end at $760^{\circ} \mathrm{F}$, flows up through the core and exits from the vessel at $1060^{\circ} \mathrm{F}$ [39].

Pertinent design characteristics of the reference LMFBR are given in Table III. A more complete description may be found in Appendix II. 


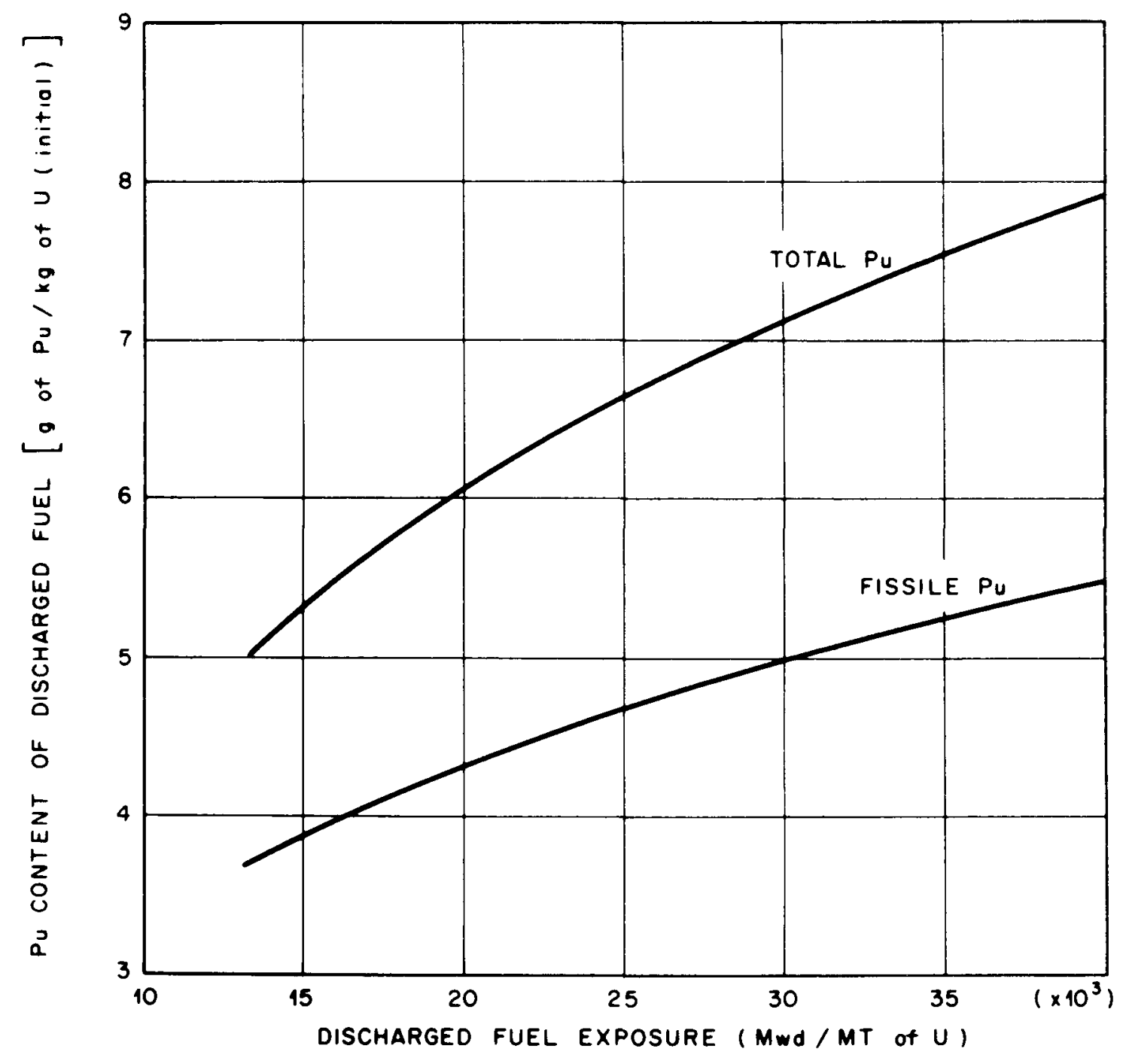

Figure 4: Plutonium Concentration in Light Water Reactor Discharged Fuel as a Function of Discharge Fuel Exposure (after ORNL-3686) 


\section{PARTIAL DESCRIPTION OF ASSUMED}

FIRST GENERATION LMFBR

\section{Reactor Power}

Total reactor power, $\mathrm{MW}(\mathrm{th})$

Core power fraction (mid-cycle)

Radial blanket power fraction

Axial blanket power fraction

0.032

Net electrical power, MW(e)

1004

Net thermodynamic efficiency, \%

Core and Fuel (mid-equilibrium cycle)

Core fissile enrichment, at \%

$$
\text { inner zone }
$$

11.4

outer zone

15.4

Fissile mass $(\mathrm{Pu}+\mathrm{U}-235), \mathrm{kg}$

\section{Core}

Axial blanket

Radial blanket

Fuel material

Blanket material

Cladding material

Peak-to-average power ratio

Average core power density, KW/Iiter

Average specific power of fuel materia $1, \mathrm{KW} / \mathrm{kg}$

Average breeding ratio

Doubling time, yr
1780

116

368

mixed $\mathrm{PuO}_{2}, \mathrm{UO}_{2}$ depleted $\mathrm{UO}_{2}$ 304 or 316 SS 1.605

390

190

1.29

Fue1 Cycle

Fuel management scheme

In-core residence time, yr

scatter reload

(at 0.8 load factor)

Average fuel burnup, MWD/MTH

1.5

Average exposure in maximum rod, MWD / MTH

75,000

100,000 
The reactor core operates in a fast neutron flux, and power is regulated by moving neutron-absorbing control elements into or out of the core. The core is surrounded radially by two rows of depleted uranium blanket elements and a single row of stainless steel reflector elements. Depleted uranium is also used above and below the fuel as an axial blanket. Fifteen control and safety rods are provided for reactivity control. Tantalum has been selected as the reference absorber material. Nine control rods are used as combined shim and safety rods, and six are used strictly for safety.

The reactor will be refueled on a six month cycle with $1 / 3$ of the core, $1 / 6$ of the inner blanket, and $1 / 9$ of the outer blanket being replaced each cycle. This corresponds to 144 days of fuel power (1000 MWe) operation. Refueling is performed during scheduled plant shutdown. Spent fuel is removed from the core and placed in one of the in-vessel storage positions for decay during the subsequent power cycle. The average exposure of the spent core fuel is 74,000 MWD/MT. The fast core elements have an average reactor residence time of 1.5 years, the inner radial blanket 3 years, the outer radial blanket 4.5 years, and the shim 
control rods 8 years. Additiona1ly at each refueling, $1 / 9$ of the outer blanket elements are rotated $180^{\circ}$ to permit uniformity of the $\mathrm{Pu}$ buildup at the edge of the core where there is a sharp flux gradient. The downtime per refueling is estimated at about ten days [39].

The fuel burnup calculations for the reference LMFBR were performed by Atomics International [40]. The calculations were made in one-dimensional geometry using neutrondiffusion theory. Two core enrichment regions were employed to facilitate control of the peak-to-average power ratio. Each enrichment region was subdivided into three burnup zones to provide greater detail in the calculations. Each of the burnup zones was divided into three equal-volume fuel batches to simulate the fuelmanagement scheme. The time history of the changes in isotopic composition of each batch was calculated on a cycle-by-cycle basis. At each refueling, one fuel batch from each burnup zone was discharged and replaced with fresh fue1. 
The radial blanket was similarly treated with six fuel batches in the inner-ring blanket and nine fuel batches in the outer-ring blanket. A uniformly distributed tantalum poison was used in the outer-core enrichment region to simulate the control rods. Equilibrium operation had been achieved by the tenth refueling cycle.

The isotopic composition for the initial loading is assumed to be $60 \%{ }^{239} \mathrm{Pu}, 24 \%^{240} \mathrm{Pu}, 12 \%{ }^{241} \mathrm{Pu}$, and $4 \%{ }^{242} \mathrm{Pu}$. This is felt to be representative of early LWR discharge compositions. The startup core employs three different enrichments in each of the two core zones to minimize the swing in reactivity during the approach to equilibrium. The lower-enrichment batches are replaced first to provide a smooth transition to high-burnup, high-enrichment fuel.

The results of their analysis consist of the mass balances describing the isotopes charged to and discharged from the reactor. These balances are shown in Table IV for the isotopes of interest. As can be seen, during equilibrium operation $610 \mathrm{~kg}$ of fissile plutonium are charged to the reactor and $721 \mathrm{~kg}$ are discharged at each refueling shutdown. AI calculates a total breeding ratio of 1.29 ; and from their assumption of the ex-core fuel inventory and processing losses, 
they conclude the simple doubling time (cf. Equation 2)

is 8.7 years. 
TABLE IV

FBR ISOTOPIC MASS BALANCES (kg)

\begin{tabular}{|c|c|c|c|c|c|c|c|c|}
\hline Feed Fuel to Equilibrium & ${ }^{235} \mathrm{U}$ & $\stackrel{338 \mathrm{U}}{ }$ & $239 \mathrm{Pu}$ & $24 \circ \mathrm{Pu}$ & $241 \mathrm{Pu}$ & ${ }^{2} 4 \mathrm{a} \mathrm{Pu}$ & $\geq^{342} \mathrm{Pu}$ & Total \\
\hline Core & 10 & 3565 & 567 & 232 & 43 & 17 & 0 & 4434 \\
\hline Axia1 Blanket & 7 & 2468 & 0 & 0 & 0 & 0 & 0 & 2475 \\
\hline Inner Radial Blanket & 4 & 1345 & 0 & 0 & 0 & 0 & 0 & 1349 \\
\hline Outer Radial Blanket & 2 & $\underline{796}$ & 0 & 0 & $\underline{0}$ & $\underline{0}$ & $\underline{0}$ & 798 \\
\hline Tota 1 & 23 & 8174 & 567 & 232 & 43 & 17 & 0 & 9056 \\
\hline
\end{tabular}

$w_{\infty}$

\section{Discharge End of}

Equilibrium Cycle

\section{Core}

Axial Blanket

Inner Radial Blanket

Outer Radial Blanket

Tota 1

\begin{tabular}{|c|c|c|c|c|c|c|c|}
\hline $35 \mathrm{U}$ & $23{ }^{8} \mathrm{U}$ & ${ }^{2{ }^{39} \mathrm{Pu}}$ & $2{ }^{20} \mathrm{Pu}$ & $241 \mathrm{Pu}$ & ${ }^{242} \mathrm{Pu}$ & $\geq^{243} \mathrm{Pu}$ & Tota 1 \\
\hline 5 & 3243 & 533 & 244 & 37 & 18 & 2 & 4082 \\
\hline 5 & 2394 & 63 & 2 & 0 & 0 & 0 & 2464 \\
\hline 3 & 1268 & 56 & 3 & 0 & 0 & 0 & 1330 \\
\hline 1 & 755 & 32 & 2 & $\underline{0}$ & 0 & $\underline{0}$ & 790 \\
\hline 14 & 7660 & 684 & 251 & 37 & 18 & 2 & 8666 \\
\hline & & $\begin{array}{l}\text { a Fi } \\
\text { Total }\end{array}$ & $\begin{array}{l}\text { e Pu } \\
\text { sile }\end{array}$ & & & & \\
\hline
\end{tabular}




\section{ASSUMPTIONS FOR ECONOMIC ANALYSIS}

The analysis for each year under consideration follows the flow diagram shown in Figure 5. The range of total nuclear generating capacity noted above is spanned in separate sets of calculations. All presently installed nuclear capacity is assumed to be composed entirely of light water reactors. Further, additions to capacity are determined on the basis

of: (1) technological capabilities (i.e., breeder cannot be constructed before the introduction date); (2) technological limitation (breeders are not constructed if there will be insufficient plutonium to fuel them); and (3) economic criteria (costs associated with each alternative). When both reactor types are technologically possible, the choice as to addition is made solely on the basis of economics. This results in the most economic, technically achievable units being installed at all times.

The extent of the added increment to nuclear capacity in any year, $\mathrm{n}$, is determined from the difference between the estimate and the previous year's installed capacity. 


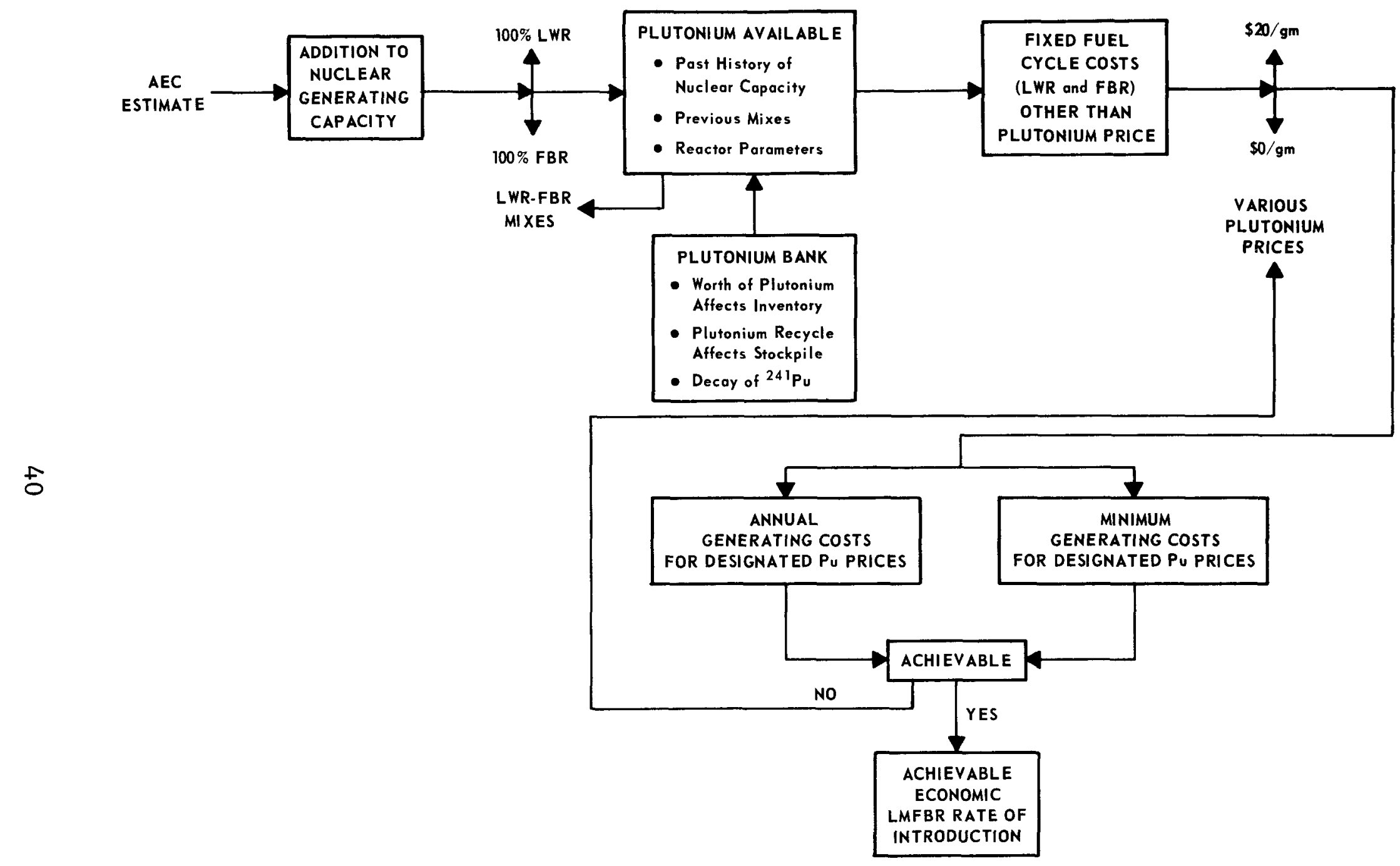

Figure 5: Flow Diagram of Annual Calculations to Determine Preferred Achievable Breeder Mix and Costs 


$$
I_{n}=E_{n}-K_{n-1}
$$

where: $I_{n}$ is the incremental nuclear generating capacity in the nth year, MWe

$E_{n}$ is the estimate of nuclear generating capacity in the nth year, MWe

$\mathrm{K}_{\mathrm{n}-1}$ is the installed nuclear capacity in the preceeding year, MWe

Once this has been established, an approximation to the permissible LWR-FBR "mix" of the incremental capacity is made from the balance of the previous year's plutonium reserve and the total (in-core and ex-core) specific inventory of the breeder. If the date of fast breeder introduction has not yet been reached, a11 of the new addition is considered to be light water reactor. However, some specific fast reactor capacity may be specified before being economically justified to simulate the commissioning of demonstration plants.

Al1 additions to fast reactor capacity are rounded to the next lowest 1000 MWe so as to assure a positive residua 1 plutonium balance. If the allowed increment of fast breeder reactor capacity is not as great as the added nuclear capacity in the particular year $\left(I_{n}\right.$ in Equation 6$)$, the balance is added as LWR capacity. The following relation must always be satisfied however: 


$$
I_{n}=I_{f n}+I_{L n} \text { * }
$$

where: $I_{F}$ is the incremental FBR capacity in the nth year, MWe

$I_{L n}$ is the incrementa 1 LWR capacity in the nth year, MWe

\section{Determination of Plutonium Requirements}

Once the allowable mix has been determined, the plutonium supply and demand for that situation is calculated. These are obtained from the prior installed capacity of light water reactors $\left(K_{L_{n-1}}\right)$ and fast breeder reactors $\left(K_{F-1}\right)$ and the quantities of plutonium produced and required by each reactor type. These parameters are presented in the previous reactor descriptions. The production and supply are also influenced by fabrication and reprocessing losses which are considered fixed for the duration of a calculation though they are varied in subsequent calculations from $0 \%$ to 10 and $5 \%$, respectively.

No material holdup time is considered; that is, plutonium is assumed to be immediately available for further use upon discharge from the reactors. This is a very generous approach since normally there would be some definite time

*Single capital subscripts are used hereafter to denote the reactor type 
associated with fuel cooling, processing, and fabrication. Other analyses of this type have considered holdup times of one year or greater [7]. The effect of no holdup time is that the availability of plutonium for fueling reactors is increased and thus this analysis represents the most optimistic expectation for the growth rate of fast breeder reactor capacity.

The net total of yearly plutonium production less the requirements, called the plutonium balance,

$$
\begin{aligned}
B^{\prime}{ }_{n}= & B_{n-1}+L_{R}\left[K_{L} P_{n-1}+K_{F} P_{F}\right] \\
& -L_{F}\left[R_{L}\left(K_{L_{n-1}}+I_{L}\right)+R_{f}\left(2 / 3 K_{F}+I_{F}\right)\right]
\end{aligned}
$$

and $R_{f}=S I(1+X)$

$$
P_{L}=U H^{a}
$$

where: $\mathrm{B}^{\prime}{ }_{\mathrm{n}}$ is the plutonium balance in the nth year, $\mathrm{kg}$

$B_{n-1}$ is the previous year's plutonium balance corrected for decay, $\mathrm{kg}$

$\mathrm{L}_{R}$ is the reprocessing loss term, 1 - losses

$L_{F}$ is the fabrication loss term, 1 + losses

$\mathrm{P}_{\mathrm{L}}$ is the plutonium production in $\mathrm{LWR}, \mathrm{kg} / \mathrm{MWe}$

$\mathrm{P}_{\mathrm{F}}$ is the plutonium production in $\mathrm{FBR}, \mathrm{kg} / \mathrm{MWe}$

$R_{L}$ is the plutonium requirement in LWR, $\mathrm{kg} / \mathrm{MWe}$

$R_{f}$ is the plutonium requirement in $F B R, \mathrm{~kg} / \mathrm{MWe}$

$\mathrm{SI}$ is the in-core specific inventory, $\mathrm{kg} / \mathrm{MWe}$

$X$ is the ex-core inventory fraction

$\mathrm{U}$ is the initial LWR uranium loading, $\mathrm{kg}$

$\mathrm{H}$ is an expression giving plutonium production as a function of burnup, gPu/kgU initial 
must always be positive. If the incremental breeder capacity initially chosen is so great as to result in a negative balance, a portion of the incremental FBR capacity must be substituted by light water reactors so as to achieve a positive plutonium balance. Similarly if the plutonium balance is greater than the total specific inventory, a larger fast breeder capacity could be supported. Fina11y, the plutonium balance must be corrected for use in the next period by accounting for the decay of the fissile plutonium fraction which is the short-lived 241 isotope.

$$
B_{n}=\left[F+(1-F) e^{-\lambda \tau}\right] B_{n}^{\prime}
$$

where: $F$ is the ratio of ${ }^{239} \mathrm{Pu} /$ total fissile $\mathrm{Pu}$

$\lambda$ is the decay constant of ${ }^{241} \mathrm{Pu}, \sec ^{-1}$

$\tau$ is the time in one year, sec

Determination of Energy Costs

The cost of producing the required amount of electrical power utilizing the above determined LWR-FBR mix must be ascertained. The costs, which vary in time, are based on the estimates of others $[41,42,43]$. Light water reactor capital cases ranging from $\$ 175 /$ KWe to $\$ 250$ KWe (in 1970 dollars) are considered. The LMFBR plants are assumed to 
suffer a $25 \%$ penalty over the light water reactors on both capital and operating expenses. Resulting capital costs are discussed in the next chapter. These agree fairly we11 with others that have been presented [44]. Future operating, maintenance, and insurance costs are a1so described in the next chapter.

The future fuel costs estimates, taken from the same above-mentioned reports, allow for changes in technology (fabrication, reprocessing, and cooling) at approximately five year intervals. The fuel costs have been broken down into two components. The first is calculated at zero plutonium price (no plutonium credit for light water reactor); a second term has been added to these costs to revea 1 the effect of the plutonium price variation.

$$
C_{F C}=Z+b V
$$

where: $C_{F} c$ is the fuel cycle costs for each reactor type, mils $/ \mathrm{kWH}$

$\mathrm{Z}$ is the fuel cycle cost at zero Pu price, $\mathrm{mils} / \mathrm{kWH}$

$\mathrm{V}$ is the plutonium price, $\$ / \mathrm{g}$

$b$ is the rate of change of fuel costs with plutonium price 
The resulting fuel cycle costs agree well with another analysis of fuel cycle cost variation due to changes in plutonium price [29]. All these costs are totaled to yield unit costs (mils $/ \mathrm{kWH}$ ) for each type of reactor.

$$
C=C_{c}+C_{0}+C_{I}+C_{F} c
$$

where: $C$ is the total unit costs for each reactor type, mils $/ \mathrm{kWH}$

$\mathrm{C}_{c}$ is the unit capital costs, mils/kWH

$\mathrm{C}_{0}$ is the unit operating and maintenance costs, $\mathrm{mils} / \mathrm{kWH}$

$\mathrm{C}_{1}$ is the unit insurance costs, $\mathrm{mils} / \mathrm{kWH}$

The annual costs per unit of electrical capacity, in dollars, for the two reactors are obtained from the product of the unit costs and the respective capacity factors (which could be time varying but have been taken as a constant $80 \%$ over plant life).

$$
\mathrm{A}=0.001 \mathrm{C} \ell \mathrm{M}
$$

where: A is the annual cost of generation, $\$ / \mathrm{kW}-\mathrm{yr}$ $l$ is the load factor, \%

$M$ is the number of hours per year

Such an assumption has been shown to be valid for a single reactor over a thirty year 1ifetime [45] and, therefore, should certain $1 y$ be reasonable when considering a large 
number of similar reactors in various stages of life. The annual nuclear generating costs (billions of dollars) are determined from products of the installed nuclear capacity for the year, the installed fraction of each reactor type, and its annual costs.

$$
G=\left[K_{f} A_{f}+K_{L_{n}} A_{L}\right] \times 10^{6}
$$

where: $G$ is the nuclear generating cost, $\$ 10^{\circ}$

Charges for plutonium inventory, determined from the plutonium balance, plutonium price, and prevailing discount rate, must be added to the annual nuclear generating costs. The total annual generating costs

$$
\mathrm{T}_{\mathrm{n}}=\left[\begin{array}{lll}
G+\mathrm{V} B_{\mathrm{n}} & D
\end{array}\right] \frac{1}{(1+\mathrm{D})^{\mathrm{n}}}
$$

where: $T_{n}$ is the total discounted nuclear generating cost in year $n, \$ 10^{\circ}$

$D$ is the discount rate, $\%$

are discounted to the year 1985 through the use of the present-worth factor (see page 21). The discounted nuclear generating costs are then added to the previous year's total to produce the cumulative nuclear generating costs to that year. 


$$
S_{N}=\sum_{1=1}^{N} T_{1}
$$

where: $S_{N}$ is the cumulative discounted generating costs, $\$ 10^{9}$

$\mathrm{N}$ is the full extent of the study, years

Determination of Economic Idea1

For the purpose of comparison, an "economic idea1" case is calculated. This is used as a base or reference for determining the additional costs of the realizable cases. The calculation of an ideal considers as the criteria for additions to nuclear capacity only the annual costs associated with each plant type. If the costs associated with the LWR for a given year (and plutonium price) are less than those for the FBR, all added capacity for that year is taken to be light water reactor. The converse is also true, of course. Additionally, if the year is after 1995 (30 years after the assumed start up of the first nuclear plant), the obsolete nuclear generating capacity is replaced with the most economical type of plant (not necessarily the same as the type replaced).

The economic generating capacity of the two reactor types are calculated along with their associated fraction of installed nuclear generating capacity. The economic 
annual nuclear generating costs are calculated similar to Equation 12.

The overa11 minimum generating costs for al1 plutonium prices, every reactor mix and each year are ascertained. These are accumulated as optimum economic nuclear generating costs for every year, $\mathrm{O}_{n}$, similar to Equation 15. It is this economically determined minimum which is tabulated and used as the base for determining the added cost.

$$
\mathrm{Y}_{\mathrm{N}}=\mathrm{S}_{\mathrm{N}}-\mathrm{O}_{\mathrm{N}}
$$

where: $Y_{N}$ is the added cost for the years in the study, $\$ 10^{\circ}$

$S_{N}$ is the actual discounted generating cost, $\$ 10^{9}$

$O_{N}$ is the optimum economic generating cost, $\$ 10^{\circ}$

The definition of economic optimum ignores the consequences of plutonium inventory. This always permits the imaginary construction of the most economic unit. For example, even if sufficient plutonium is not available, the breeder is always able to be added. Plutonium inventory charges need not be considered in the ideal economic case because the demand for plutonium would (nearly) equal its supply. 
These charges (cf. Equation 14) may be ignored if: 1) The plutonium balance is very nearly zero; 2) The plutonium price is equal to zero; or 3 ) The discount rate equal to zero. While none of these options are realistic, it will be found that the inventory charges may effectively be minimized by approaching these limits.

For greater speed, a digital computer program, MIN-E-COST, has been formulated to perform the above series of calculations for the time period 1965 to 2010. It is known that in taking as the horizon a year which is too near there is a risk of making an error which can lead to economic losses. The choice of this horizon also corresponds to the degree of uncertainty in the future [46]. Another study [44] has shown that such an analysis is not greatly affected by end effects, provided the calculations range over 40 to 50 years.

The output of the MIN-E-COST program is displayed both in the form of tables and graphs of annual costs for the range of plutonium values desired. Most parameters affecting these results may be internally varied. The results of this program have been found to be in exact agreement with manual calculations utilizing the same parameters. 


\section{DISCUSSION OF VARIABLES AFFECTING MINIMUM GENERATING COSTS}

The principal parameters affecting the minimization of nuclear generating costs can be considered to be either nuclear-related or not. The non-nuclear-related parameters, besides including such diverse technological elements as plant conversion efficiencies, plant load factors and siting, incorporate the economic variables associated with the light water reactor and fast breeder plants. These consist of such items as the capital cost of nuclear units, associated maintenance, the cost of raw materials and so forth.

The nuclear parameters govern the quantity of available plutonium and its possible uses. These subsequently limit the growth rate of fast breeder reactors. The costs of generating electricity will be substantially reduced if there is an established market for the plutonium produced. This market ultimately will be the plutonium-fueled breeders. The breeder generating costs, on the other hand, will decrease as a greater supply of plutonium becomes available for their use. 
NUCLEAR PARAMETERS AFFECTING GENERATING COSTS

All of the nuclear variables that affect the generating costs are embodied in an assessment of the production of plutonium and its subsequent use. Some of the factors that directly influence the plutonium supply are the specific and ex-core inventories and plutonium production rates. Implicit in these values are atom densities and cross sections of each material averaged over the reactor energy spectrum, average neutron fluxes, and irradiation times. The requirements and production rates are considered in turn for the fast breeder and light water reactors.

Fast Breeder Reactor Plutonium Requirements

The plutonium requirements of a fast breeder reactor are determined by its design characteristics. These include items such as core geometry, desired fuel lifetime, maximum heat generation rate, and fue1 properties. Since the combination of these is different for various reactor concepts, the resulting specific inventory (quantity of fue1 required per unit of energy output) can differ over a wide range. Ear1y 1000 MWe fast breeder designs have required from 1.79 to $5.77^{\mathrm{Kg}_{\text {fiss/MWe [47] while later }}}$ demonstration plants of lower output have narrowed this to 
the range 2.2 to $3.9 \mathrm{Kg}_{\text {fiss/MWe [48]. Along with this }}$ quantity of plutonium which resides in the reactor, a certain fraction of this amount is held up in the ex-core fuel cycle activities. This allows for cooling, reprocessing, fabrication, and shipment between each step. The magnitude of this fraction is governed by the amount of time required relative to that of the reactor residence time. Current estimates of ex-core time vary from just under a year [49] to as much as 1.5 years [50]. For a reactor with a 1.5 year fuel lifetime, this would correspond to an ex-core inventory of 0.6 to 1.0 . It is expected that with future advances in reprocessing technology not so much time will be required for cooling, and the ex-core inventory may ultimately be reduced to 0.2 or 0.3 . In the present work the ex-core inventory was considered to be $50 \%$ in the reference case but, in order to test for sensitivity, this parameter has been varied from $10 \%$ to $100 \%$

Fast Breeder Reactor Plutonium Production

The plutonium production in a fast breeder reactor is measured in terms of its breeding ratio and doubling time. The production rate is extremely dependent upon the amount of fuel exposure, generally decreasing with 
increasing burnup at the normally high burnups [52]. In this work the results of the Atomics International calculations (see Table IV) have been used to establish the rate of plutonium production. However, the approximate annual plutonium production of any breeder reactor can be estimated by

$$
P_{F}=\frac{R_{F}(S D T)+S I_{T 0 I}}{S D T}
$$

where: $P_{F}$ is the annual plutonium production in the fast reactor, $\mathrm{Kg} / \mathrm{yr}$

$R_{F}$ is the annual fast breeder reactor plutonium requirement, $\mathrm{Kg} / \mathrm{yr}$

SDT is the simple doubling time, yr

$\mathrm{SI}_{T_{\text {O }}}$ is the total initial specific inventory, $\mathrm{Kg}$

Annual plutonium production from fast breeder reactors will be highly dependent on the breeder installed capacity which is in turn limited by the breeder growth rate. The fast breeder reactor plutonium demand and supply is shown in Figure 6 assuming a 11 plutonium generated in light water reactors has been accumulated so that fast breeder reactors are installed at the most rapid possible rate after 1985 , limited only by the plutonium available and the rate of addition to nuclear generating capacity. Consequently, these assumptions result in the upper limit of breeder reactor deployment and plutonium demand. 


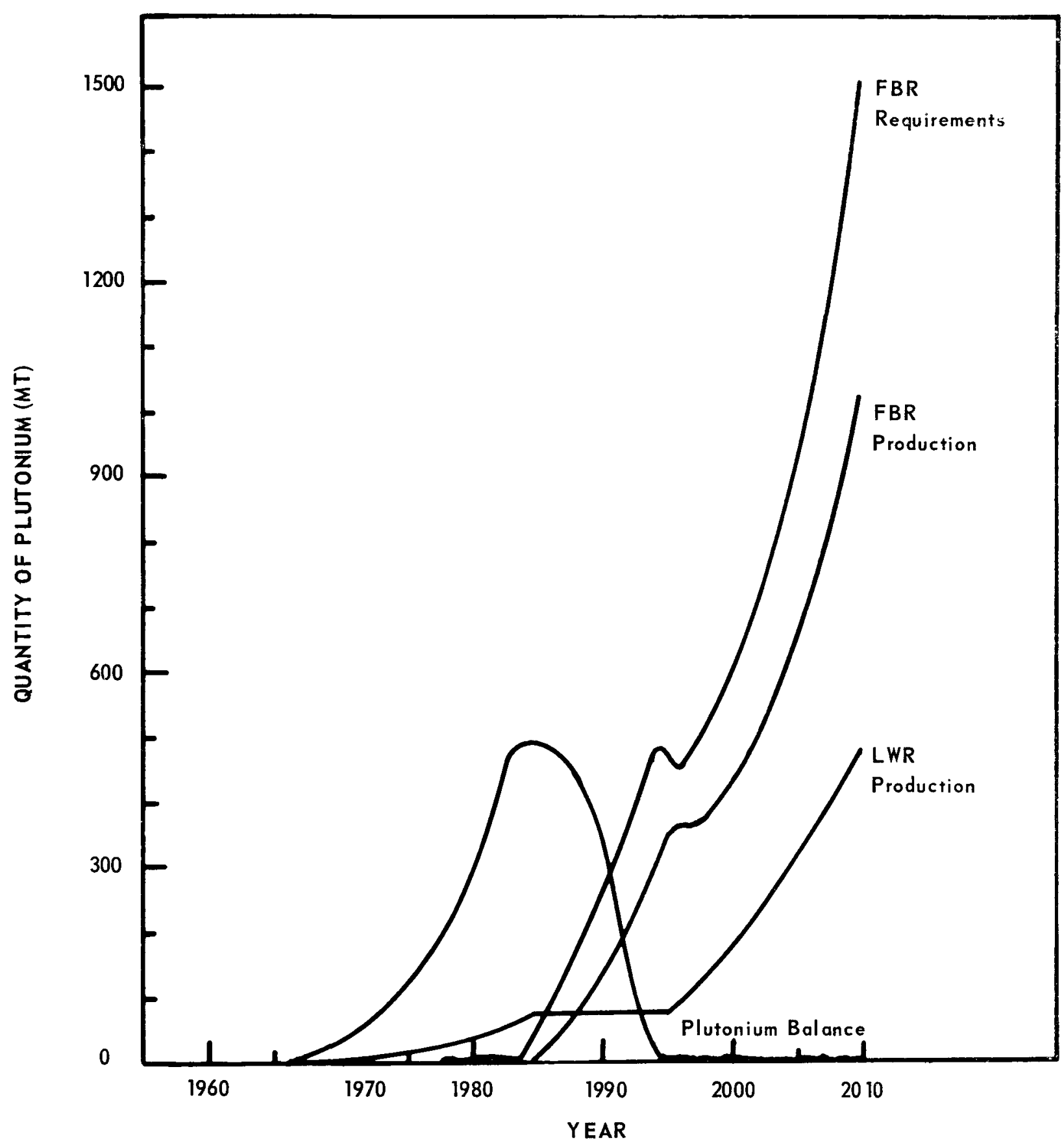

Figure 6: Annual Plutonium Production, Requirements, and Balance for Fastest Breeder Growth Rate Following 1985 Introduction 
In lieu of sufficient plutonium production to sustain the desired rate of addition of fast breeder reactors, their start up on enriched uranium is a possibility. However, it has been found that due to the greater value of plutonium in a fast system, the reactor operator cannot afford to pay more than about $2 / 3$ the value of plutonium for ${ }^{235} \mathrm{U}$ in competition with plutonium [53]. With the current cost of fully enriched uranium at about $\$ 12 / g$, due to the inherent1y expensive enrichment process, this practice no doubt will find limited application.

\section{Light Water Reactor Plutonium Production}

The production of plutonium in light water reactors is seen to increase with burnup (cf. Figure 4) at the level of present technology. The plutonium production rate (grams/MWe) appears to be slightly greater in a boiling water reactor than in a pressurized water reactor although this difference is not appreciable [54]. While the discharge fissile plutonium content per $\mathrm{KgU}$ charged is greater in a pressurized water reactor, the difference (per MWe) between the two reactor types results from the higher specific power of the PWR. 
A comparison of the annual light water reactor plutonium production used in these calculations shows agreement with some results [55]. However, others [56] have estimated annual production figures less than the present ones. A reason for the discrepancy may be the fact that the reference burnup is higher than what is presently being achieved [57]. The higher burnup should correspond more nearly to the future technology but to minimize these differences, the effect of burnups as low as 10,000 MWD/MTU have been considered. The LWR plutonium production is a1so shown in Figure 6.

Another effect of long burnups is that there is present in the fuel a greater fraction of the higher plutonium isotopes: 240,241 , and 242. Since these isotopes grow-in sequentially, there soon becomes an unfavorably high proportion of nonfissile isotopes [58]. This results in the plutonium being less desirable for use as fuel for a fast reactor and especially for recycle in a light water reactor since higher plutonium isotopes (with the exception of 241) act as neutron poisons. The variation in this quantity is represented by the values of $239 /$ fissile $\mathrm{Pu}$ fractions that have been considered. These ranged from 0.80 to 0.94 typical of $\mathrm{Pu}$ generated in 1 ight water reactors 
to "commercially pure" or weapons grade material.

\section{Light Water Reactor Plutonium Requirements}

If plutonium is used for recycle in light water reactors, the amount of plutonium utilizied in this manner will be somewhat uncertain. The reason for this is that up to about one-third of the fissile uranium in the reactor core can be replaced by plutonium while the reactor still retains the physics properties of an enriched uranium core having about 20,000 MWD/MTU fue1 exposure [59]. However, a greater fraction of the fissile content could be plutonium, and studies have been performed in which the entire uranium enrichment has been replaced with plutonium [60]. One result of this was that plutonium could not be economica11y employed in equilibrium recycle if its price was in excess of $\$ 10$ or $\$ 11 / \mathrm{g}$. This is considerably higher than the breakeven price found in an earlier analysis. Here the ceiling price in some light water reactors was $\$ 8.50$ for "commercially pure" plutonium, and $\$ 2.30 / g$ for once recycled material [61]. These factors al1 contribute to the uncertainty of the degree of employment of recycle and the quantity of plutonium demanded for it. 
As an outer limit, the generating costs have been calculated assuming al1 plutonium that is produced is burned in light water reactors. The other limiting case, the accumulation of al1 plutonium produced in light water reactors, has already been considered above.

Plutonium Value

When the well's dry they know the Worth of Water. B. Frank1in Poor Richard's Almanack

The importance of the value of plutonium to the light water reactor fuel cycle has been frequently noted $[62,63]$. Formerly the U. S. Atomic Energy Commission had agreed to purchase all the plutonium anyone could produce at a fixed "buy back price" of $\$ 9.28 / g$. However, now the AEC purchase agreement has expired, and the price of plutonium is expected to adjust to a nearly-free market level. The only controls still imposed by the AEC are ceilings on the quantities that may be sold and to whom [64].

A light water reactor can be viewed as producing joint products - electrical energy and plutonium. It is recognized that a relation exists between the market price of one joint product and the supply price of the other 
joint product. The supply price of a quantity of electrical energy is the total costs of generation for that quantity of electricity minus the demand price of the quantity of plutonium consistent with the quantity of electrical power generated. When the AEC "buy back price" was in effect, the supply price of electrical power could be reduced $\$ 9.28$ for each gram of plutonium produced at every leve1 of power generation.

The revenue from plutonium is directly proportional to the plutonium price and so the LWR fuel cycle costs decrease with increasing plutonium price. At the AEC's fixed market price, the plutonium produced during irradiation can mean a reduction of 0.15 to $0.20 \mathrm{mils} / \mathrm{KWH}$ or approximate $1 y$ 10\% of the 1 ight water reactor fuel cycle costs. Now, without the AEC purchase agreement, the relation is far more complicated in that the plutonium price is a market-determined price. The basic relation still holds that in a light water reactor there will exist an inverse relation between the market price of plutonium and the supply price of the electrical energy generated. 
The situation in a fast breeder reactor is somewhat different. Unless the breeder has an exceptional1y high breeding ratio $(\gtrsim 1.6)$, the fast reactor fuel cycle costs increase with increasing plutonium price [29]. This is primarily due to the inventory charges on the amount of capital that is tied-up in the reactor inventory and in the ex-core activities. This charge component also increases with burnup and fuel lifetime. Based on the same plutonium price mentioned above, the fast breeder reactor inventory charges ( 0.5 to $0.6 \mathrm{mils} / \mathrm{KWH})$ can be from $60 \%$ to over $100 \%$ of the net fuel cycle costs while at the same time the aggregate plutonium credit will be from $30 \%$ to $70 \%$ of the net fuel cycle costs [65].

Numerous studies have been performed to determine how the value of plutonium might fluctuate for different reactors at different points in time $[5,9,10]$. The usual approach is to calculate the "indifference value" of the fuel to that of enriched uranium in the given reactor [66]. Fue1 cycle costs for the reactor employing both fuels are plotted against the fuel value. The point at which the two curves intersect is the point of indifference, and the fuel value corresponding to this is the "indifference value" of the fuel. This means the same fuel costs result whether 
the reactor is fueled with uranium or plutonium. Such "shadow-pricing" methods yield a value for plutonium from $80 \%$ that of fully enriched uranium in a light water reactor, to 1.5 to 2.5 times the uranium price in a fast reactor. What must not be forgotten regarding the results of this type of analysis are: 1) That the comparison is one based on comparative neutronic properties alone;

2) That the value is not a function of the inherent energy residing in the fuel; and 3) That the indifference value is the maximum market price which the fuel can assume for that reactor in competition with enriched uranium.

The major problem intrinsic in this type of value analysis is that plutonium may have one value in a fast reactor and an entirely different value in a thermal reactor. These represent on $1 y$ "reference" values for those respective reactor types. The market value may be quite different from these [67].

The British viewpoint on indifference values is advanced by I1iffe:

"For any nuclear power system which is large enough to be self-sufficient in plutonium . . . generating costs based on the assignment of a fixed value of plutonium are wellnigh meaningless. Nevertheless, generating costs 
determined in this way still appear to be fairly popular and may well be responsible for a widely held view that the cost of nuclear power depends, amongst other things, on the value of plutonium. But insofar as plutonium is a by-product of nuclear power for re-use with it, it would appear to be the value of plutonium that depends on the cost of nuclear power and not the other way about. In any event, a significant nuclear power programme would be dealing in several tonnes of plutonium a year and it would seem imprudent in this case to base a national power policy on the assumed existence of predictable markets for such quantities of plutonium well into the future. Again, the use of indifference curves is so hedged with restrictions that it can yield little information of practical value." [68]

From the viewpoint of economics, a fast breeder reactor is an electrical generating plant which requires a greater capital investment but has lower annual expenses (due to lower fuel costs) than a light water reactor. It has been stated that in this context the value of plutonium is that which makes the annual fixed charges on the plutonium investment the same as the alternative annual costs that are avoided through the use of plutonium [69]. The only result of such a solution is to have the annual costs by either method identical. In this condition there appears to be no advantage to either method of generation, especially not where there is a predominence of one type 
plant over another. It would seem that the preferred value for plutonium in such a case would be that which would amplify any differences.

The possibility of using a dual value concept has been proposed in which marginal power costs would be equated to marginal plutonium costs. A marginal value of plutonium results from the additional expenditure occasioned by the withdrawal of a unit of plutonium during one year and its re-introduction at the start of the next. The economic effect entailed by this withdrawal is the price of plutonium in that year. This method is said to be definitive and not for one year only. Hence, it is suggested that there is an optimum combination of thermal and fast reactors making it possible to minimize the total expenditure apart from plutonium [70].

The results of a number of different analyses of the future value of plutonium is shown in Figure 7. (One forecast has been divided into three regions in which there is either transient plutonium stocks, zero plutonium stocks or inevitably rising plutonium stocks [71].) One point on which almost everyone seems to be agreed is that in the 
long term, when there are a large number of breeder reactors producing great quantities of plutonium so that the supply overcomes the demand, the price will decline. The degree of price decline due to oversupply is not consistent, however. It is expected that during a period such as this, the excess plutonium could be burned in light water reactors. It is evident that any successful prediction of plutonium value must be based on supply and demand.

What is needed, and what will be the more realistic case, is the worth of plutonium in a mixed reactor economy as a function of time. Such a market price, besides including the effect of a higher neutronic value in a fast reactor, will take into account the increased fabrication charges that must be paid for remote handling. This is required by the greater degree of radioactivity and toxicity of plutonium than that of uranium. In an attempt to identify the correct market price, plutonium prices from $\$ 0$ to $\$ 30 / g$ have been examined to identify the importance of this variable with regards to: 1) total discounted energy costs; 2) its effect on the fast breeder introduction date; and 3) the effect on breeder growth rate. 


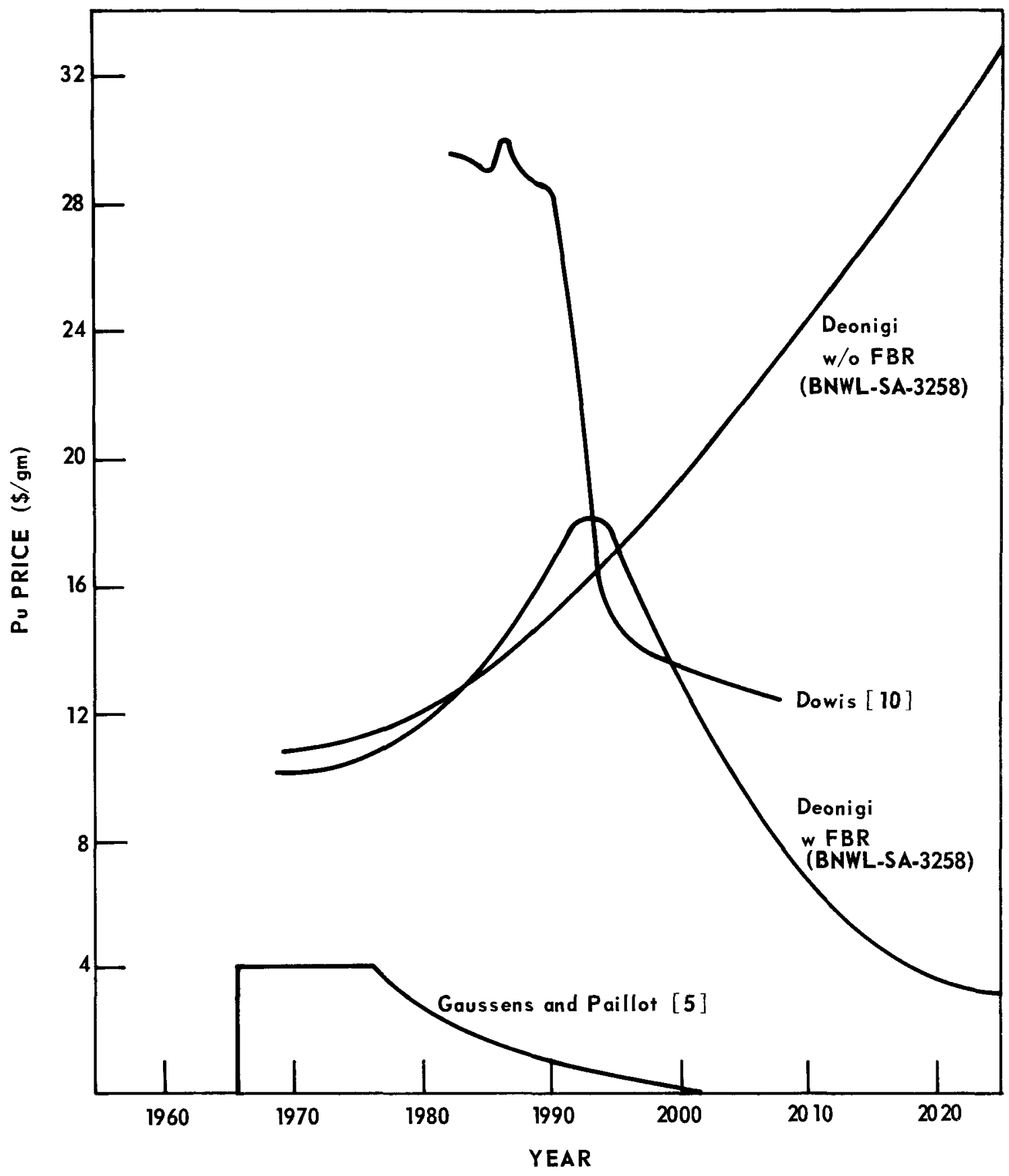

Figure 7: Contradistinctive Prognoses of Future Plutonium Worth 
NON-NUCLEAR FACTORS AFFECTING NUCLEAR GENERATING COSTS

There are myriad non-nuclear parameters which can affect the unit generating costs. The plant conversion efficiency and load factors both have the potential to greatly increase or reduce the generating costs. While the former is generally constant over the life of the plant, the latter is found to vary considerably due to plant start-up problems early in life and obsolesence in later life. The absolute plant costs $(\$ / \mathrm{KWe})$ can be significantly influenced by plant rating and plant site. Although these factors would not substantially affect the differential dollars per kilowatt between the two plants [72], they do have a large effect on the differential generating costs as the fixed charges are a greater fraction of fast breeder reactor generating costs than of light water reactor costs. Decreases in economic life also adversely affect the generating costs. However, the use of present-worth accounting tends to minimize this as the unrealized future revenues would be those having very low present-worth factors. Thus the non-nuclear technological factors will be considered as fixed. The economic factors, which cannot be considered to be constant, must be commented upon . 


\section{Capital Costs}

Although it is extremely difficult to project the future costs of large components, there have been a number of attempts to do so $[41,42,43,73]$. These generally commence with the present capital costs and assume some sort of "learning curve" decrease to represent savings which will be wrought through standardization and increased production. In the manufacturing industry the trend in standardization and experience gained has generally followed a $90 \%$ learning curve, i.e., each time the number of manufactured units is doubled, the unit costs are reduced by $10 \%$ [74]. Extrapolation of capita1 costs based on learning curves can be risky and is perhaps naive. Based on events of the past few years, a strong argument could be made for assuming no cost reduction due to learning at a11 [75].

Another potential source for reduction of these costs is the increase in unit size which yields some savings. This reduction is not being considered here as the units are assumed to be constant in size for a11 time. 
The resulting projections of the capital costs are shown in Figure 8. These capital costs are presented in constant dollars, i.e., no allowance has been made for inflation. Four different initial capital costs were chosen for the present day light water reactor costs. These cover the range of $\$ 175 / \mathrm{KWe}$ to $\$ 250 / \mathrm{KWe}$ representing the scatter in costs currently being quoted [76]. The current trend is toward the higher costs. Historically, there has been an inherent lower bias in the estimated capital costs of plants which have not yet been built. Further problem areas, which often require large capital expenditures, are either not anticipated or are minimized [77]. For this reason, an additiona $125 \%$ has been added to the costs of the light water plants to obtain the costs for the fast breeder reactors. Conversion of capital costs from $\$ /$ KWe to mils/KWH was made on the basis of $14 \%$ fixed charges and $80 \%$ load factor yielding $0.02 \frac{\mathrm{mils} / \mathrm{KWH}}{\$ / \mathrm{KWe}}$.

Operating, Maintenance, and Insurance Costs

Operating and maintenance charges are determined assuming a decrease in time based on experience similar to a learning curve. They are based on current data presented in WASH-1082 [78]. The variation with time is that given in 


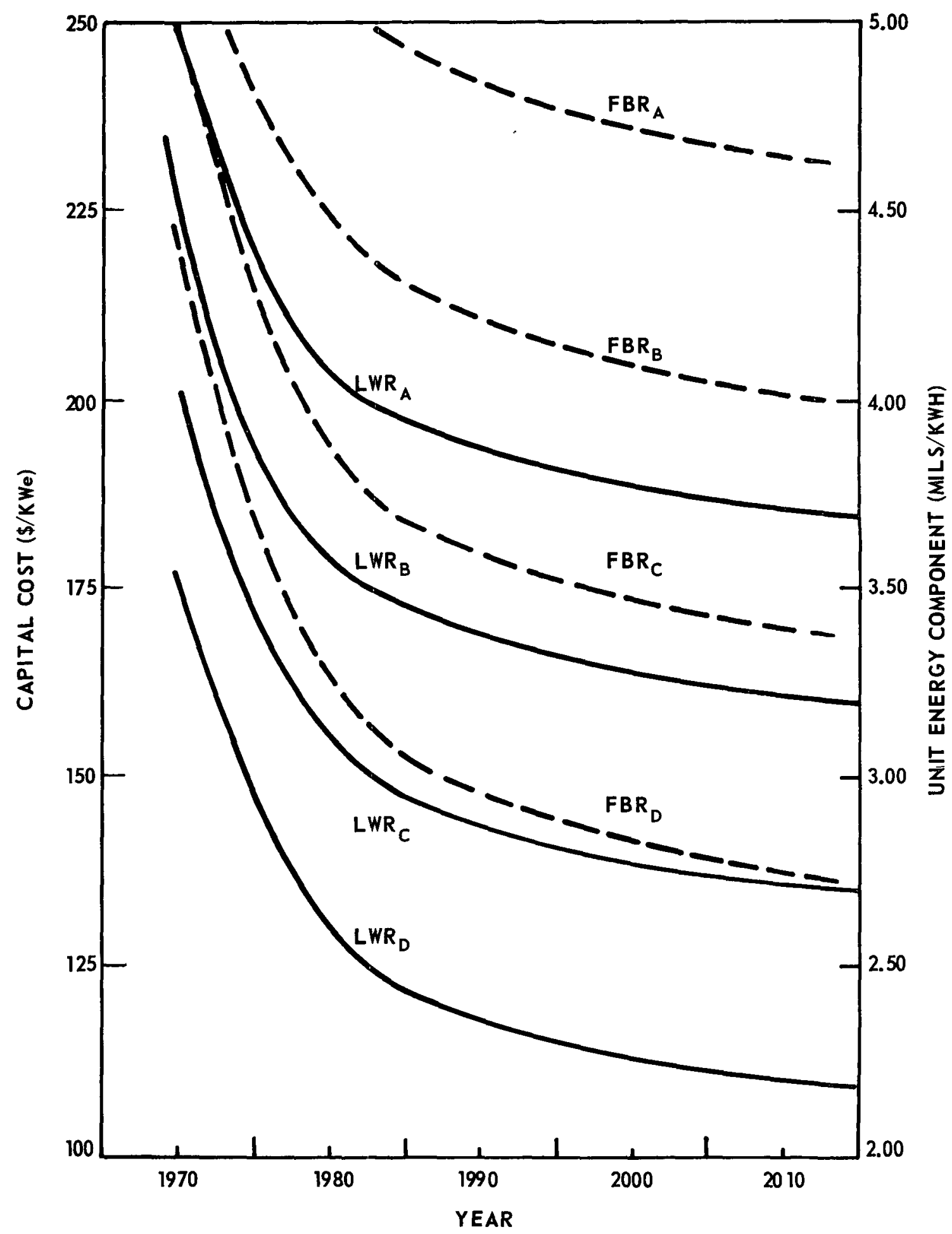

Figure 8: Potential Range of Future Capital Costs for Light Water and Fast Breeder Reactors 
the 1962 Report to the President [79]. Again the same penalty is added to obtain the LMFBR operating and maintenance costs. The resulting charges are plotted in Figure 9.

Insurance costs include property insurance as well as nuclear liability insurance and government indemnity. Initial rates have been obtained from the former report [78] and are considered to reduce in the future based on good records, refunds, etc. When computing insurance costs, no penalty is assumed for LMFBRs. Figure 9 also shows the portion of the generating costs that are allotted to insurance.

Bases for Fue1 Cycle Costs

The LMFBR fuel cycle technology is presumed to change at five year intervals as described in the Atomics International Follow-on Design [80]. The first five year period begins with the introduction of the LMFBR in 1985. Bases initia11y are: fabrication costs $\$ 225 / \mathrm{KgH}$ for core, $\$ 35-45$ for blanket; reprocessing charges and shipping charges are $\$ 70 / \mathrm{KgH}$ and $\$ 20 / \mathrm{KgH}$, respectively. Al1 these charges reduce during the five year periods. $\mathrm{U}_{3} \mathrm{O}_{8}$ prices are assumed to be $\$ 8 / 1 \mathrm{~b}$ and increase slightly while enrichment costs are $\$ 30 /$ unit of 


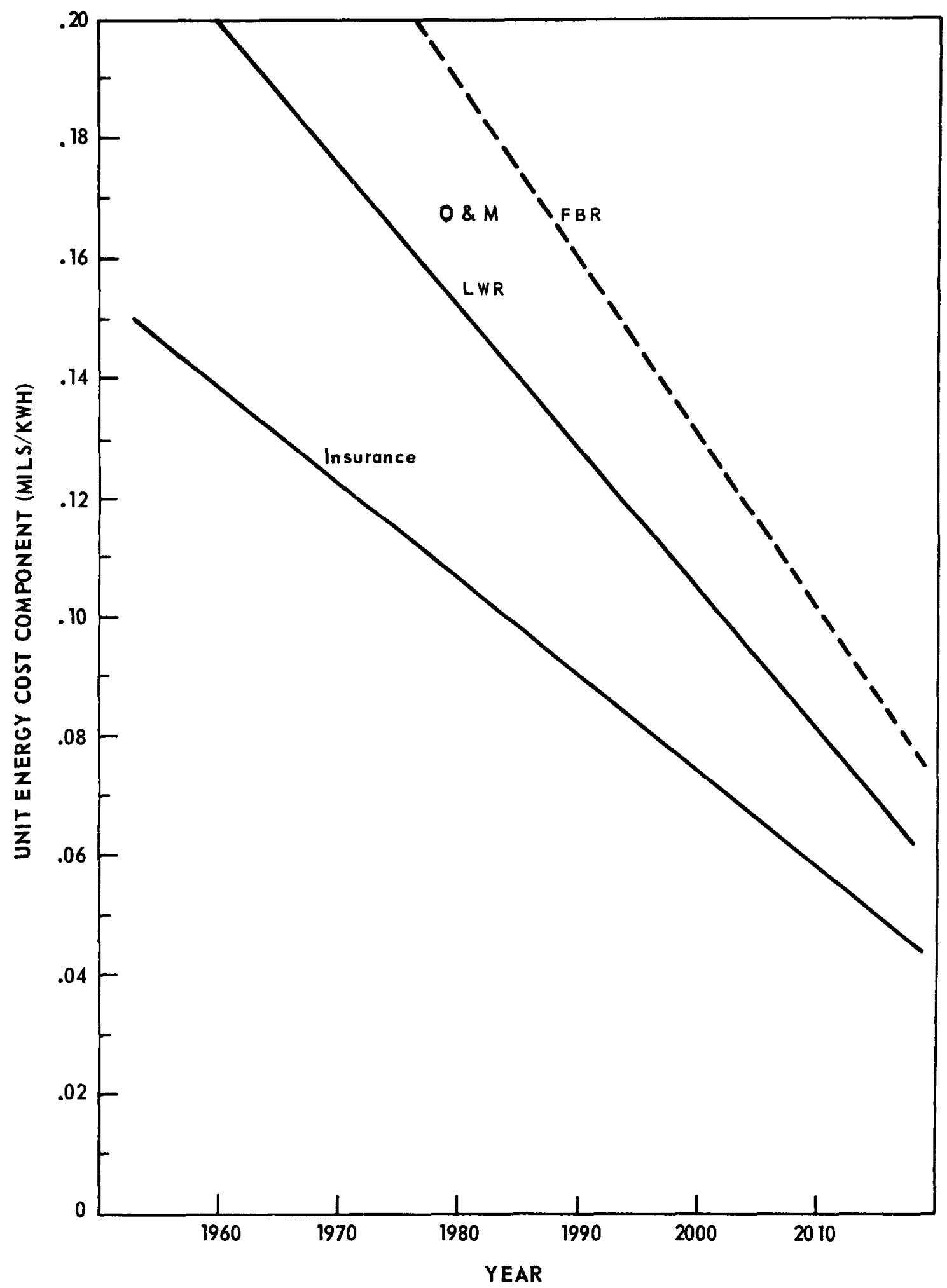

Figure 9: Estimated Future Operating, Maintenance, and Insurance Costs for Light water and Fast Breeder Reactors 
separative work and conversion charges amount to $\$ 2.20 / \mathrm{Kg}$. The latter charges are assumed to remain constant. Future increases in any of these values (like the recent rise in separative work charges) will result in the plutonium market price rising comparably.

Light water reactor fuel technology is also presumed to be time-varying in the same manner as that of the LMFBR.

Estimates of this were obtained from the AEC report on the Future Potential of Light Water Reactor Plants (WASH-1082) [81]. Fabrication costs for uranium fuel are considerably less than for plutonium fuel and at the inception of these estimates (1970), the price is $\$ 70 / \mathrm{KgU}$.

Instead of assuming traditional $1 \%$ fabrication and reprocessing losses, these have been varied in subsequent calculations from $0 \%$ to 10 and $5 \%$, respectively. Besides affecting the fuel cycle costs, these losses decrease the quantity of plutonium that is available for future uses. The total generating costs for the plants consist of the sum of the capita1, operating, maintenance, insurance, and fuel cycle components. These costs for both the light water reactor and the fast breeder are shown in Figure 10 as a function of time. These costs have been determined 


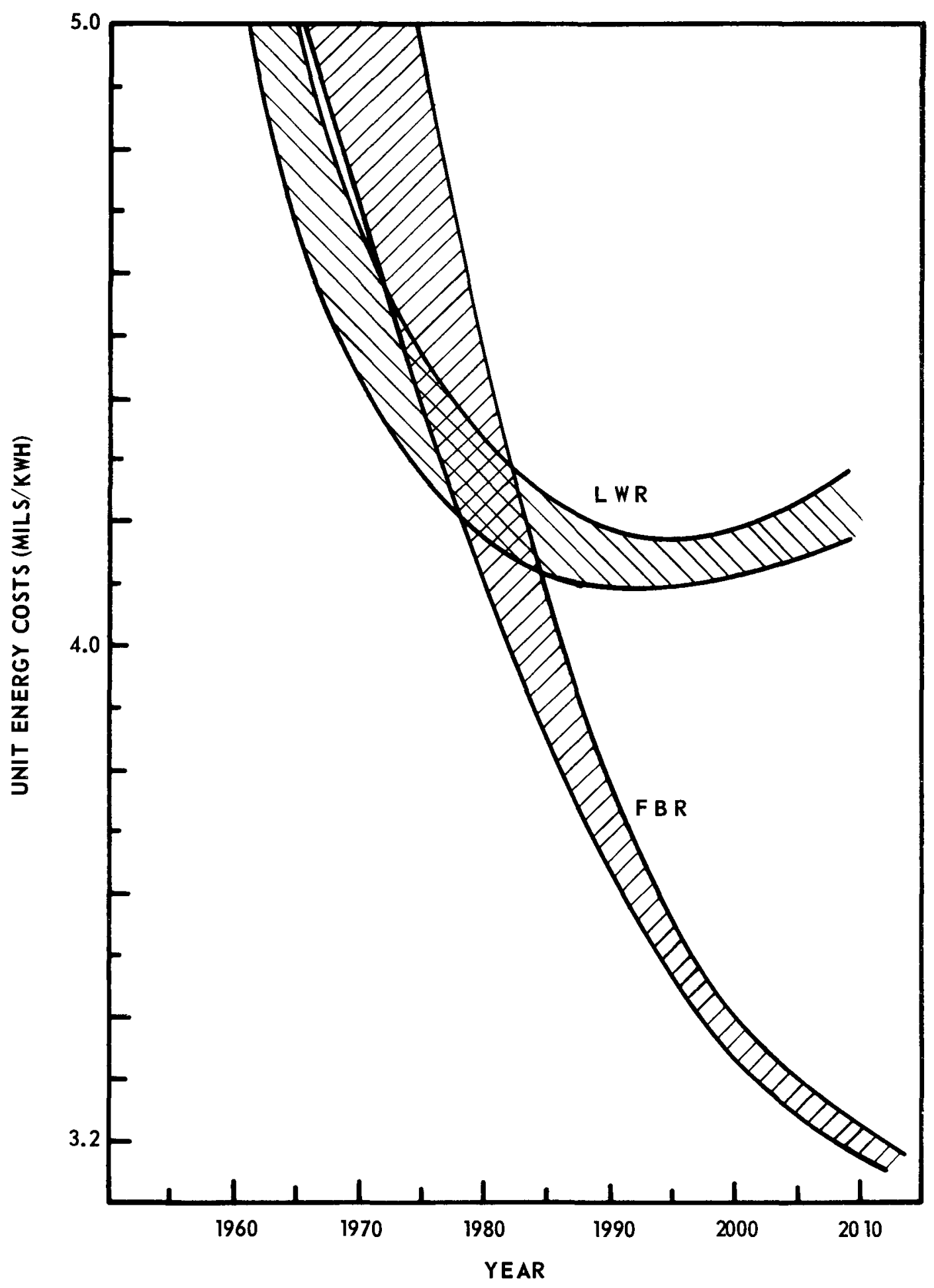

Figure 10: An Appraisal of Future Unit Energy Costs of Light Water and Fast Breeder Reactors at a Plutonium Price of $\$ 0 / \mathrm{g}$ 
at zero plutonium price. Figure 11 shows the effect of plutonium price on the generating costs of each reactor.

$\underline{\text { Discount Rate }}$

Around the mysteries of finance

We must perform a ritual dance

Because the long term interest rate

Determines any project's fate.

At four percent the case is clear;

At five some sneaking doubts appear;

At six it draws its final breath,

While seven percent is certain death.

Prof. Kenneth Boulding

University of Michigan

The economic optimum allocation of resources requires that capital resources be used in the manner providing the largest return, i.e., where the difference between benefits (revenues) and costs are the greatest. This necessitates the comparison of disparate items: dollars now versus dollars later. Such a comparison requires converting future dollars to current dollars through the process of discounting. (See footnote, page 21).

Almost a11 projects generally involve a series of annual costs and a flow of benefits over time. Calculation of the present value of costs and benefits through discounting gives consideration to the time periods in which benefits 


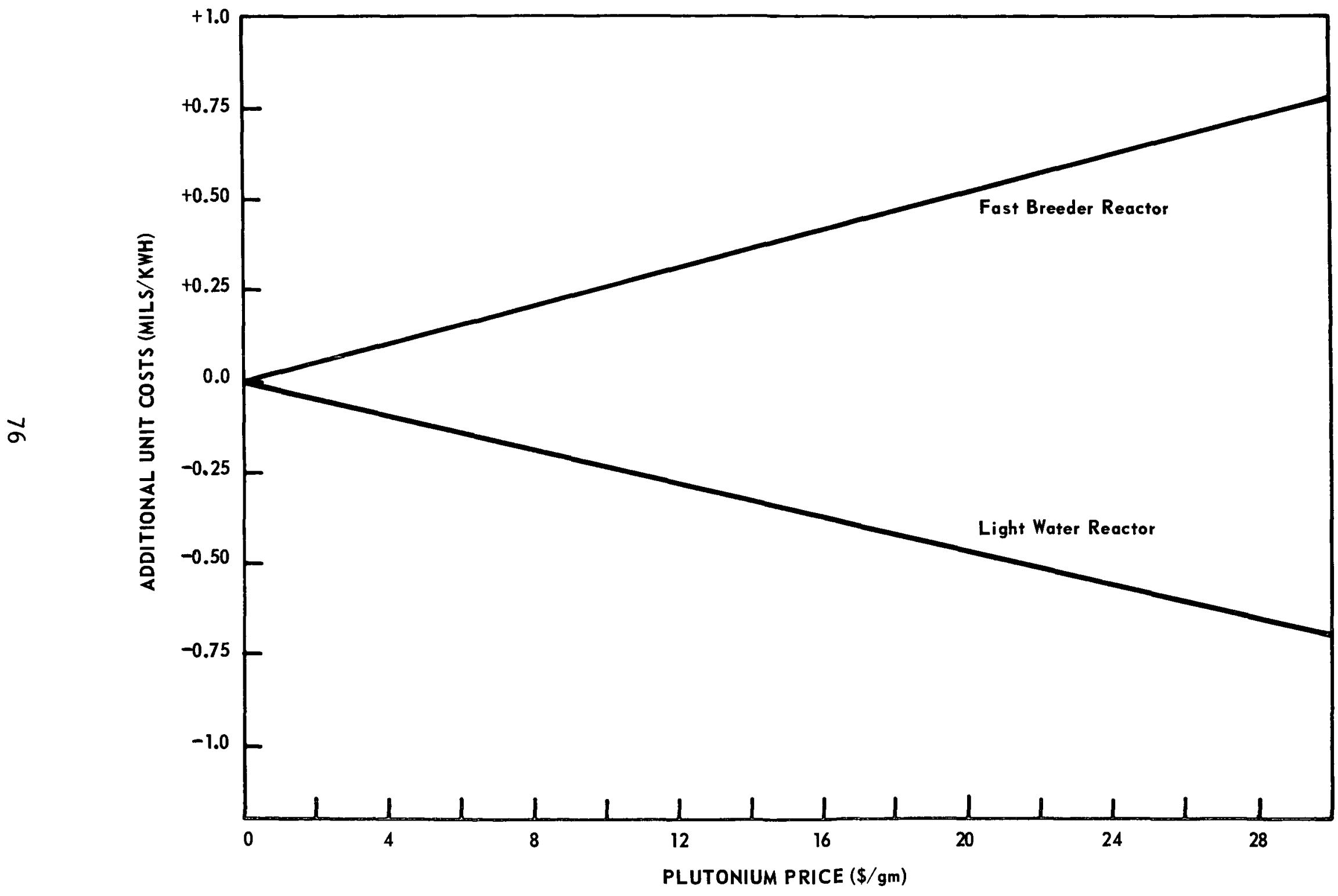

Figure 11: Variation in Light Water and Fast Breeder Reactor Fuel Cycle and Unit Energy Costs for Particular Plutonium Prices 
will be realized and costs incurred and the time value of money. The present value of $\$ 100$ in the future is shown in Figure 12 for various discount rates. At a low or zero interest rate, the present-worth of expenditures in the distant future is very nearly the current worth. At high interest rates, the present-worth of future undertakings is very small. This means that a project proposed at a high discount rate will have to show much higher future benefits than the same project at a lower rate of return. The selction of the discount rate is of particular importance in our problem since the discount rate has a large impact on benefits distant in time [82].

In private capital markets, investors do not choose investments to maximize the present value of expected returns alone, but to maximize the present value of returns with the risk factor adequately weighed. To do this, they employ either the time-preference discount rate or the opportunity cost rate. Time preference assigns current values to future consumption and need not take the form of a constant discount rate [83]. Opportunity cost is a measure of the value to the investor of the next best alternative to which his capital might have been put. 


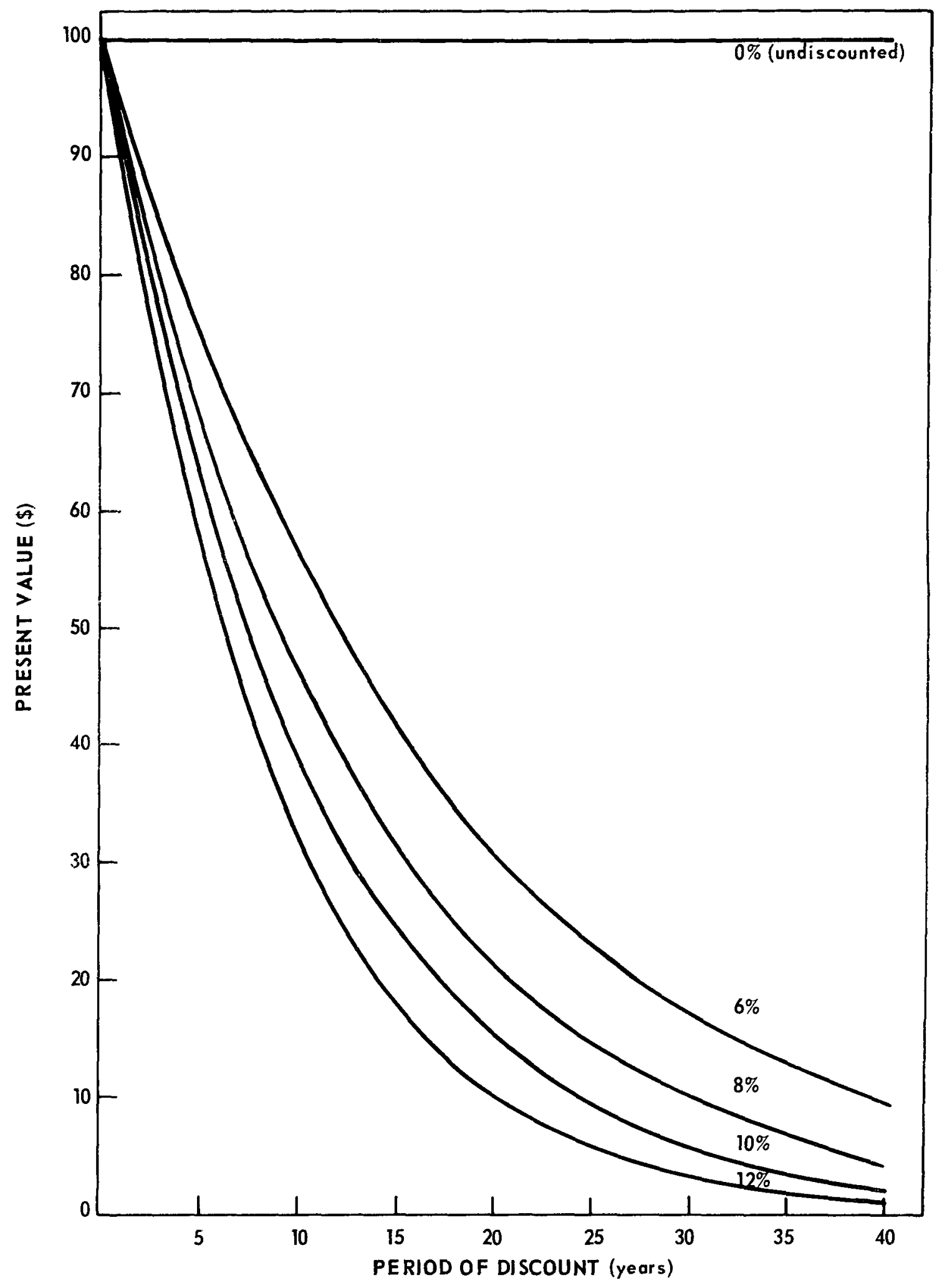

Figure 12: Dependence of the Present Value of $\$ 100$ on Discount Rate for Years in the Future 
There are three basic problems in identifying the social discount rate with the market rate. These are first a divergence between private values and market behavior because of capital market imperfections; second, a divergence between social (public) values and private costs in the products of government investment activity; and third, the divergence between social and private values with regard to perspectives for the future [84].

The argument in favor of this last is simply that when the marginal social discount rate (or rate to achieve benefits that will accure to future generations) is lower than the market rate then it is the obligation of the community in its collective political capacity to properly see to it that investment opportunities with future returns too low to justify private exploitation without the intervention of the state are, in fact, undertaken [85]. In the public sector paralleling the two types of discount rates being used in the private sector are social time preference and social opportunity cost. Under social time preference, public investments provide benefits for future generations, and it is unlikely that the current cost of capita1 provides the correct interest rate for evaluating 
public investments. Thus it is contended that current interest rates do not permit future generations to express their preference, and that the government ought to adjust their current rate downward to assure these necessary projects. In perfect capital markets, however, since investments are discounted in both time and risk, the discount rate obtained in these markets should be used to evaluate public investments. Thus a single discount rate should be used, whether a project is private or public, in making efficiency calculations for any given state-pattern of returns. When the recommendation is made to employ for government investments the private market discount rate for "comparable" projects, it must be understood that "comparable" projects are those having the same proportionate time-state distribution of returns [86].

It is acknowledged that the social time preference rate would probably be the best discount rate in a perfectly competative, perfectly functioning market economy. Since the actual market economy that is envisioned here is somewhat less than perfect, it is necessary to identify what other actual investiunts or corsumption are foregone, and what their return would have been [87]. 
Another school of thought maintains that the overall cost of money in the public sector is the composite rate individuals and corporations in the private sector earn on their marginal incomes. Marginal incomes are defined as that part of society's total income that is foregone in paying the last increment of federal income taxes. This composite rate, called the opportunity cost of money, is very difficult to compute and able economists arrive at different values [88]. However, nearly all of the computations made result in the opportunity rate being considerably higher than the government's cost of 1ong-term borrowing [89].

The social opportunity cost is a measure of the value to society of the next best alternative use to which funds employed in the public project might otherwise have been put. The opportunity cost of consumers is at least equal to the rate they can receive on riskless Government bonds currently estimated to be about 5-1/2 percent. Judged by interest rates consumers are willing to pay, rather than forego current consumption, the opportunity cost of capital to consumers is considerably higher, ranging upwards from 7 percent. Thus perhaps the relevant interest rate for use in evaluating public investments 
should be in the range 8 to 10 percent [90].

The issue which must be resolved is whether it is appropriate to discount public investments in the same way as private investments. There are several positions on this issue. One is that risk should be discounted in the same way for public investments as for private investments. A second position is that government, being better able to cope with uncertainty than private investors, should ignore uncertainty and behave as if it were indifferent to risk. In support of this position, it is argued that the government invests in a greater number of diverse projects and is, therefore, able to pool risks to a much greater extent than private investors. A third viewpoint asserts that time and risk preference relevant for government action should be a constant for al1 projects, estab1ished as a matter of National Policy. The rate of discount and attitudes toward risk would be specified by the appropriate authorities, and the procedures for evaluation would incorporate these time and risk preferences [91]. 
As far as government financing is concerned, it has been suggested that an interest rate equal to the cost to the Federa1 Government of borrowing be employed. This concept has been explored, and it was estimated that including lost tax revenues and other adjustments the true cost of government borrowing, even at an apparent rate of 3.2 to $5 \%$, was actually $7.6 \%[92]$. In its role as an investor it was felt the government should make those worthwhile investments which private investors cannot undertake, fail to undertake, or undertake in insufficient quantity.

A U. S. Joint Congressional Subcommittee on Economy in the Government recommended that no public investment be deemed "economic" or "efficient" if it fails to yield overall benefits which are at least as great as those which the same resources would have produced if left in the private sector [93]. The reason for the study conducted by this Joint Committee was that the range of interest rates applied by government agencies extends from $0 \%$ to more than $20 \%$ [94]. The effect of this discrepancy is to bias the decision process in favor of projects using low or zero interest rates as against those using higher 
rates. By applying a standard discount rate to alternatives within a single program, the agency is in a better position to select the most economical alternative. The need for a common discount rate is especially important for deciding between many competing projects in diverse fields of endeavor.

As its conclusion, the Joint Subcommittee found that the appropriate discount rate to be utilized by the government for investing in the public sector was the opportunity cost of displaced private spending [95]. Thus the discount rate which should be employed by all large scale capital projects, pub1ic or private, is somewhere in the neighborhood of $10 \%$. In order to incorporate this development into the present calculations, a reference rate of $10 \%$ has been used for discounting. A range of discount rates from $5 \%$ to $12 \%$ has also been considered so that the final results should be applicable to either private market discount or to the recommended social rate of discount. 


\section{RESULTS}

Numerous interesting consequences arise out of performing the calculations described above. The discounted nuclear generating costs accumulated through the year 2010 in all of the cases considered ranged from a lower of $\$ 167$ billion to a high of $\$ 425$ billion. This study is primarily concerned with the determination of the effect of each variable on the cumulative discounted nuclear generating costs. However, it is also possible to predict from the same results the effect of these variables on the plutonium price to achieve equilvalent unit generating costs, the introduction date of fast breeder reactors, the achievable breeder growth rate, the peak fraction of breeder reactors, the ultimate fraction of breeders and the plutonium price as a function of time.

The fast breeder reactor introduction date is considered to be the year in which the unit energy costs of the breeder equal those of the light water reactor. At this time, it is considered to be economically feasible for their commercial introduction. The breeder growth rate that has been utilized here is the greatest rate 
technologica11y achievable, i.e., limited only by constraints such as plutonium availability. Such a breeder growth rate can result, for some cases, in breeder reactors being the only addition for a number of years. There are some obvious reasons why this may not be the most desirable alternative.

The breeder fraction is defined to be the fraction of installed breeder reactors to a11 installed nuclear capacity, not just the fraction of one year's nuclear addition that is breeder. The peak breeder fraction is the maximum fraction of total installed capacity which breeder reactors can achieve due to limitations from breeder deployment policy or plutonium availability. The ultimate fraction is that level of fast breeder activity that may be sustained indefinitely. These new concepts of peak and ultimate breeder fractions have been found to be useful criteria for measuring the effectiveness of different fast breeder reactor introduction and growth strategies. 
The variables will be considered separately so that their effects may be isolated. The effect of different generating capacity estimates and the various capital cases is discussed first since they are the least able to be quantified and predicted with confidence. The estimate of capacity and relative capital costs have so great an effect that it is desirable to fix these for the duration of an analysis so that the effects of the other variables may be determined. Later when comparing the results of the other variables, the costs are normally shown for a single capacity estimate and capital case. The lowest cost is usually shown so that any differences will be more evident. It should be mentioned, however, that the trend in the results does hold true from one capital case to another although the differences are less pronounced at higher capital cases.

Effect of Nuclear Generating Capacity and Capital Case The difference in nuclear generating capacity estimates has a nearly proportionate influence on the total amount of money expended in generating costs. The reason it does not have an exactly proportionate effect is that there is a difference in the time distribution of the expended costs which is affected by discounting. When the 
discounted costs are accumulated, they are not proportionate to capacity as seen in Figure 13. The extent of the nuclear generating capacity has little effect upon the plutonium price at which a breeder and light water reactor yield equivalent unit generating costs (see Table V) and, hence, on the breeder introduction date.

The installed nuclear generating capacity does have considerable effect on the ultimate fraction of fast breeder reactors that can be built. Figure 14 shows that for the same capital cost case in the two different generating capacity estimates, the fast breeder reactor maximum portion occurs at about the same fraction. However, as time proceeds in the lower estimate this fraction drops off to approximately $60 \%$ while in the higher estimate it is possible to maintain a fraction slightly greater than $68 \%$. The difference is attributable entirely to the difference in installed capacity and thus the different absolute amount of plutonium that is available for use. About $8 \%$ difference in the two ultimate fractions corresponds to an installed fast breeder reactor capacity of some 120-150,000 MWe. If the higher capacity does materialize, it would mean that there would be sufficient 


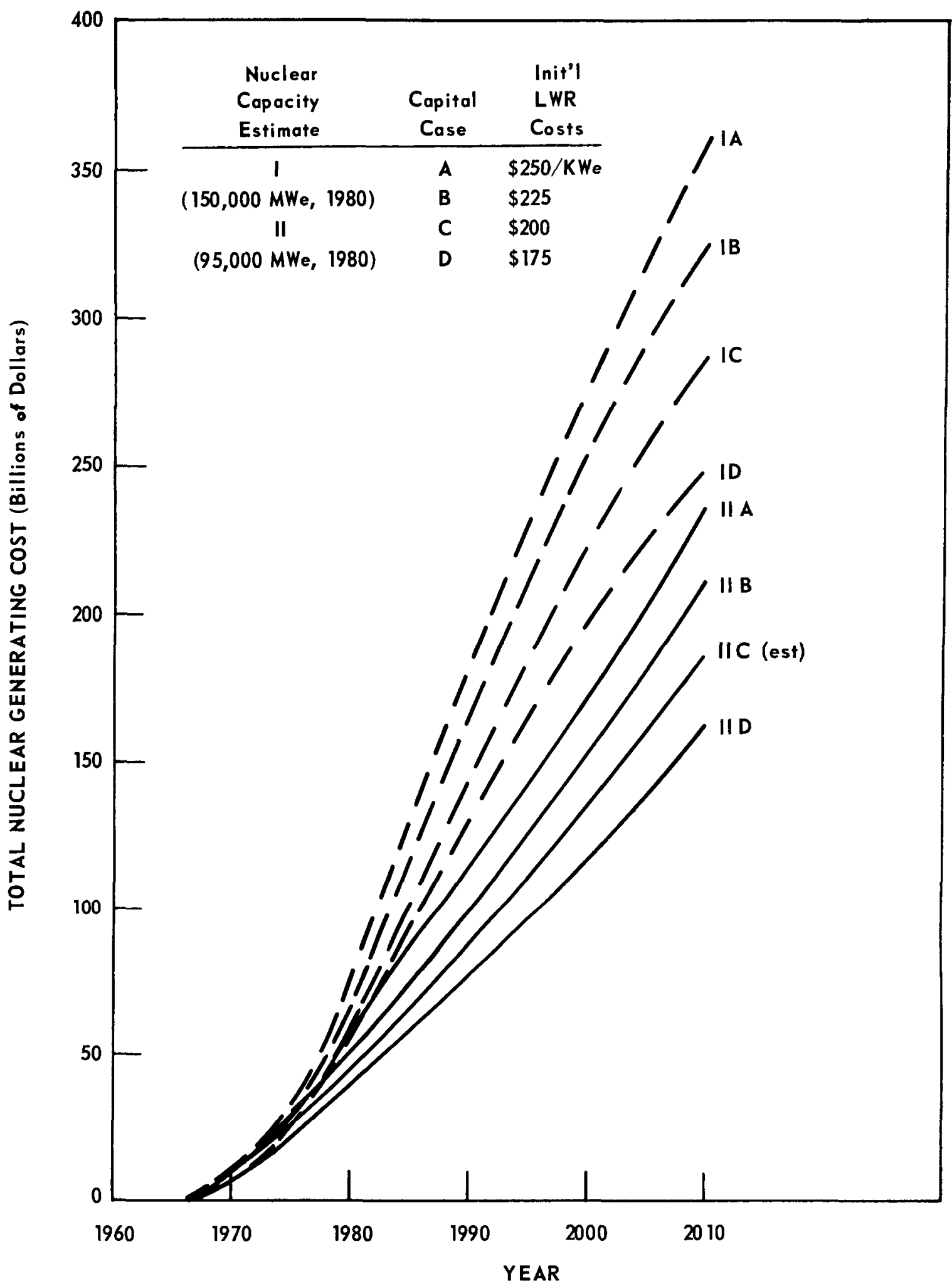

Figure 13: Cumulative Idea 1 Generating Costs in Future Years as Affected by Generating Capacity Estimates and Capital Case 
TABLE V

CONDITIONS FOR COMPETITIVE LWR-FBR UNIT ENERGY COSTS

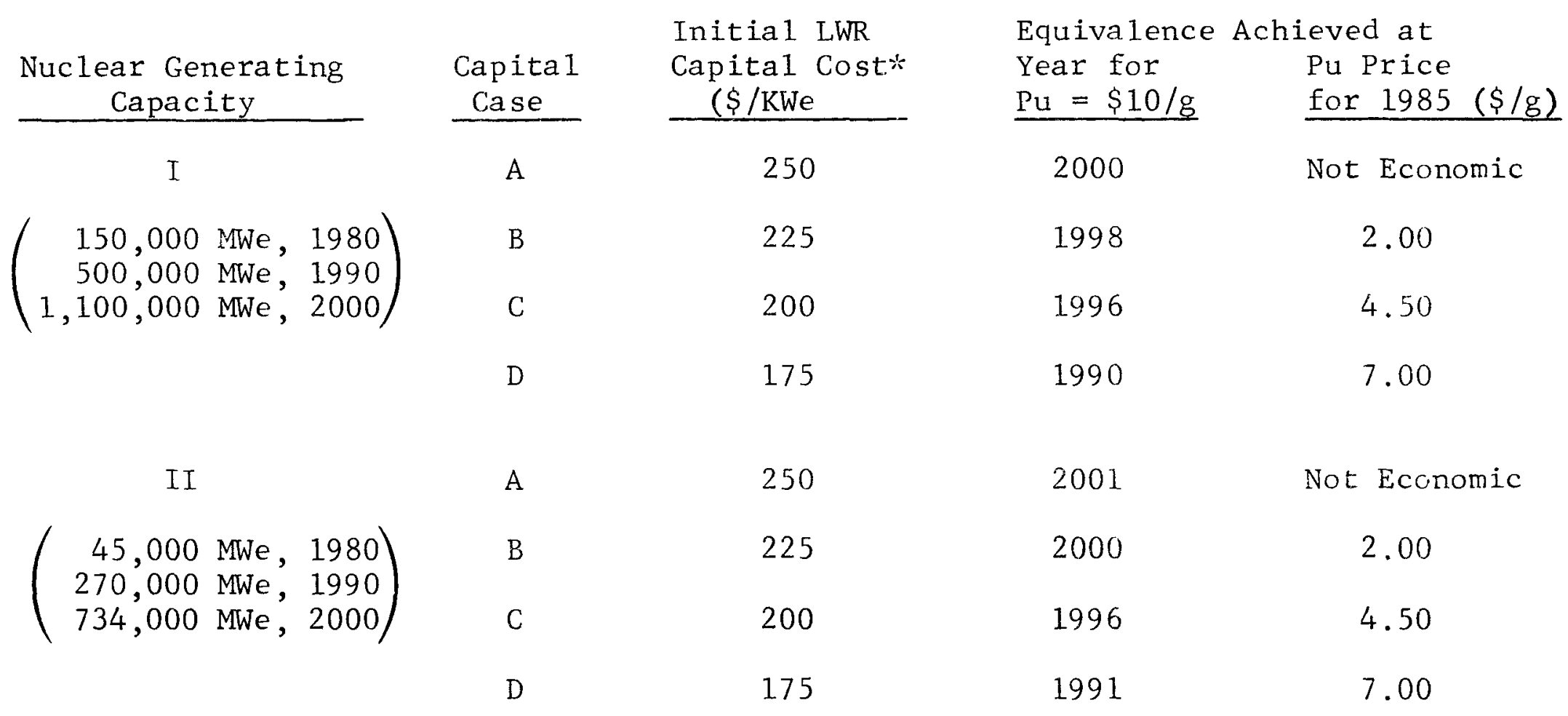

$*$ In al1 instances FBR capita 1 costs $=1.25 \cdot($ LWR capita 1 costs) 


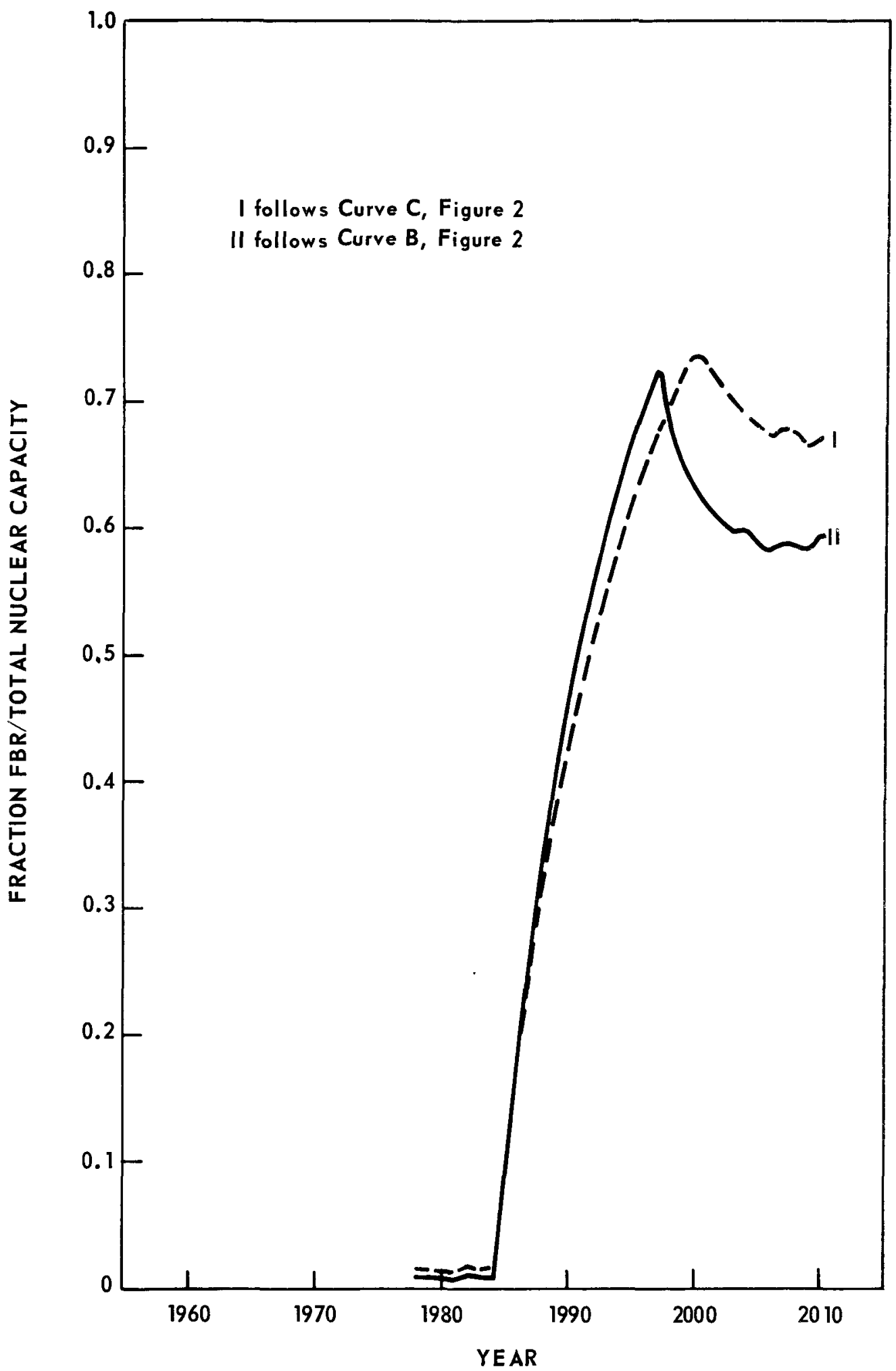

Figure 14: Largest Possible Fast Breeder Reactor Fraction Versus Time for Two Nuclear Capacity Estimates 
additional plutonium to fuel more than one hundred fast breeder reactors of 1000 MWe capacity.

As might be expected, the magnitude of the capital costs has a considerable effect on the cumulative nuclear generating costs (see Figure 13). The higher capital costs result in greater accumulated generating costs; there being at any time a constant ratio between the two. Capital costs should not and do not affect the rate of growth of breeder reactors because of the way the mode1 has been defined. However, since capital costs comprise a greater fraction of fast breeder reactor unit costs than in the case of the light water reactor, they bear heavily on the date of economic competition between the two reactor types for a given plutonium price (see Table V). Conversely, the plutonium price required to achieve equivalent unit energy costs in 1985 is widely diverse. A greater differential between light water reactor and fast breeder reactor capital costs will require a later introduction time or a lower plutonium price for 1985 introduction. 
Thus, from a consideration of Table $\mathrm{V}$ it can be seen that in order to have breeders that will economically compete with light water reactors by 1985 or 1990 either: 1) The capital cost must be toward the lower portion of the range considered; or 2) The fast breeder reactor-light water reactor capital cost differential must be lower than considered; or 3) The plutonium price must be extremely low to offset the higher capital costs.

Effect of Plutonium Price

One of the most important variables affecting the total nuclear generating costs as well as the breeder introduction date and rate of growth is the price of plutonium. This is because the energy costs of light water reactors calculated according to present practices improve with increasing plutonium price (credit) while those of fast breeder reactors worsen*. Since the unit energy costs of the two plant types are greatly influenced by plutonium price, the annual generating costs can vary by as much as $25 \%$ depending upon the breeder fraction in that year and the plutonium price. A difference of this magnitude can

*In this analysis, the plutonium credit and charges have been included in the nuclear fuel cycle cost as is the practice in the nuclear industry. 
amount to more than $\$ 10$ billion in annual generating costs for some of the later years. Because of this great difference, the most economical reactor type should be as great a portion of the installed nuclear capacity as possible. Figure 15 shows such a variation for capital case $C$ in the year 1985; the LWR-FBR break-even point can be noticed at a plutonium price of about $\$ 4.50 / g$ (cf. Table v). This same pattern is found to apply for al1 other capital cases considered as well.

This figure also suggests that there is a "mix" of light water reactors and breeders which is insensitive to variations in the price of plutonium. Such a relationship has been found to occur in all capital cases for a fast breeder fraction of $47 \%$. Furthermore for a given case, the fast breeder fraction yielding this insensitivity to plutonium price remains constant for the duration of the study. This suggests that the impact of varying plutonium prices can be minimized if the breeder fraction is kept adjusted to this value.

While the $47 \%$ fraction is the result of the parameters used in this model, the concept of a "mix" insensitive to plutonium price is valid for whatever type of reactors 


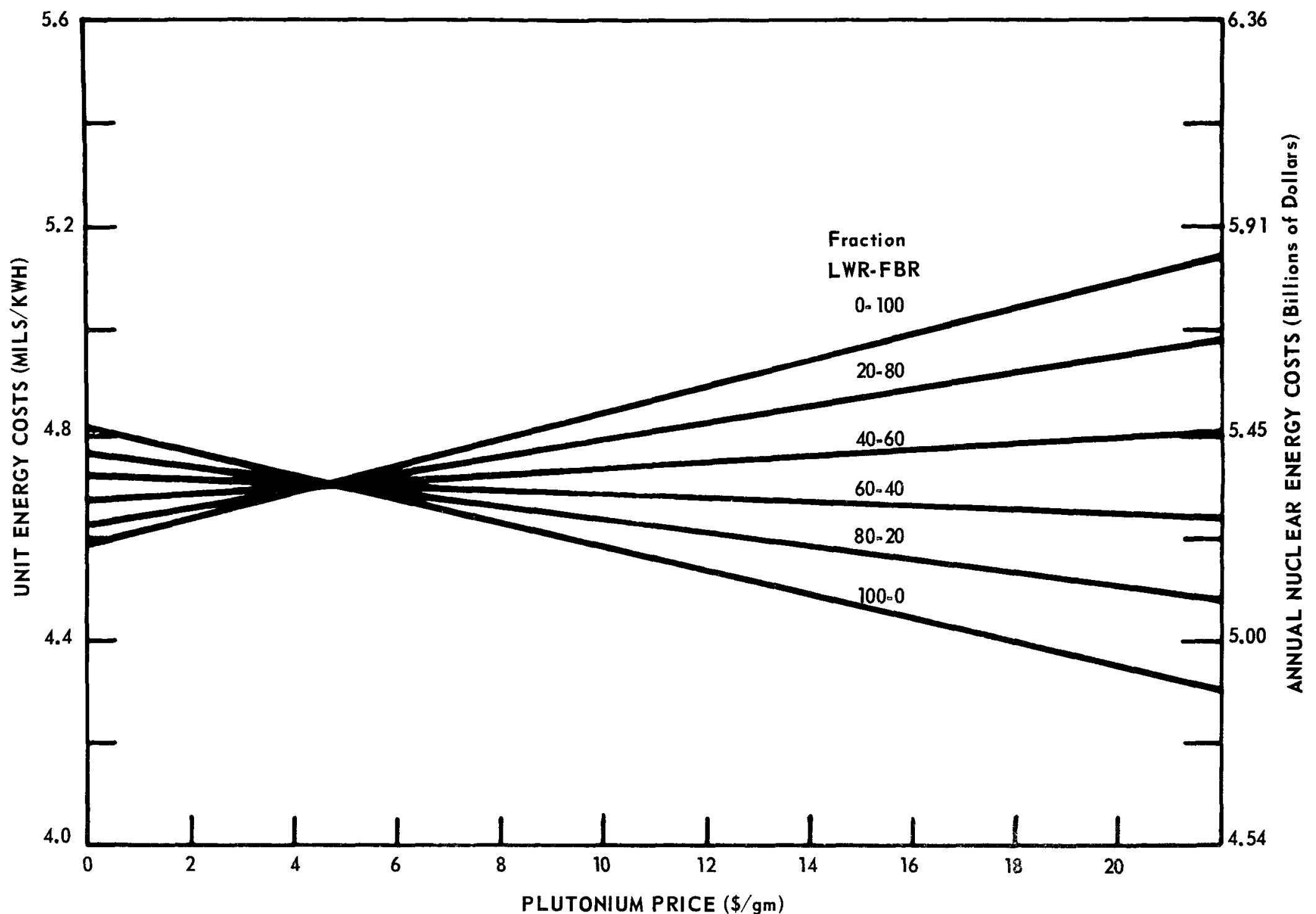

Figure 15: Unit Energy and Annual Generating Costs in the Year 1985 as a Function of Plutonium Price for Various LWR-FBR Mixes of Capita1 Case $\mathrm{C}$ 
make up a system and whatever parametric values are used in the analysis.

Figure 16 indicates the earliest economic breeder introduction time and rate of growth as a function of plutonium price for the lowest capital case (II-D) where the conditions for breeder introduction are most favorable. A11 other capital cases result in later FBR competitiveness (cf. Table V) but similar trends in growth rate. Even this low capital cost case does not permit competitive breeders by the year 2010 for plutonium prices above $\$ 21 / g$.

The effect of plutonium price on the four capital cases assuming the faster nuclear capacity growth is shown in Figure 17. This figure is a plot of the additional cumulative costs versus plutonium price. The increase in plutonium price from 0 to $\$ 25 / g$ alone adds as much as $\$ 20$ billion (discounted) through the year 2010 to the nuclear generating cost. This represents an increase well over ten percent of the total generating costs. 


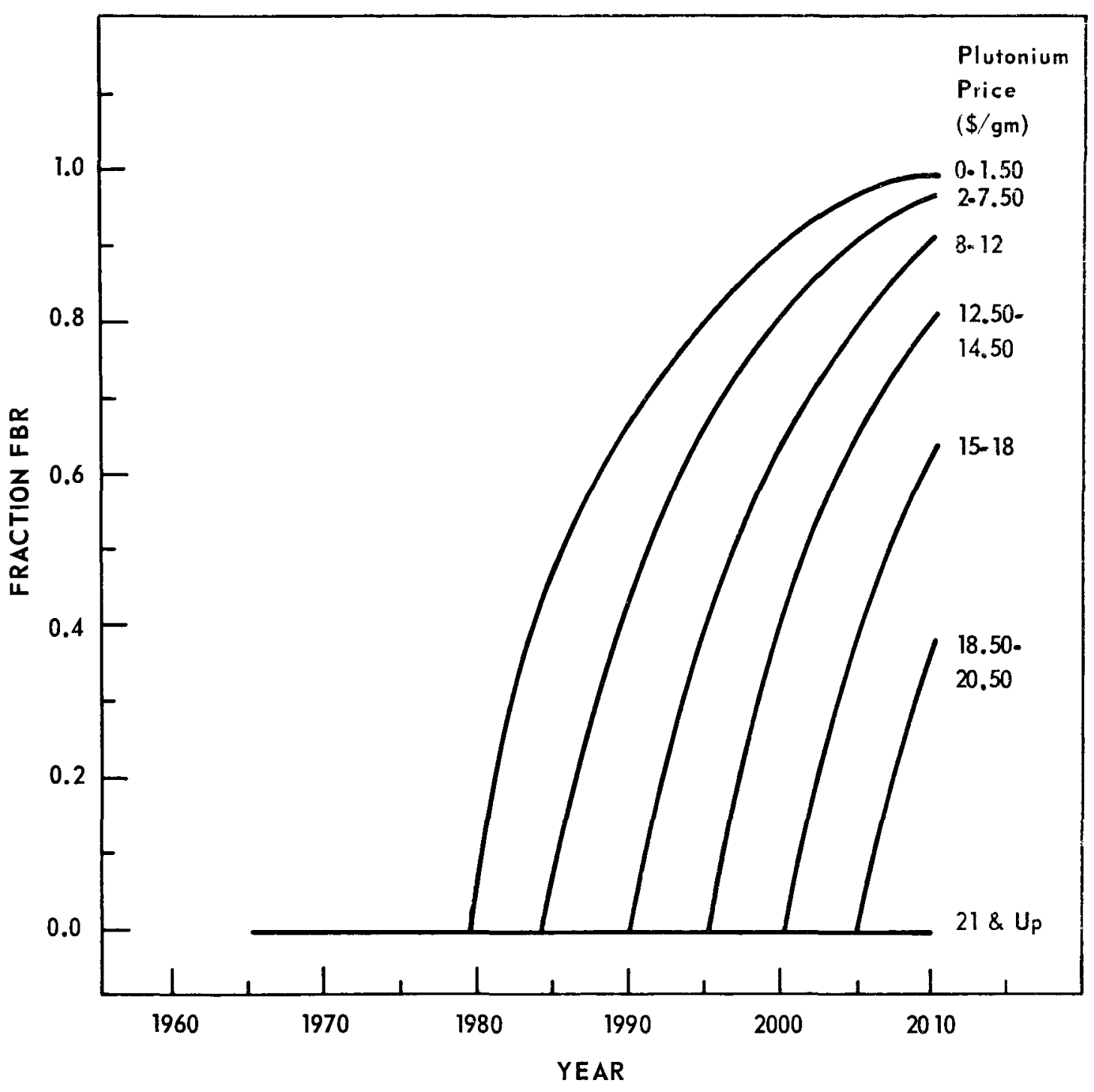

Figure 16: Dependence of Introduction Date and Ideal Breeder Reactor Fraction on Plutonium Price for Capital Case D 


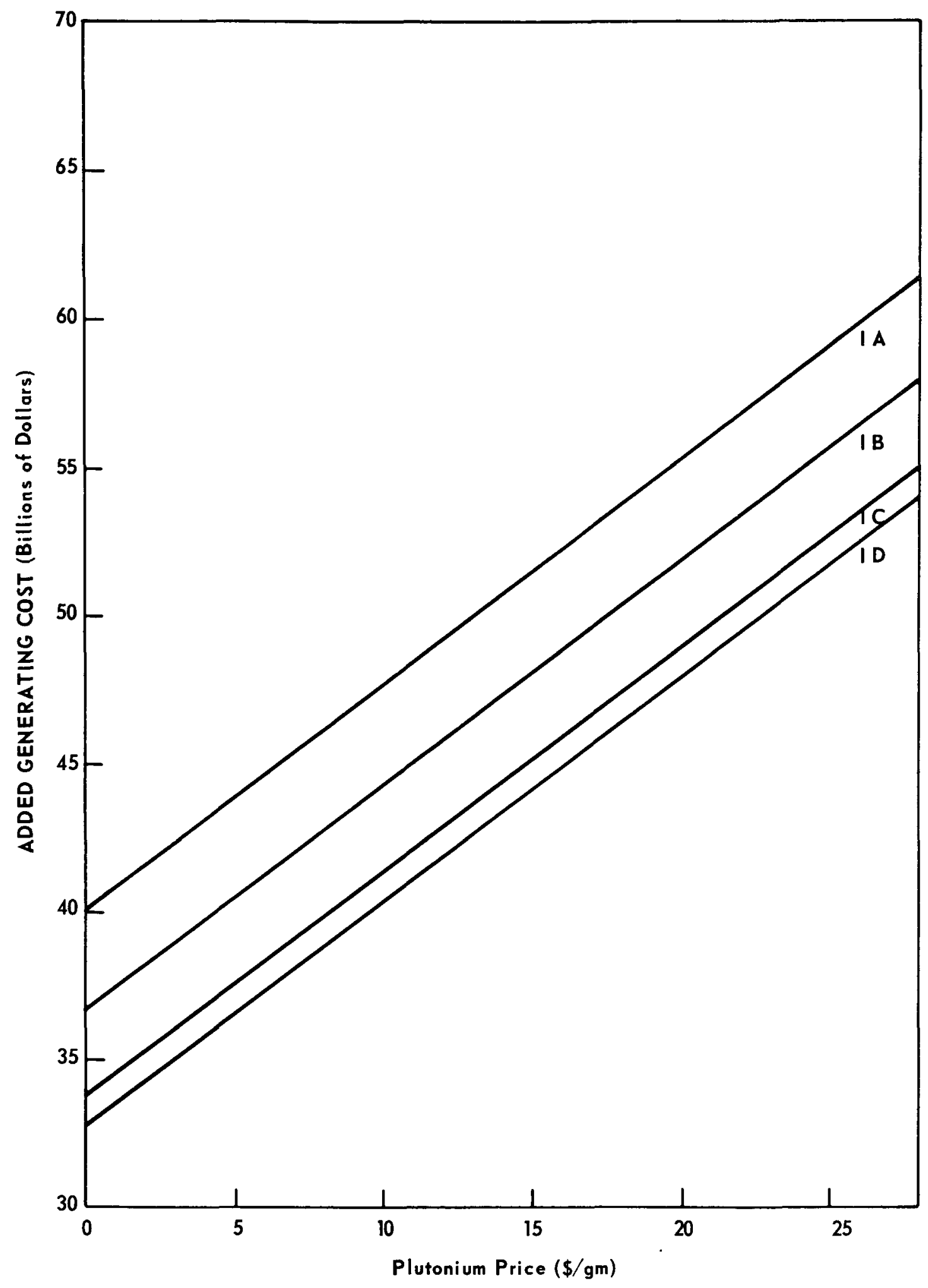

Figure 17: Added Nuclear Generating Costs (to the Year 2010) as a Function of Plutonium Price for the Various Capital Cases 
Effect of Plutonium Utilization

The policy that has been pursued regarding plutonium utilization in light water reactors affects the cumulative generating cost, the breeder growth rate, and both peak and ultimate breeder fractions. The two extremes are to hoard all the plutonium that is generated in light water reactors for future use in fast breeder reactors or to burn all the plutonium recycling it in light water reactors as fast as it is produced. There are, of course, a variety of intermediate strategies which could be assumed such as recycling all plutonium except that produced perhaps five years before the breeder introduction date.

The economic consequences of the extreme plutonium recycle philosophies are demonstrated in Figure 18. Comparing curves 1 and 2 which are for the same plutonium price $(\$ 5 / g)$ and discount rate $(10 \%)$, the first shows the added generating costs associated with total recycle; the second with all plutonium being stockpiled for exclusive use in fast breeder reactors. It is seen that plutonium recycling pays dividends in the short term by reducing the added costs. However, if the comparison is continued for a longer period, the reverse situation is true by the 


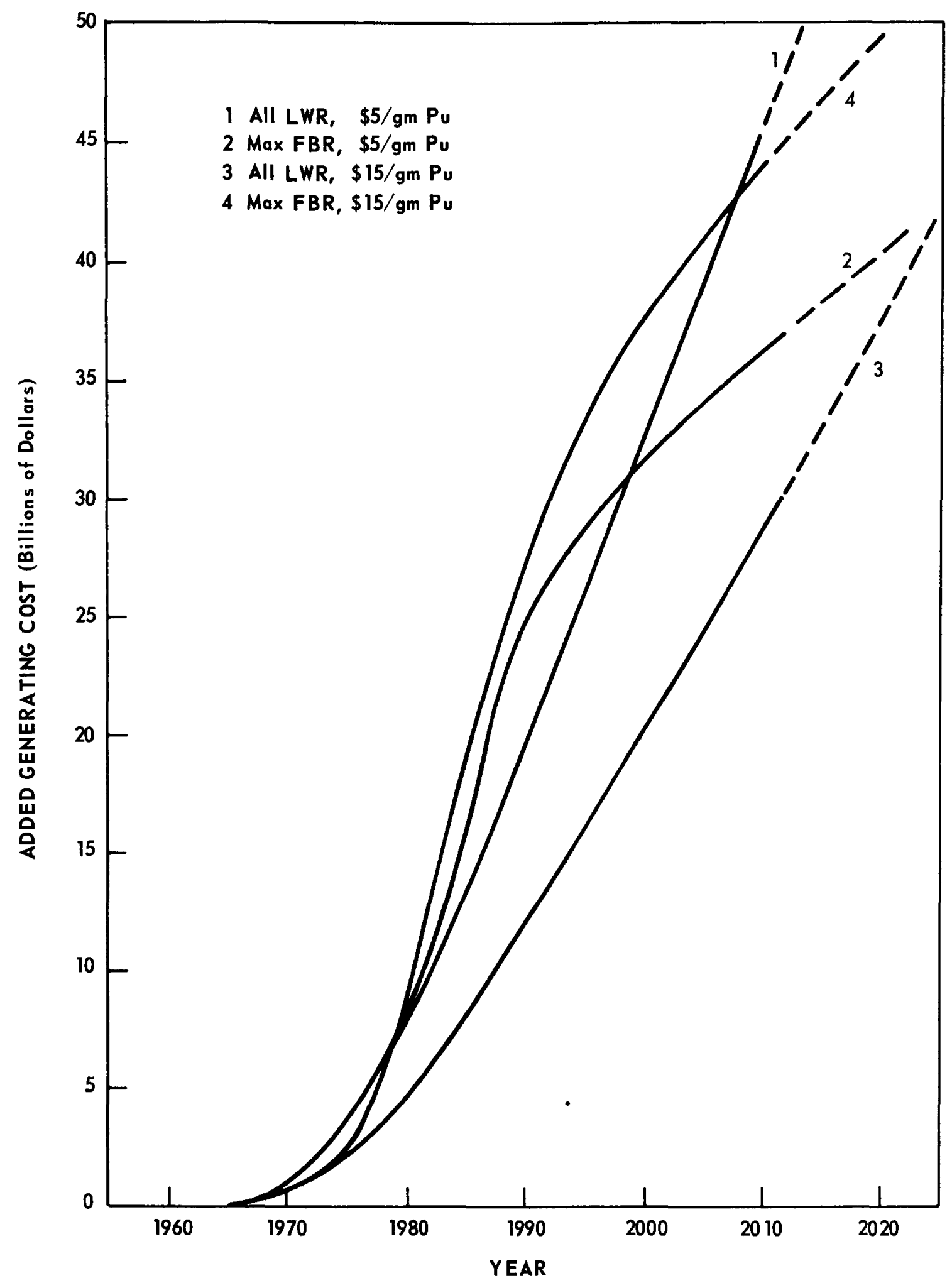

Figure 18: Added Nuclear Generating Costs (to the Year 2010) for Extreme Plutonium Utilization Schemes and Representative Plutonium Prices 
year 2000. Thus, of the two extremes, saving plutonium for the total commitment to fast breeder reactors is found to be eventually less expensive even including the costs of plutonium inventory. Curves 3 and 4 show that the same trend still appears to hold true for a higher plutonium value $(\$ 15 / g)$. Here, however, one must wait still longer for the investment to bear fruit.

This figure thus demonstrates the need for using a sufficient1y long horizon in a study of this kind. Had the results been compared through 1995, for instance, a different conclusion would be arrived at.

While the economic results (discounted cumulative generating costs) are greatly dependent on the plutonium price along with the strategy of plutonium disposition, the maximum fast breeder reactor growth rate is controlled purely by the quantity of available plutonium rather than by economic factors.

The amount of plutonium that would be required in order for the breeder to be added at the fastest possible rate has been presented in Figure $6(\mathrm{p} .55)$. It can be seen that, even in the case where all plutonium has been stockpiled, the rate of breeder addition must be sharply curtailed after about 
eight to ten years. Such limitations on plutonium supply severely limit both the peak and the ultimate fast breeder fraction. If the alternate strategy is pursued, there is no plutonium with which to fuel the fast breeder. Even with breeders being introduced at the fastest possible rate, more than thirty percent of the plutonium produced in the year 2010 is from light water reactors.

Since light water reactors must be built within ten years, it may not be desirable to install solely breeders following their introduction but to strike for a balance in addition between the two reactor types. This arrangement would reduce the total plutonium requirements of the fast breeder reactor and permit a greater amount of recycle in light water reactors.

The way in which plutonium is utilized will have an obvious impact on the variation of plutonium price with time. If there is a sma11 supply of plutonium when breeders are introduced, the demand for plutonium will be great. This demand will force the plutonium market price as high as the breeder fuel cycle costs can tolerate. 
Effects of Reactor Variables and Losses

There are three principal design parameters associated with a light water reactor that influence the generating costs and the breeder growth rate. These are the initial fuel enrichment; the degree of burnup and, consequently, the plutonium production; and the ratio of ${ }^{239} \mathrm{Pu}$ to fissile plutonium. The first two of these heavily influence the LWR fuel cycle cost and, hence, the unit energy costs. The last two primarily influence the quantity of available plutonium and, therefore, limit the breeder growth rate.

Since the light water reactor initial enrichment requirement, burnup, and plutonium production are all related, the effect of these can be considered together. The effect of variations in these parameters on the cumulative generating costs is shown in Figure 19. The principal detail which is immediately evident is the increase in generating costs with increasing plutonium price. The extent of these differences is not too appreciable, however, accounting for a variation of about $\$ 10$ billion out of $\$ 40$ billion added cost and $\$ 200$ billion tota 1 . The variation of the costs with plutonium price indicates that although there is a great difference in the total plutonium 


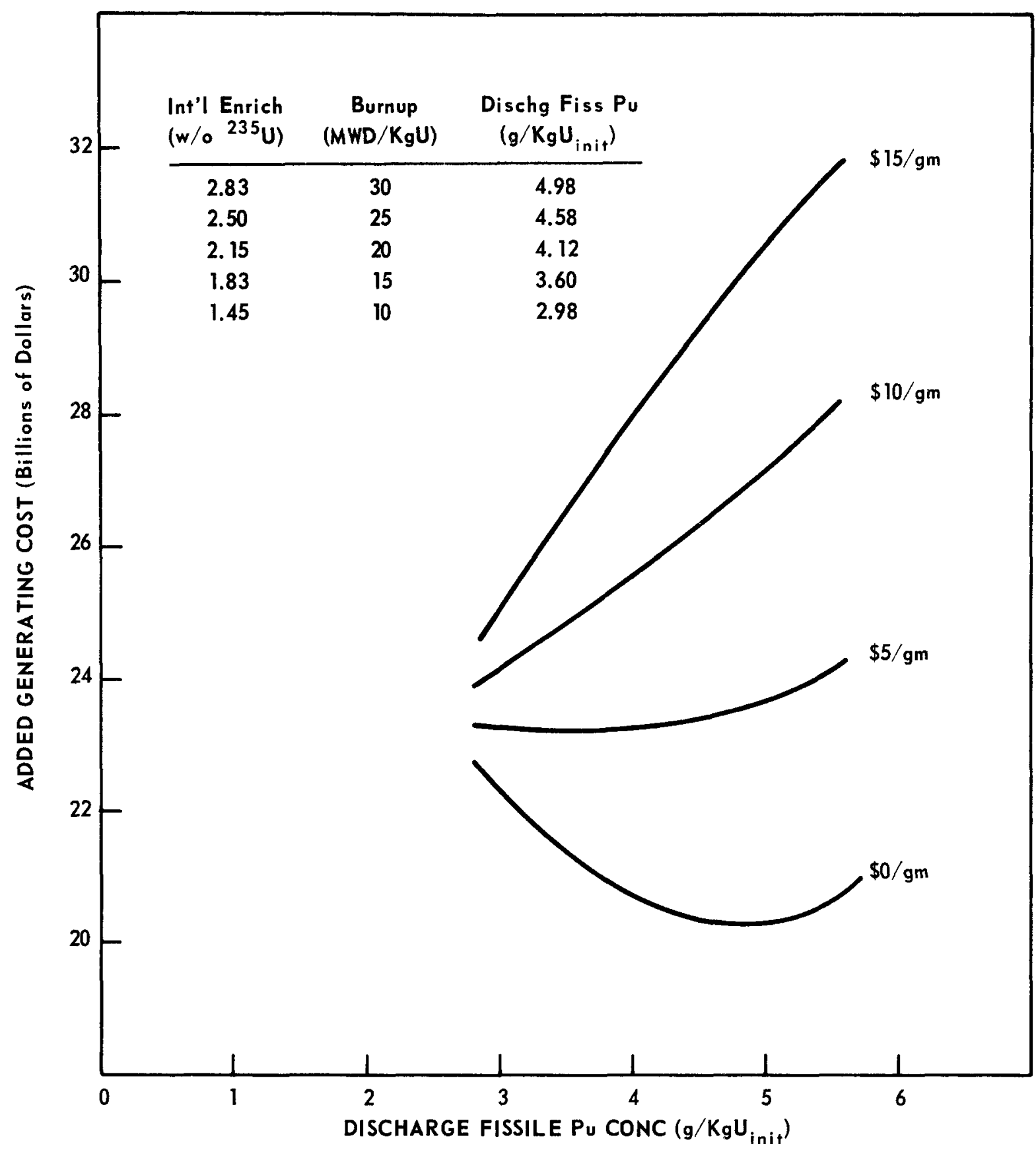

Figure 19: Added Nuclear Generating Costs (to the year 2010) as a Function of Discharge Plutonium Concentration for Various Plutonium Prices 
production, the charges for early plutonium inventory soon override any benefit of high production. Even though cumulative generating costs generally increase at high burnup, higher burnups are required to justify light water reactor fabrication and reprocessing. Thus these costs are to some extent compensated for by the quantity of power which may be extracted per dollar paid in fuel reuse.

The light water reactor plutonium production is a factor which seriously affects the potential growth rate of fast breeder reactors. This is a factor, however, which can be regulated to a certain degree. Since electrical energy and plutonium are joint products of the same process, there could be trade off adjustments made if so desired and if the increase in plutonium revenues would balance the economic penalty to the electrical production. The amount of plutonium produced in light water reactors also influences the price of plutonium. Thus in producing greater quantities of plutonium there is the real possibility of reducing its market value. 
Because a reduction in the fraction of ${ }^{239} \mathrm{Pu}$ to tota 1 fissile plutonium is like losing plutonium, and since this and the fabrication and reprocessing losses are of the same order of magnitude, their effect can be considered together. These losses which have an uppermost limit of about $10 \%$ (see Figure 20 ) do not make very significant deviations in the cumulative generating costs. The maximum difference in all of these cases is less than $10 \%$ of the added cost and much less of the total costs. The effect on the added generating cost is relatively sma11 for al1 plutonium prices considered.

The fast breeder reactor growth rate is slightly reduced with higher losses due to less plutonium being available. Since these losses should not amount to more than a few percent, the actual limitation on breeder installation is almost negligible compared to other factors.

The effect due to higher LMFBR specific inventory has a number of different facets. If the breeding ratio remains constant, the relative amounts of plutonium required and generated in fast breeder reactors does not change but the doubling time (cf. Equation 2) increases. The 


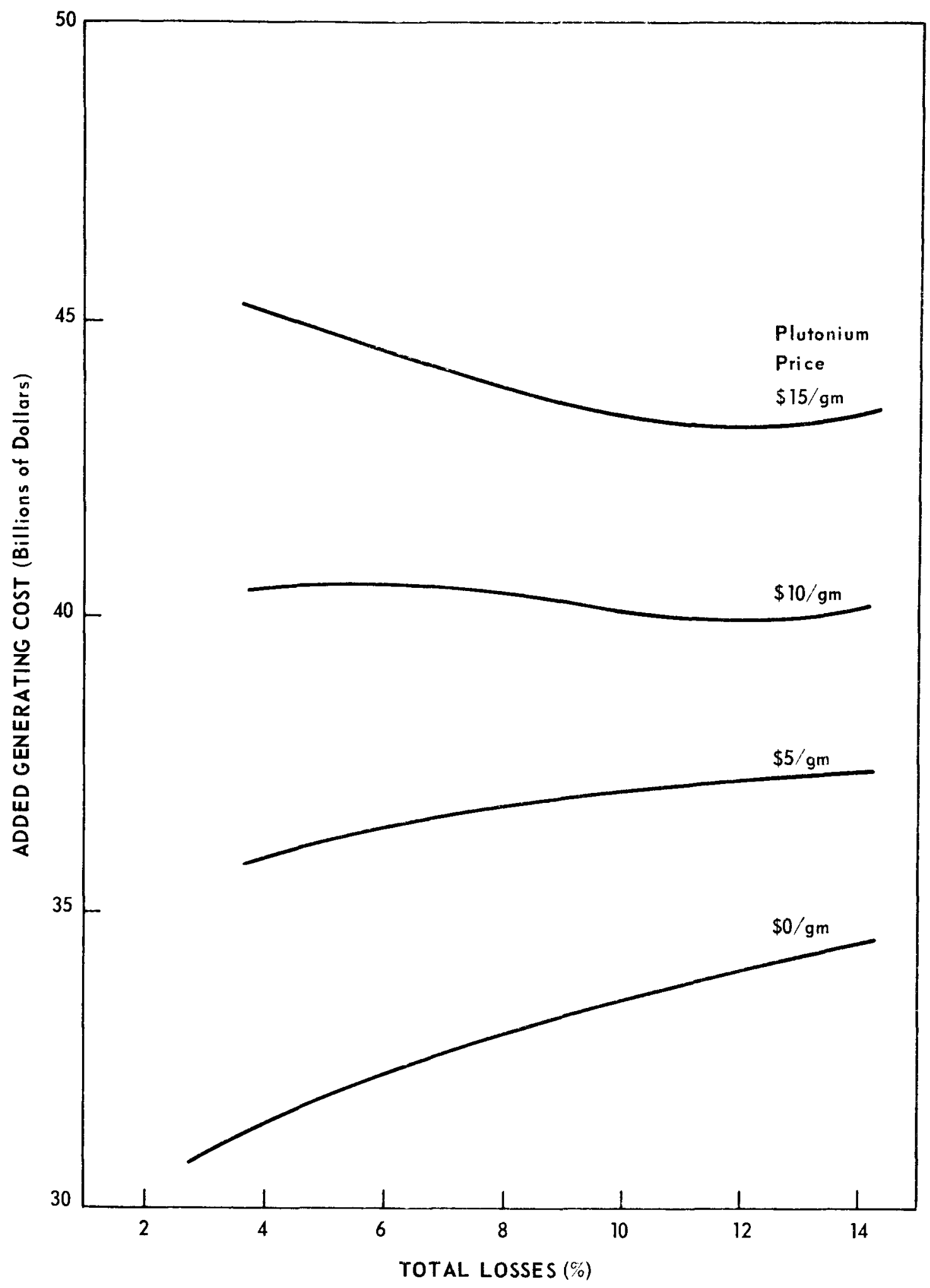

Figure 20: Changes in Added Nuclear Generating Costs (to the Year 2010) Resulting from Losses with Plutonium Price as a Parameter 
difference in generating costs for two specific inventories (1830 kg/MW and $2187 \mathrm{~kg} / \mathrm{MW}$ ) are shown at the bottom of Figure 21. A change of roughly ten percent in specific inventory does not significantly influence the net generating costs. However, the maximum and ultimate fractions of the breeder reactor are limited. The increase in the difference is due to the greater plutonium demanded by the higher specific inventory reactor and, hence, a reduction in the external inventory charges (this is not considered to be a part of the fuel cycle costs).

Later on, however, due to the lower doubling time the reactor with the lower specific inventory is able to continue additions at a greater pace while the higher specific inventory reactor has had to curtail additions. This results in a greater fraction of fast breeder reactors to total nuclear capacity (about six percent greater or 125,000 MWe in the case considered here) and, hence, a continual decrease in generating costs.

If a decrease in specific inventory is accomplished at the expense of breeding ratio, which would be the normal case due to higher leakage, etc., no great change in the doubling time would be expected. This should then result in no 


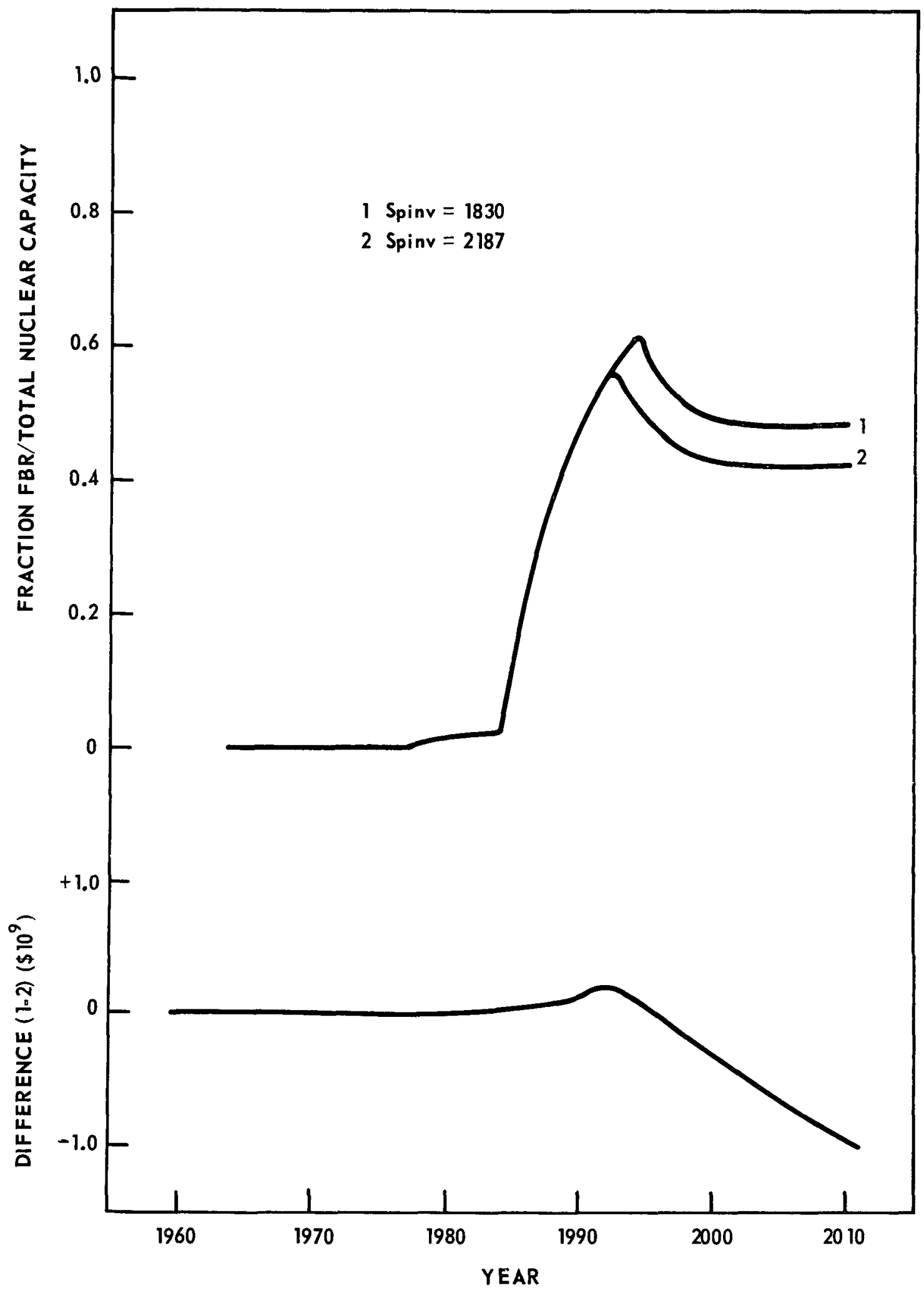

Figure 21: Differences in the Added Nuclear Generating Costs and the Fast Breeder Reactor Fraction due to FBR Specific Inventory 
appreciable change in the final breeder fraction or in the generating costs.

Effect of Ex-core Inventory

The ex-core inventory has an appreciable effect on the cumulative nuclear generating costs as well as on the peak and final fast breeder reactor fraction of total nuclear generating capacity (similar to upper curves of Figure 21). Until the peak the rate of growth is not appreciably affected because breeders are considered to be normally added at the maximum possible rate. The results of variations in ex-core inventory are shown in Table VI. The ultimate FBR fraction is severely limited by the ex-core inventory decreasing from $70 \%$ to about $40 \%$ of the total nuclear capacity as the ex-core inventory increases. It is seen that higher ex-core inventory results in an earlier peak fraction and a lower final fraction fast breeder reactor capacity.

The effects of ex-core inventory changes on the additional cumulative gerierating costs range from $\$ 6$ billion at a plutonium price of $\$ 0 / g$ to $\$ 10$ billion at $\$ 30 / g$ plutonium price. It can be seen from this that there is an appreciable savings to be made if the ex-core inventory 
TABLE VI

EFFECT OF EX-CORE INVENTORY ON CASE II-D

\begin{tabular}{|c|c|c|c|c|c|}
\hline $\begin{array}{l}\text { Ex-core Inventory } \\
(\% \text { of SI })\end{array}$ & $\begin{array}{l}\text { FBR Fraction } \\
\text { Year of } \\
\text { Peak } \\
\end{array}$ & $\begin{array}{l}\text { of Ni } \\
\text { Peak } \\
(\%)\end{array}$ & $\begin{array}{l}\text { ar Capacity } \\
\text { U1timate } \\
\text { Leve1 }(\%)\end{array}$ & $\begin{array}{c}\text { Final Cap } \\
\text { (MWe) }\end{array}$ & $\begin{array}{c}\text { Added Cost } \\
\left(\$ 10^{\circ}\right)\end{array}$ \\
\hline 10 & 2000 & 81 & $73-74$ & $1,352,000$ & 20.0 \\
\hline 20 & 1997 & 74 & $63-64$ & $1,168,000$ & 21.6 \\
\hline 30 & 1995 & 68 & $55-56$ & $1,021,000$ & 22.9 \\
\hline 40 & 1994 & 65 & $49-50$ & 911,000 & 24.1 \\
\hline 50 & 1993 & 62 & $44-45$ & 819,000 & 25.0 \\
\hline 60 & 1993 & 62 & $43-44$ & 800,000 & 25.2 \\
\hline 70 & 1993 & 60 & $42-43$ & 782,000 & 25.4 \\
\hline 80 & 1992 & 58 & $41-42$ & 764,000 & 25.6 \\
\hline 90 & 1992 & 58 & $40-41$ & 745,000 & 25.8 \\
\hline 100 & 1992 & 56 & $39-40$ & 727,000 & 26.0 \\
\hline
\end{tabular}


is kept low since the greater savings per percent reduction in ex-core inventory occur at lower fractions. Thus, if ex-core inventories can be reduced to the range of $20 \%$, a significant saving can be realized in both dollars and in earlier breeder introduction.

\section{Effect of Discount Rate}

The discount rate chosen has a considerable effect on the cumulative ideal costs. While undiscounted cumulative generating costs through the year 2010 total over $\$ 600$ billion, the application of discounting procedures reduce this until at $12 \%$ the generating costs discounted to 1985 are reduced to $\$ 200$ billion. In discounting to this year, the past expenditures are weighted more heavily (discount factor greater than one) while the future expenditures produce a smaller increase (discount factor less than one). For higher discount rates, this factor disproportionately weights the past costs and de-emphasizes the future ones (cf. p. 21).

The effect of the discount rate on the added costs is shown for various plutonium values in Figure 22. As the plutonium price becomes more appreciable, it combines with the earlier years' plutonium inventories; and the interest 


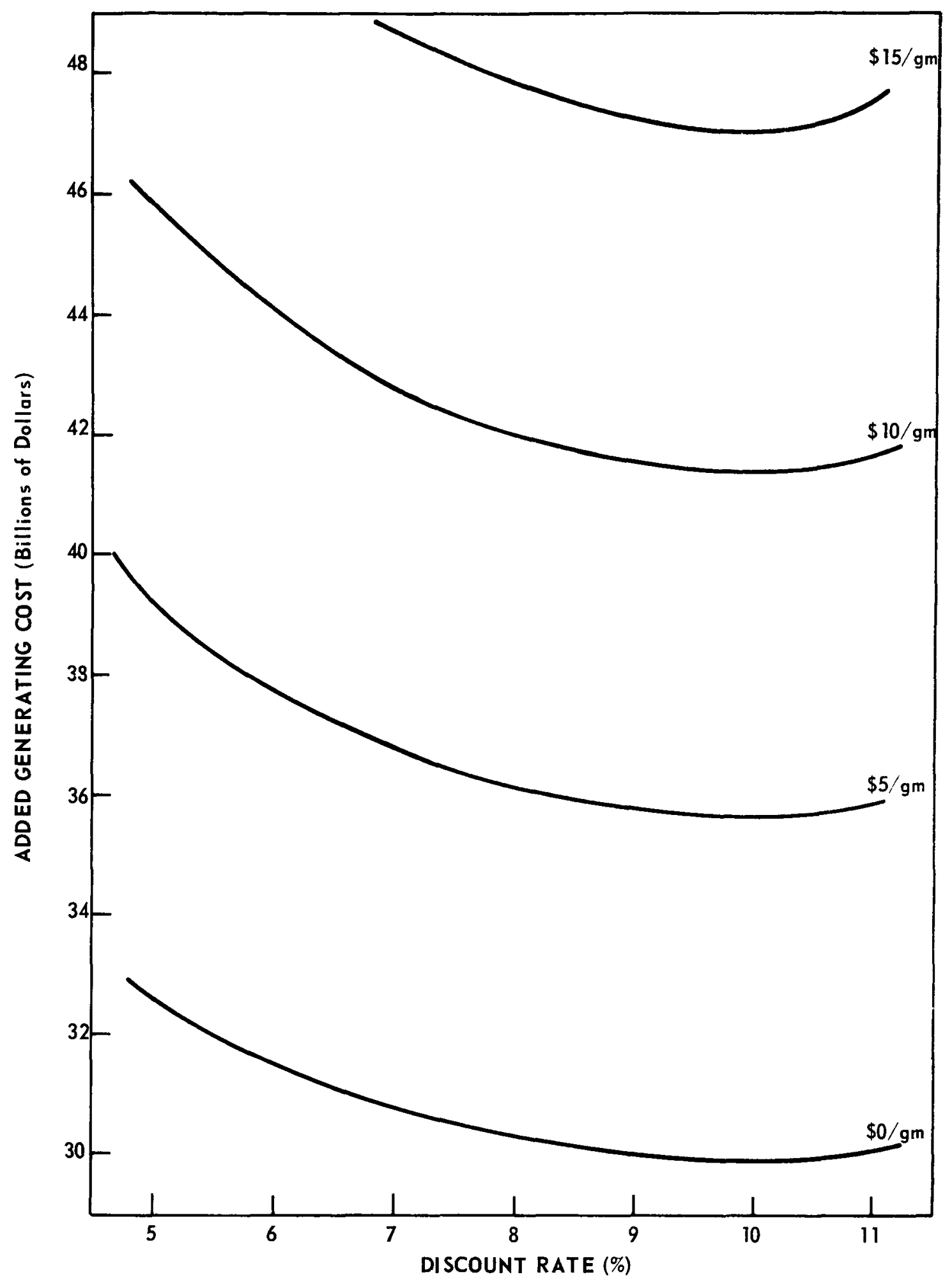

Figure 22: Effect of Discount Rate on the Added Nuclear Generating Costs (to the Year 2010) with Plutonium Price as a Parameter 
rate mechanism mentioned above to produce an up-turn in the costs. It appears as though for the starting point, ending point, and year to which costs have been presentworthed, the minimum costs are obtained at $10 \%$ interest rate.

The discount rate can also have an effect, not considered here, on the supply of plutonium. At a given plutonium price and discount rate it is only economical to store plutonium for a particular period of time. If the price of plutonium remains the same but the interest rate increases it is not economical to retain the plutonium for as long a time. Thus at higher interest rates plutonium that could otherwise be saved is consumed.

\section{Recapitulation}

The most important variables associated with the nuclear generating costs for a mixed LWR-FBR system besides the capital costs and the rate of growth of nuclear capacity have been shown to be the price of plutonium, discount rate, and ex-core inventory fur the fast breeder reactor. The plutonium price is an especially insidious and important parameter as the value this assumes has side effects on many of the other variables. This interdependence is shown in Table VII. 
TABLE VII

INTERDEPENDENCE OF PLUTONIUM PRICE AND OTHER

IMPORTANT PARAMETERS ON CUMULATIVE GENERATING COSTS

\begin{tabular}{|c|c|c|c|c|}
\hline Parameter & $\begin{array}{c}\quad c u \\
\text { Range at } \\
\$ 0 / g \\
\left(\$ 10^{9}\right) \\
\end{array}$ & $\begin{array}{c}\text { dative Gen } \\
\text { Difference } \\
25-0 \$ / g \\
\left(\$ 10^{9}\right) \\
\end{array}$ & $\begin{array}{c}\text { ting Costs } \\
\text { Range at } \\
\$ 25 / \mathrm{g} \\
\left(\$ 10^{\circ}\right) \\
\end{array}$ & $\begin{array}{l}\text { Effect } \\
\text { seen } \\
\text { in } \\
\end{array}$ \\
\hline $\begin{array}{l}\text { Discount } \\
\text { Rate }\end{array}$ & 3 & $17-25$ & 9 & Figure \\
\hline $\begin{array}{l}\text { Ex-core } \\
\text { Inventory }\end{array}$ & 6 & $5-21$ & 10 & Table \\
\hline $\begin{array}{l}\text { FBR Spec. } \\
\text { Inventory }\end{array}$ & 2 & 12 & 3 & Figure \\
\hline $\begin{array}{l}\text { LWR Pu } \\
\text { Production }\end{array}$ & 2 & $3-10$ & 6 & Figure \\
\hline $\begin{array}{l}\text { Fissile } \\
\text { Fraction, } \\
\text { Losses }\end{array}$ & 4 & $10-15$ & 3 & Figure \\
\hline
\end{tabular}

Since the price of plutonium must be determined from a supply-demand relationship, a firmer grasp on the price of plutonium as a function of time in a breeder economy may be obtained from the following considerations:

1. Plutonium derives its value only from its marketability. Therefore, the price for plutonium will be determined by its utility in fast breeder reactors in competition with 
light water reactors selling their plutonium to the breeders. Thus, the price of plutonium as a function of time cannot exceed the break-even price in the least expensive breeder.

A higher capital cost breeder would have to purchase plutonium at even lower prices in order to compete.

2. Eventua11y, and it appears to be longer than the time period utilized in this work, the amount of plutonium being produced in breeders will exceed their requirements. (This presumes the breeder reactor doubling times become less than both the nuclear and the total generating capacity doubling time.) Then the price of plutonium will begin to decrease, ultimately stabilizing no lower than the minimum recycle price in light water reactors.

These two restrictions are shown in Figure 23 along with the estimates of others concerning future plutonium price. 


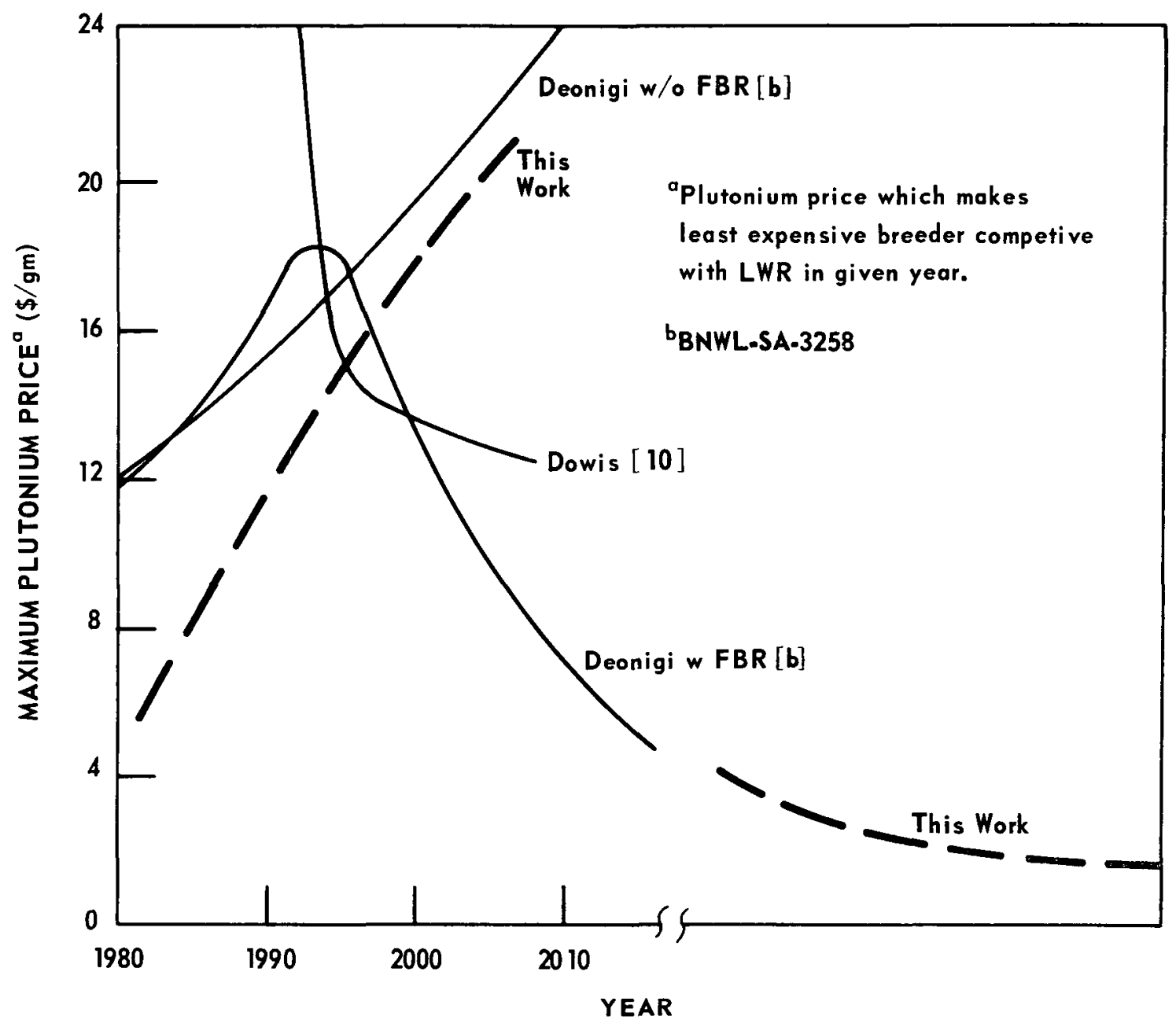

Figure 23: Forecast of Future Plutonium Price Limited by Supp1y-Demand and Market Constraints 
There has been found to be a fast breeder fraction that makes generating costs insensitive to variations in plutonium price. The benefits of such a property to a nuclear generating system need no further embellishment. While the result found here, $47 \%$ breeder, is attributable to the simple mix of two reactor types, in principle a more complex system would combine to produce some other ratio of reactors that would produce the same type of effect. This fact would be especially useful to a particular utility which may choose to remain aloof of the plutonium market.

The method of plutonium utilization has been found to have significant impact on the supply of plutonium. This has consequences on the rate of breeder addition which in turn has economic repercussions. The extent of plutonium recycle in light water reactors will determine whether the savings that are achieved are short-term or 1ong-range. 


\section{CONCLUS IONS}

An assessment of the technical and economic parameters affecting fast breeder reactor deployment indicates an inevitable conflict between long-range benefits and short-term gains. The factors which contribute to this can be altered by improvements in technological variables or by more organized and deliberate planning.

As might be expected, the fast breeder reactor ex-core inventory has the potential to limit the growth of breeders by suppressing the plutonium supp1y. In order to permit the greatest number of breeders to be installed with a constant quantity of plutonium, the ex-core inventory must be as small as possible.

Another fact which is not overly surprising is that losses from fabrication and reprocessing and differences in fissile fraction are generally negligible in their effect on generating costs when compared to such factors as ex-core inventory. However, it may be possible to make a series of small savings with the same net result as a single large one. 
The absolute level of capital costs and operating and maintenance expenses are not extremely important as these are presumed to vary in the same way for 1 ight water reactors and fast breeders. However, the differential capital and operating costs between these two plant types is a factor of great importance in determining the breeder introduction date. Lower capital differentials will permit competitiveness at higher plutonium price. This is an encouraging development as overal1 reductions in capital costs, especially when considering inflation, seem remote. A11 that is necessary is for the cost associated with the breeder to advance at a slightly slower pace.

The discount rate makes an appreciable difference as to what appears as the most economic situation. This is primarily due to the distribution of expenditures in time and the subsequent effect of discounting. It appears as if the groundwork has at least been laid for standardization and better definition of this essential parameter [93].

The variation of fuel cycle costs with plutonium price strongly affects the competitiveness of breeder reactors with light water reactors. In the future, the price of 
plutonium will be set in a supply and demand market structure. The maximum stabilized (i.e., other than transient situations such as experimental purposes) future price of plutonium is the price which, in the least expensive fast breeder, yields generating costs competitive with light water reactors. The minimum future price is the minimum recycle value in the least economical light water reactor.

A decrease in the range of plutonium price will lessen to some extent the dependence of generating costs on this high1y uncertain parameter. Certain fractions of fast breeder reactors to total installed nuclear capacity, however, yield generating costs insensitive to variations in plutonium price. These exist for all capital cases and for all time. This would be a desirable goal as the ultimate fraction since it provides a hedge against a fluctuation in price for plutonium users and producers. Similar conclusions have been arrived at by different types of analyses for other economies $[5,7]$. Thus such a result is independent of the mode1 utilized.

The philosophy adopted regarding plutonium recycle in light water reactors will have a great influence on the rate of 
growth of breeders and their ultimate fraction of the generating capacity. Although minimum short-term savings may be achieved through recycle, it is clear that this policy does not lead to long-range savings for all discount rates and plutonium prices. If desired, the amount of plutonium produced in a light water reactor may be altered by trading off electrical energy generation for plutonium production. However, this would necessitate either a rise in generating costs or in plutonium price or both.

It does not seem advisable to add only fast breeder capacity for eight to ten years following their commercial introduction even if sufficient plutonium is available. Although the costs associated with the suspension and later resumption of light water reactor manufacture are unknown, it is expected they would be great enough to warrant striking a balance in additions of the two reactor types .

As far as commercial LMFBR introduction is concerned, there are several alternatives which could assure this by 1985 or 1990 . Either 1) The capital costs of the reactor type must be in the lower portion of the region considered, or 2) FBR-LWR capital cost differentials 
must be lower than that assumed, or 3) Plutonium price must be extremely low (considerably below $\$ 10 / g$ ). A smal1 change in all these areas may combine tu make 1985 introduction feasible.

If it were considered necessary to store all the plutonium produced so that breeders could be added at the fastest possible rate, there is a method that would accomplish this economically. Since it is not entirely proper to receive credit on plutonium until it is sold, and if no revenue from plutonium sale is considered in the LWR fuel cycle calculations, any plutonium generated can be justifiably carried without inventory charges. Although this type of accounting increases light water reactor unit energy costs slightly (about $5 \%$ ), it will ultimately prove more economical since it enables faster breeder growth without the need for interim inventory charges. When the plutonium is finally sold, a revenue (probably greater than would be possible in the case of recycle) is realized. Thus a method of recovering any losses that have occurred in past generating costs as well as insuring lower future costs from breeder generation is provided. 


\section{IMPLICATION OF CONCLUSIONS}

If credit for plutonium produced in light water reactors is not taken in the fuel cycle calculations, no price has been assumed paid for the plutonium and it can be carried without the need to charge inventory. The credit that is taken in the fuel cycle calculations is proportionate to the price expected to be received for the plutonium; thus this much is "invented" in the plutonium, and inventory charges are mandatory. Although taking no credit for plutonium will make present light water reactor fuel cycle costs about $10 \%$ greater and total generating costs perhaps $3-5 \%$ higher, such action would permit the long-term storage of plutonium at essentially no expense.

If it were feasible for the plutonium to be stored for long times for use in breeder reactors, the desire for immediate recycle would be lessened. Much expense could be saved in developing plutonium recycle technology and higher fuel costs associated with preparing plutonium fue1s. This action, however, would entail an increase in uranium enrichment demands. Subsequent improvement and upgrading of existing cascades would be required along 
with a larger number of new enrichment facilities.

The very low ex-core inventories desirable will be difficult to achieve because of the short cooling time required. Present technology does not favor ex-core inventories under approximately fifty percent. To achieve a shorter turn around outside the core will require more advanced reprocessing methods and fuel fabrication procedures that can deal with hotter materials. A great cost penalty will be paid in the fabrication of this materia1.

The prolonged practice of recycle in light-water reactors will reduce the quantity of plutonium that is available for use in fast breeder reactors. The government could overcome this obstacle by providing its stockpile of weapons-grade plutonium for sale in the interest of making greater quantities of energy affordable by all of its citizens. This material, because of its higher fissile content, would be especially desirable as a fuel for the first generation of breeders. Such action would assure an adequate supply of otherwise unavailable plutonium at a critical time. This would offer a means of reducing near-future generating costs as well as providing 
minimum 1ong-term costs.

If it is not advisable to add only fast breeder reactors but to keep the manufacture of light water reactors viable in the years immediately following the commercial introduction of the breeder, it must be determined in what proportion these two should be added. In a changing plutonium market, the earliest achievement of the breeder fraction insensitive to plutonium price would result in increased savings and an independence of the plutonium market. Thus the breeder fraction yielding total annual generating costs insensitive to plutonium price would be a desirable choice for this proportion. As noted previously ( $p .25)$, because of the uncertainties involved the possible introduction of fusion reactors has been ignored. Should this energy source be developed for commercial use within this century the balance of fission reactors would be affected from that time on. Since unrestrained fluctuations in plutonium price could result, the installed FBR fraction impervious to changes in plutonium price would prove advantageous in this instance. 


\section{FUTURE WORK}

There are additional investigations which have yet to be carried out in the area of generating costs and plutonium supply .

Better attempts to define the plutonium market structure are necessary in order to predict more accurately the effect of plutonium price changes on future generating costs. This is a difficult problem as all the factors affecting uranium supply are also involved.

An examination should be made to determine the effect on such an analysis of discounting the costs to different times. Although no change in the relative order of the results would be expected, it would prove most disconcerting if there should be any.

The effect of employing different FBR-LWR capital cost differentials needs to be determined. The direction which changes of this kind would entail is known, but the magnitude and impact on generating costs is undetermined. 
The effects of different isotopic compositions in the feed of fast breeder reactors is not well-known. Neither are the effects of repeated high burnup and frequent recycle of the same material.

Fina11y, it might be instructive to compare these results with the degree of competition offered by conventional electric generating stations. Although it may be more difficult to estimate fossil fuel costs with time, determining the comparative costs could suggest an a1teration of trends in the ratio of nuclear and conventional capacities. This would permit even greater commensurate savings in total electric generating costs. 


\section{REFERENCES}

1. L. A. DuBridge, Hearings Before the Joint Committee on Atomic Energy, 91 st Congress, 1st Session, Part 1, p. 24 (October 28, 1969).

2. G. T. Seaborg and J. L. Bloom, "Fast Breeder Reactors", Scientific American, 223, 5, pp. 13-21 (November, 1970).

3. H. M. Dieckamp, J. A. Falcon and B. L. Hoffman, "Planning Today for Tomorrow's Nuclear Needs", Nuclear News, 10, 9, p. 48 (September, 1967).

4. C. E. Iliffe, Computer Programme DISCOUNT for Estimating Costs of Electricity and Prices of Plutonium from Nuclear Power Systems, TRG-Report-198 (R), (1962).

5. J. Gaussens et H. Paillot, Etude Des Valeurs et Des Prix du Plutonium a Long Terme; Un Modele Parametre Simplifie, CEA-R-2795, Vo1. I, II, (May, 1965).

6. Civilian Nuclear Power - Potential Nuclear Power Growth Patterns, U. S. Atomic Energy Commission, WASH-1098, (December, 1970).

7. C. E. Iliffe, "Assessing the Economics of Nuclear Power Stations in an Electric Generating System", presented at IAEA Symposium on Economic Integration of Nuclear Power Stations in Electrica1 Power Systems, IAEA-SM139/32, Vienna, (October 5-9, 1970).

8. R. E. Larson and F. J. Rees, Application of Advanced Dynamic Programming Computational Procedures to the Planning of Nuclear Fue1 Reprocessing Plants and Nuclear Power Reactors, Final Report ORNL Subcontract 3240, Systems Contro1, Inc. (November, 1969).

9. E. A. Eschbach, "Plutonium Value Analysis", Proceedings of the Third International Conference on the Peaceful Uses of Atomic Energy, p. 246, Geneva (1964). 
10. W. J. Dowis, Future Value of Plutonium, DUN-SA-81 (December, 1968).

11. S. E. Nunn and D. E. Deonigi, Fuel Cycle Parameters of Sodium Cooled Fast Breeders, BNWL-965 (July, 1969).

12. J. R. Dietrich, "Efficient Utilization of Nuclear Fuels", Power Reactor Technology, 6, 4pp. 1-37 (fa11, 1963).

13. Fast Breeder Reactor Report, Edison Electric Institute (April, 1968).

14. W. I. Neff and E. D. Jones, Jr., "Conservation Economics and Reactor Technology", Nuclear Applications, 3, 1, pp. 32-42 (January, 1967).

15. Cost-Benefit Analysis of the U. S. Breeder Reactor Program, U. S. Atomic Energy Commission, WASH-1126 (Apri1, 1969).

16. P. W. MacAvoy, Economic Strategy for Developing Nuclear Breeder Reactors, MIT Press (1969).

17. F. S. Brown, "Trends and Growth Projections of the Electrical Power Industry", accompanying statement of J. N. Nassikas, Hearings Before the Joint Committee on Atomic Energy, 91 st Congress, 1st Session, Part 1, p. 35, 53 et. seq. (October 28, 1969).

18. Civilian Nuclear Power . . A Report to the President 1962, U. S. Atomic Energy Commission, Washington, D. C., Appendix IV, p. 66 (November, 1962).

19. Civilian Nuclear Power, The 1967 Supplement to the 1962 Report to the President, U. S. Atomic Energy Commission, Washington, D. C., p. 19 (February, 1967).

20. Civilian Nuclear Power, Current Status and Future Technical and Economic Potential of Light Water Reactors, WASH-1082, U. S. Atomic Energy Commis sion, Washington, D. C., pp. 1-3. (March, 1968). 
21. Fast Breeder Reactor Report, op. cit. p. 8.

22. Nucleonics Week, 12,6, p. 7 (February 11, 1971).

23. Nuclear Industry, 18,1, p. 4 (January, 1971).

24. S. Siege1, "Fast Breeder Reactors", Nuclear News, 10,1, p. 30 (January, 1967).

25. B. I. Spinrod, "On the Definition of Breeding", Proceedings on the Conference on the Physics of Breeding, ANL-6122, p. 23, (October, 1959).

26. H. M. Dieckamp, et a1, op. cit., p. 54.

27. J. H. Wright, "Core Design and Performance Considerations of Fast Breeder Reactors", Westinghouse Engineer, 28, 1, p. 16 .

28. An Evaluation of Four Design Studies of a 1000 MWe Ceramic-Fueled FBR, CO0-279, Table 3.6, (December, 1964).

29. Fuel Recycle, LMFBR Liquid Metal Fast Breeder Reactor Program Plan, 8, WASH-1108, pp. 8-210 (August, 1968).

30. F. Hittman, M. Raber, "The Importance of Plutonium Recycle", Nuclear News, 11,11, p. 48 (November, 1968).

31. D. Hicks, "Light Water Lattice Calculations in the United Kingdom" in Light Water Latties, International Atomic Energy Agency, pp. 99-131 (1962).

32. M. W. Rosentha1, et a1, A Comparative Evaluation of Advanced Connecters, ORNL-3686, Oak Ridge National Laboratory, Oak Ridge, Tennessee, p. $12 \mathrm{ff}$, (January, 1965).

33. R. E. Anderson, D. F. Casey, ed., 1000 MWe Liquid Meta1 Fast Breeder Reactor Follow-on Conceptual Design Report, AI-12792, Vo1. I, II, III, Atomics International, Canoga Park, California (no date).

34. WASH-1082, op. cit., p. I-34-6. 
35. ORNL-3686, op. cit., p. 12 .

36. Ibid, p. 34 .

37. Ibid, p. 39 .

38. Ibid, p. 152 .

39. ANL 1000 MWe LMFBR (Liquid Metal Fast Breeder Reactor) Follow-on Study Task I Report, Vo1. I, AI-12765 (Vo1. I), Atomics International, Canoga Park, California, p. IV-13, (November, 1968).

40. ANL 1000 MWe LMFBR (Liquid Metal Fast Breeder Reactor) Follow-on Study Task I Report, Vo1. II, AI-12765 (Vo1. II), Atomics Internationa1, Canoga Park, California, pp. II-71-82 (November, 1968).

41. Trends in the Cost of Light Water Power Plants for Utilities, WASH-1150, U. S. Atomic Energy Commission, Washington, D. C., (May, 1970).

42. Civilian Nuclear Power 1962 Report to the President, op. cit., Appendix IV, p.p. 51-63.

43. AI-12792, op. cit., pp. 258-263.

44. P. R. Kasten, L. L. Bennett, W. E. Thomas, Transactions of the American Nuclear Society, 14, 1, 88 (1971).

45. J. T. Day, Transactions of the American Nuclear Society, $13,2,770(1970)$.

46. J. Gaussens, et H. Pailot, op. cit., Vol. II, p. 25.

47. An Evaluation of the Atomics International 1000 MWe Fast Breeder Reactor, $\mathrm{COO}-285$, U. S . Atomic Energy Commission, Chicago Operations Office, p. 2-2 (July, 1966).

48. EEI, Fast Breeder Reactor Report, op. cit., p. 52.

49. AI-12792, Vo1. II, op. cit., p. 248.

50. WASH-1082, op. cit., pp. 5-60. 
51. WASH-1108, op. cit., pp. 8-204.

52. AI-12792, Vo1. II, op. cit., p. 76.

53. E. L. Zebrowski, B. Wolfe, P. Greebler, J. Sueoka, "Plutonium Recycle Values in Thermal and Fast Reactors and Expected Pattern of Use of Plutonium" in Plutonium As A Power Reactor Fuel, HW-75007, General Electric Co., Hanford Works, p. 23-23 (December, 1962).

54. F. Hittman, M. Raber, op. cit.

55. D. J. Stokes, S. Golan and S. Siege1, "Wanted: A Balanced Nuclear Economy", Nucleonics, 21, 6, 80 (June, 1963).

56. EEI, Fast Breeder Reactor Report, op. cit., p. 16.

57. WA-SH-1082, op. cit., p. 5-9.

58. J. B. Roll, "Commercial Plutonium Recycle", Power Engineering, p. 34 (November, 1970).

59. F. Hittman, M. Raber, op. cit., p. 54.

60. Economic Utilization of Plutonium in Pressurized Water Reactors, WCAP-7160, Vol. II, Westinghouse Electric Corp., Pittsburgh, PA, p. 3-3 (February, 1968).

61. S. Jaye, L. L. Bennett, M. P. Lietzke, A Study of the Fue1 Value of Plutonium, CF-60-2-34, Oak Ridge National Laboratory, Oak Ridge, Tenn., p. 3 (February, 1960).

62. WASH-1082, op. cit., pp. 5-84.

63. F. Hittman, M. Raber, op. cit., p. 49.

64. "AEC Drops Restrictive Export Terms for U. S. Market", Nucleonics Week, p. 4 (January 21, 1971).

65. AI-12792, Vo1. II, op. cit., p. 259. 
66. E. A. Eschbach, M. F. Kannien, Uranium Price Schedule and Bred Fuel Value, HW-72219, General Electric Co., Hanford Works (December, 1964).

67. C. E. Iliffe, "Assessing the Economics...", op. cit., p. 8 .

68. Ibid, p. 9 .

69. W. J. Dowis, op. cit., p. 1.

70. J. Gaussens et H. Pailot, op. cit., Vo1. II, pp. $6,7,24,29$.

71. Ibid, p. 31 .

72. WASH-1150, op. cit., p. 25.

73. H. I. Bowen, M. L. Meyers, Estimated Capital Costs of Nuclear and Fossil Power Plants, ORNL-TM-3243, Oak Ridge Nationa1 Laboratory, Oak Ridge, Tenn. (March 5, 1971).

74. WASH-1082, op. cit., pp. 3-2 to 3-4.

75. Bowen and Meyers, op. cit., pp. 17, 21.

76. EEI, Fast Breeder Reactor Report, op. cit., p. 11.

77. Potentia1 Nuclear Power Growth Patterns, WASH-1098, U. S. Atomic Energy Commission, Washington, D. C., pp. 2-24 (December, 1970).

78. WASH-1082, op. cit., pp. 2-4.

79. Appendices to 1962 Report to the President, op. cit., p. 59 .

80. AI-12792, Vo1. II, op. cit., pp. 248, 259-60.

81. WASH-1082, op. cit., pp. 5-61, ff.

82. J. M. Vernon, "Benefits and Costs of Developing Advanced Nuclear Power Reactors", Applied Economics, 1, 1, 5 (January, 1969). 
83. M. S. Feldstein, "The Social Time Preference Discount Rate in Cost-Benefit Analysis", The Economic Journal, p. 361 (June, 1964).

84. K. J. Arrow, M. Kurz, Public Investment, The Rate of Return and Optima1 Fiscal Policy, Johns Hopkins Press, Baltimore, p. xiv (1970).

85. S. A. Marglin, "The Social Rate of Discount and the Optimal Rate of Investment", Quarterly Journal of Economics 77, 2, 111 (February, 1963).

86. J. Hirschleifer, "Investment Decision under Uncertainty: Application of the State-Preference Approach", Quarterly Jouran1 of Economics, 80, 5, 272 (May, 1966).

87. 0. Eckstein in "Economic Analysis of Public Investment Decisions" - Hearings Before the Subcommittee on Economy in Government, Joint Economic Committee Ninetieth Congress of the United States, p. 52 (August, 1968).

88. A. C. Herberger in "Economic Analysis . . ibid," p. $57 \mathrm{ff}$.

89. St. G. T. Arnold, Three Methods of Evaluating Capital Expenditures in the Public Sector, ORO-674 (OPP Report No. 4, Revision 2), U. S. Atomic Energy Commission, Oak Ridge Operations Office, p. 12 (December, 1969).

90. B. N. Behling in "Economic Analysis", Hearings, op. cit., p. 189 .

91. K. J. Arrow, R. C. Lind, "Uncertainty and the Evaluation of Public Investment Decisions", American Economic Review, pp. 364,5 (June, 1970).

92. "Interest Rate Guidelines", op. cit., pp. 60-63.

93. "Economic Analysis of Pub1ic Investment Decision: Interest Rate Policy and Discounting Analysis", Report of the Subcommittee on Economy in Government, Joint Economic Committee, Ninetieth Congress of the United States, p. 1 (September, 1968). 
94. E. B. Staats in "Interest Rate Guidelines for Federal Decision Making", Hearings Before the Subcommittee on Economy in Government, Joint Economic Committee Ninetieth Congress of the United States, pp. 3-7 (January, 1968).

95. "Economic Analysis .. .", Report, op. cit., p. 10, ff. 
APPENDIX I

Further Description

of

Light Water Reactor 
The typical light water reactor is fueled with slightly enriched $\mathrm{UO}_{2}$ and both moderated and cooled by means of pressurized $\mathrm{H}_{2} \mathrm{O}$. The design characteristics are presented in Table VIII. The reactor is cooled by seven loops, with one pump and one steam generator per 1oop. A single pressurizer serves to regulate the water pressure in all seven loops. Flow through the core is single-pass upward. The active core is 11 feet high and 12.8 feet in diameter. The reactor contains 264 fuel assemblies and 109 control rods. A cross section drawing of a fuel assembly and cruciform-shaped control rod is shown in Figure 24. The fuel assembly contains a $16 \times 16$ square array of rods. The rods with highest specific power, near the control rods, are of a reduced diameter. Chemical poison control in the form of a boric acid solution is used for shim control to reduce the control rod requirements. 
TABLE VIII

DESCRIPTION OF TYPICAL LIGHT WATER REACTOR

\begin{tabular}{ll}
\multicolumn{3}{c}{ Reactor Power } \\
Core nuclear power, MW(th) & 3220 \\
Net electrical power, MW(e) & 1002 \\
Net thermodynamic efficiency, \% & 31.1
\end{tabular}

Coolant

Composition

Core inlet pressure, psia

$\mathrm{H}_{2} \mathrm{O}$

Core pressure drop, psi

2050

Flow rate, $1 \mathrm{~b} / \mathrm{hr}$

34

Core inlet temperature, ${ }^{\circ} \mathrm{F}$

$160 \times 10^{6}$

Mean core outlet temperature, ${ }^{\circ} \mathrm{F}$

546

Maximum hot channel outlet temperature

598

at rated overpower, ${ }^{\circ} \mathrm{F}$

Number of coolant loops

Coolant velocity in core, $\mathrm{ft} / \mathrm{sec}$

639

7

12.7

\section{Core Therma 1 Performance}

Average heat flux at rated power, $\mathrm{BTU} / \mathrm{hr} \cdot \mathrm{ft}^{2}$

Maximum heat flux at rated power, $\mathrm{BTU} / \mathrm{hr} \cdot \mathrm{ft} \mathrm{t}^{2}$

Maximum fuel pin surface temperature, ${ }^{\circ} \mathrm{F} \quad 640$

Peak-to-Average power ratio 3.3

Average core power density, KW/1iter 80.7

Average specific power, $\mathrm{KW} / \mathrm{kg}$ of fertile 31.7 material

Ratio of maximum to average enthalpy rise 1.8

Flow reduction factor used 1.07

Fluid mixing factor used

0.94

Minimum DNB ratio at rated overpower

1.23 (boiling)

Rated overpower factor

1.15 
TABLE VIII (CONTINUED)

\section{Description of Fue1 Cycle}

Fuel management scheme

In-core residence time (at 0.8

load factor), yr

Average core fuel exposure, MWD/MT

Average exposure in maximum rod, $\mathrm{MWD} / \mathrm{MT}$ three batch scatter reloading

2.3

25,000

30,000

\section{Contro1 System}

Method of shim control Method of safety control Number of rods

Rod material soluble poison poison rods

109

$\mathrm{Ag}, \mathrm{In}, \mathrm{Cd}$

\section{Reactor Vesse1}

$\begin{array}{ll}\text { Type } & \text { cylindrical } \\ \text { Material } & \begin{array}{l}\text { stainless steel } \\ \text { clad carbon steel }\end{array} \\ \text { Inside diameter, ft } & 15.8\end{array}$

Turbine Plant

Throttle steam pressure, psig

635

Throttle steam temperature, ${ }^{\circ} \mathrm{F}$

495

Type of steam cycle saturated with reheat

Feedwater return temperature, ${ }^{\circ} \mathrm{F} 443$

Arrangement of turbine generacompound, six flow 


\section{TABLE VIII (CONTINUED)}

\section{Description of Core and Fuel}

Moderator material

Reflector material

Fue1 material

Fuel fabrication

Fuel theoretical density

Maximum $\int \mathrm{kd} \theta$ at rated power, $w / \mathrm{cm}$

Fue1 life, yr

Equivalent diameter of core, ft

Active height of core, ft

Number of fuel assemblies

Fue1 element spacing, in

Fue1 rod outside diameter, in

Cladding material

Cladding thickness, in
$\mathrm{H}_{2} \mathrm{O}$

$\mathrm{H}_{2} \mathrm{O}$

$\mathrm{UO}_{2}$

pelletized

96.5

41.2

3

12.8

11.0

264

8.4

0.378 and 0.320

Zircaloy 4

0.020 


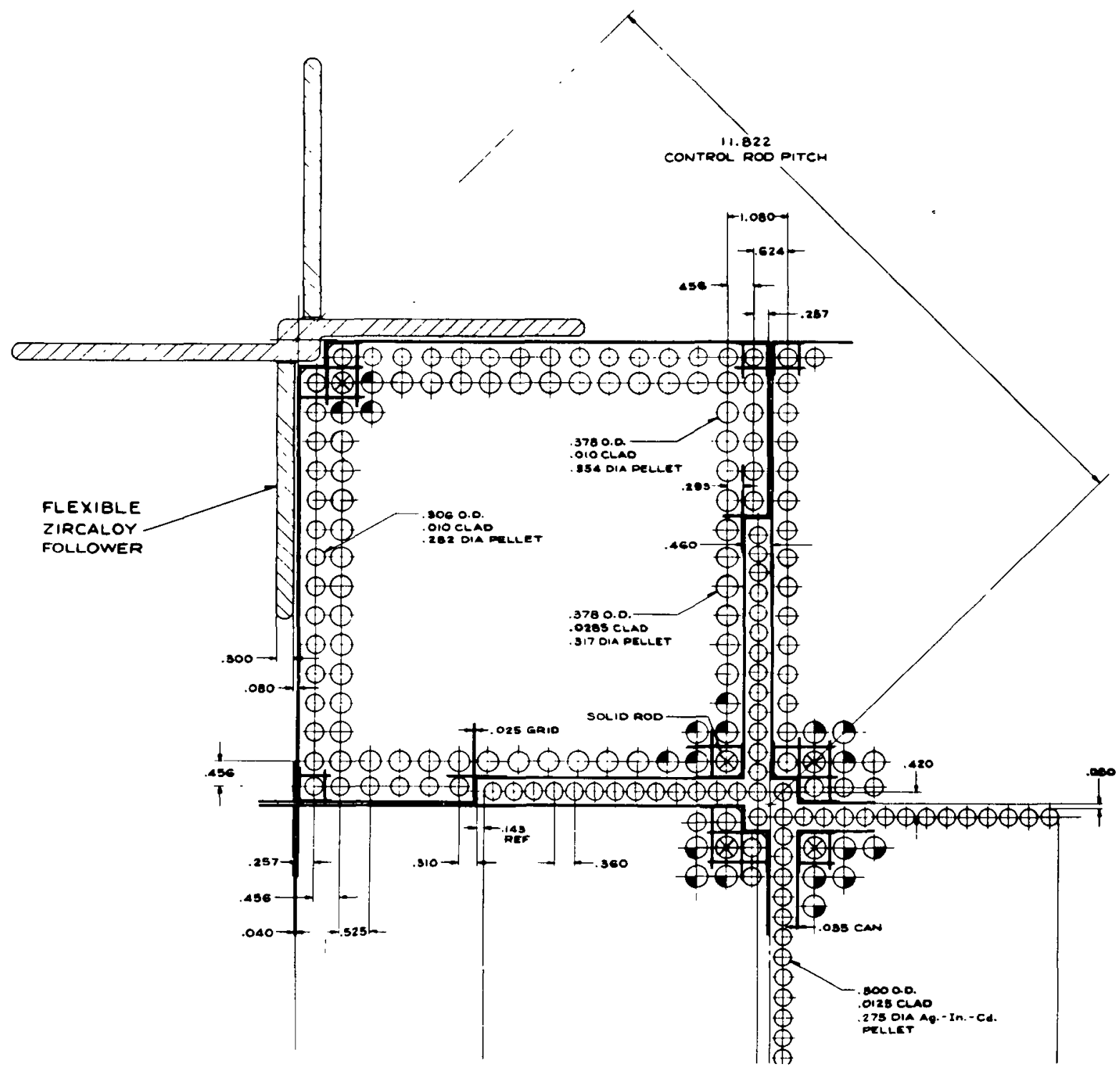

Figure 24: Horizontal Cross-Sectional Diagram of LWR Fuel Assembly and Cruciform-Shaped Control Rod (after ORNL-3686) 
The typical light water reactor has a maximum-to-average heat flux ratio of 3.3 , a core power density of $80.7 \frac{\mathrm{KW}}{\text { liter }}$, and a coolant outlet temperature of $598^{\circ} \mathrm{F}$. Although chemical shim is used to limit the power distortion normally due to the presence of control rods, no use is made of varying fue1 enrichment to flatten the power distribution. However, fuel rods having smaller diameters thrin normal rods are placed next to the water gap (where the control rods would be were they inserted) to reduce the heat rating. Short control rod followers that extend 3.7 feet into the 11 foot core and other mixing devices force the interchange of coolant between and within assemblies.

The fuel element of the pressurized water reactor design is 155 inches long, with an active fueled length of 132 inches. It consists of 194 tubes 0.378 inches in diameter and 40 smaller tubes 0.320 inches in diameter. These tubes have 0.020 inch thick Zicaloy- 4 walls and are filled with $\mathrm{UO}_{2}$ pellets of $96.5 \%$ theoretical density. They are designed to operate for three years at a linear heat rating of $16 \frac{\mathrm{KW}}{\mathrm{ft}}$ and a maximum heat flux of 544,000 $\mathrm{BTU} / \mathrm{hr} \cdot \mathrm{ft}^{2}$ to a maximum burnup of $30,000 \mathrm{MWD} / \mathrm{MT}$ of uranium. The peak cladding temperature is $640^{\circ} \mathrm{F}$; coolant pressure is 2050 psi. 
The reactor is shutdown once each year for refueling, and one-third of the 264 fuel assemblies are replaced each time. The reactor vessel head and the control rod driver and drive support grid are removed to gain access to the fuel. Semi-remote methods and special powerdriven hoisting devices are used for handling the fuel. Fue1 assemblies are withdrawn from the reactor into the flooded reactor cavity and then moved through a cana 1 and an underwater lock to the fuel storage pit. Physics calculations of the $1000 \mathrm{MW}(\mathrm{e})$ pressurized water reactor were performed by Oak Ridge National Laboratory. These were made with the TONG point depletion code, describing the neutron spectrum in 15 gourps. The reference fuel management scheme was the "three-batch roundelay" or "scatter-reload" program in which one-third of the core loading is discharged at each shutdown. The reference design specified that the initial core loading have three batches of fuel (each occupying one-third of the core) with enrichment ratios approximating the ratios existing at the start of an equilibrium cycle. This was simulated in the TONG calculations by specifying three batches of fue1 (homogeneously mixed) having enrichment 
ratios (relative to average core enrichment) of $0.7,1.0$, and 1.3, respective1y. The fuel with the lowest enrichment would be discharged at the first shutdown and replaced with new fuel. Excess reactivity (with rods withdrawn) at the start of each cycle was specified, and the enrichment required in the reloaded zone to obtain that reactivity was determined by a direct eigenvalue calculation. During the depletion cycle, a uniform poison concentration was determined to keep the reactor critical. Initial excess reactivity (i.e., feed fuel enrichment) was treated as a parameter in these calculations in order to optimize fuel costs. 


\section{APPENDIX II}

Further Description

of

Fast Breeder Reactor 
The typical first generation LMFBR consists of a core of mixed (uranium and plutonium) oxide fuel, suitably contained and subdivided to assure adequate heat removed by the circulating liquid-sodium coolant. The core operates in a fast neutron flux, and power is regulated by moving neutron-absorbing control elements into or out of the core. The core is surrounded both radially an 1 axially by natural or depleted uranium blankets. The entire system, along with vacant positions for fuel storage, is housed in a stainless-stee 1 reactor vessel which provides containment for the sodium coolant. The upper end of the vesse 1 is closed by means of a thick double rotating plug shield which is also part of the fuel handling system. At full load, sodium enters the vessel at the lower end at $760^{\circ} \mathrm{F}$, flows up through the core, and exists from the vessel at $1060^{\circ} \mathrm{F}$. The design characteristics of the reference LMFBR are given in Table IX.

The reactor core is made up of 256 vertical hexagonal elements of a 5.389 triangular lattice (cf. Figure 25). The core is surrounded by two rows of radial blanket elements and a single row of stainless steel reflector elements. Fifteen control and safety rods are provided for reactivity control. Tantalum has been selected as the reference absorber material. 
TABLE IX

DESCRIPTION OF ASSUMED FIRST GENERATION LMFBR

\section{Reactor Power}

Tota 1 reactor power, Mw(th) 2500

Core power fraction (mid cycle) 0.899

Radia1 blanket power fraction 0.069

Axial blanket power fraction 0.032

Net electrical power, Mwe 1004

Net thermodynamic efficiency, \% 40.7

\section{Coolant}

Composition

Reactor outlet pressure, psig

Core pressure drop, psi

Sodium

Core flow rate, $1 \mathrm{~b} / \mathrm{hr}$

100

Core inlet temperature, ${ }^{\circ} \mathrm{F}$

$93 \times 10^{6}$

Mean coolant outlet temperature, ${ }^{\circ} \mathrm{F} \quad 1060$

Number of coolant loops

Coolant velocity in core $(\max ), \mathrm{ft} / \mathrm{sec} 32.8$

\section{Core Therma1 Performance}

Average heat flux at rated power, BTU/hr $\cdot \mathrm{ft}^{2}$

Maximum heat flux, BTU/hr. $f t^{2}$

495,000

Maximum fue 1 pin surface temperature, ${ }^{\circ} \mathrm{F}$

Peak fuel pin power, $\mathrm{kw} / \mathrm{ft}$

1200

Cladding hot channe1 factor

16

Peak-to-Average power ratio

1.16

Radial peaking factor

1.65

1.26

Axial peaking factor

1.25

Average core power density, $\mathrm{kw} /$ iter 390

Average specific power of fuel materia1, kw/kg 190 
TABLE IX (CONTINUED)

Core and Fuel (mid equilibrium)

Core fissile enrichments at \%

inner zone

11.4

outer zone

15.4

Fissile mass $(\mathrm{Pu}+\mathrm{U}-235), \mathrm{kg}$

core

1780

axial blanket

116

radia1 blanket

368

Average breeding ratio

Average fuel burnup MWD $/ \mathrm{kgH}$

1.29

75

Doubling time, yr

10

Core residence time @ .8 LF, yr 1.5

Geometry

hexagonal

5.389

Lattice spacing, in

Pins per subassembly/o.d. (in)

fuel and axial blanket

$217 / 0.25$

inner radial blanket

$91 / 0.47$

outer radial blanket

$61 / 0.58$

Fuel and cladding material

Blanket and cladding material

mixed $\mathrm{PuO}_{2} \quad \mathrm{UO}_{z}$

304 or 316 SS

depleted $\mathrm{UO}_{2}$

304 or 316 SS

\section{Control and Safety}

$\begin{array}{ll}\text { Reactivity swing over equilib. cycle, } \$ & 5.0 \\ \text { Absorber material } & \text { tantalum } \\ \text { Pins in array } & 16 \\ \quad \text { shim-safety } & 9 \\ \quad \text { safety } & 1.6 \\ \text { Average rod worth, } \$ & 2.0 \\ \quad \text { shim-safety } & \\ \quad \text { safety } & -0.0096 \\ \text { Reactivity coefficient } & 6.82 \\ \quad \text { doppler constant, t dk/dt } & 6.03 \\ \quad \text { maximum radial sodium void, } \$ & 3.3 \times 10^{-6} \\ \quad \text { istal sodium void, core only, } \$ & \end{array}$


TABLE IX (CONTINUED)

\section{Reactor Vessel}

$\begin{array}{ll}\text { Type } & \text { cylinder } \\ \text { Material } & 304 \text { stainless stee1 } \\ \text { Inside diameter, ft } & 22\end{array}$

\section{Turbine Plant}

Main steam pressure, psig

Main steam temperature, ${ }^{\circ} \mathrm{F}$

Final feedwater temperature, ${ }^{\circ} \mathrm{F}$

Type of steam cycle

Type of turbine
2400

900

478

superheat with reheat

cross-compound 


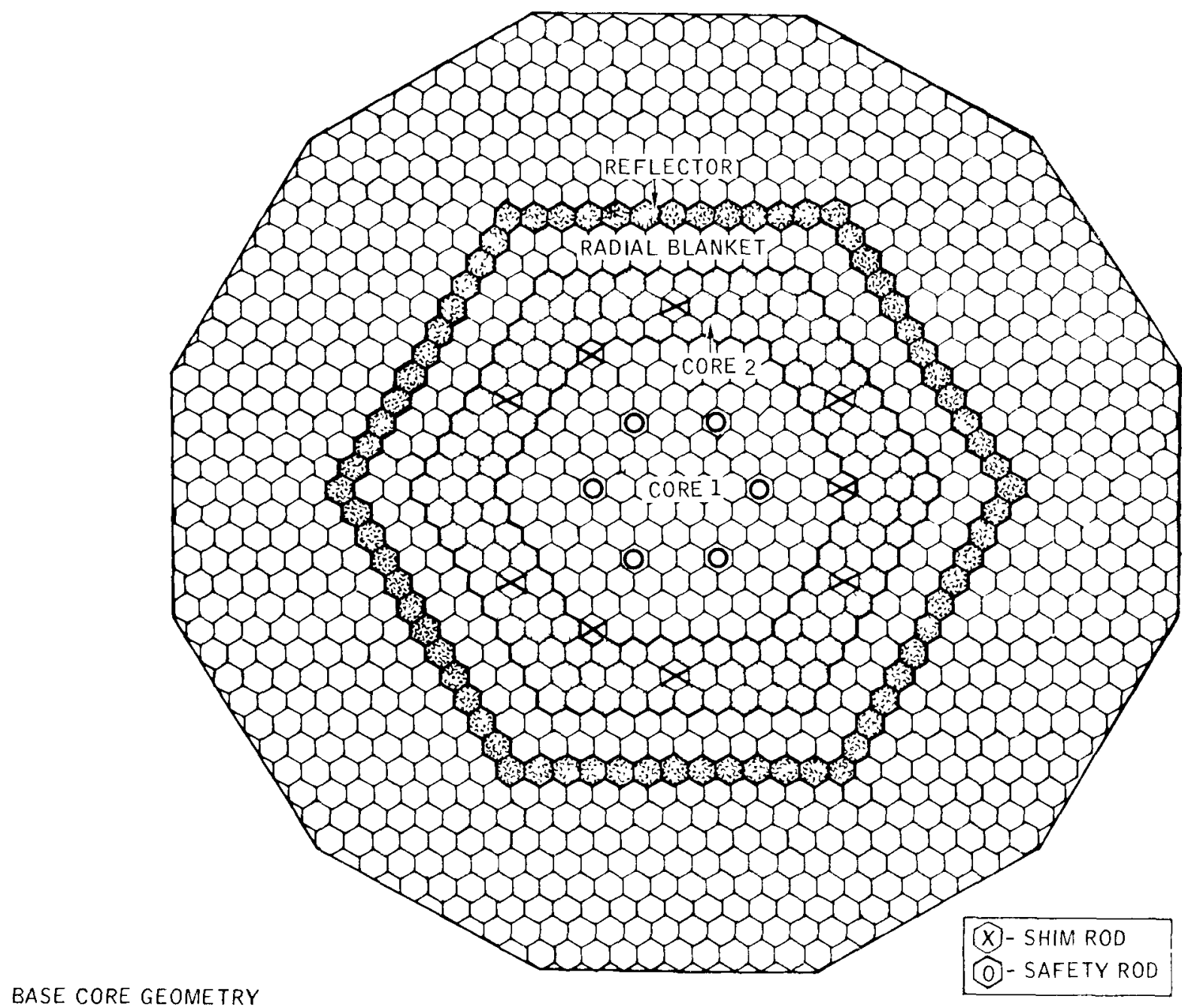

BASE CORE GEOMETRY

ZONE 1: 118 FUEL ELEMENTS +9 CONTROL RODS $=127$

$$
\frac{138}{256} \text { FUEL ELEMENTS }+\frac{6}{15} \text { CONTROL RODS }=\frac{144}{271}
$$

RADIAL BLANKET

INNER (RBI) 60

OUTER (RB2) 66

REFLECTOR 72

TOTAL LOCATIONS $=469$

Figure 25: Horizontal Cross-Sectional Diagram of LMFBR Core and Blankets (after AI-12792) 
Nine control rods are used as combined shim and safety rods, and six are used strictly for safety.

A fast fuel element consists of a bundle of 217 fuel pins vertically supported at their lower ends on support bias inside a hexagonal SS housing. Fuel pellets of mixed $\mathrm{PuO}_{a}$ and $\mathrm{UO}_{2}, 0.215$ inch diameter, are contained in 0.250 o.d., 0.015 inch wal1 thickness, SS cladding. The cladding is a gastight container for the fuel and sufficient excess length is provided for the storage of fission gas to achieve the required fuel burnup (cf. Figure 26). The fast fuel elements have a 50 inch active fuel section and 12 inch axial blanket section at each end. The inner and outer radial blankets are identical in configuration to the fast elements except that the inner blanket element have 91 pins 0.47 inch diameter, and the outer have 61 pins 0.58 inch diameter. The reflector elements are made of stainless steel plates. Fuel elements are transferred between core and storage by an in-core fuel handling machine.

The reactor will be refueled on a six month cycle with $1 / 3$ of the core, $1 / 6$ of the inner blanket, and $1 / 9$ of the outer blanket being replaced each cycle. Refueling is performed during scheduled plant shutdown. Spent fuel is removed from 


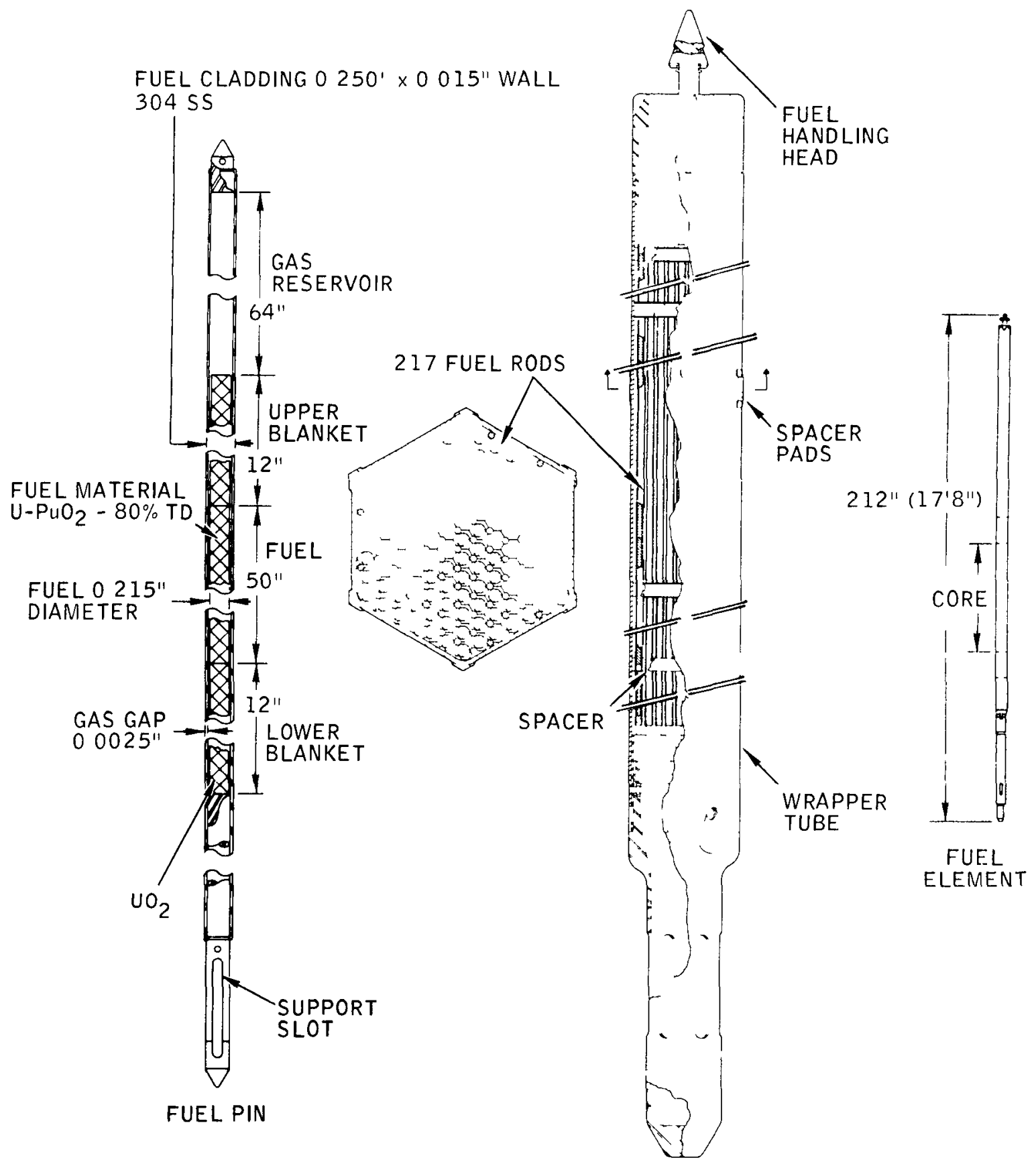

Figure 26: Typical LMFBR Fue1 $P$ in and Element Design (after AI-68-Memo-37, Vo1. I) 
the core and placed in one of the in-vessel storage positions for decay during the subsequent power cycle. The average exposure of the spent core fuel is 74,000 MWD/MT. The fast core elements have an average reactor residence time of 1.5 years, the inner radial blanket 3 years, the outer radial blanket 4.5 years, and the shim control rods 8 years. Thus, on the average, 103.3 core assemblies are exchanged at each refueling. Additiona 11 y $1 / 9$ of the outer blanket elements are rotated $180^{\circ}$ to permit uniformity of the $\mathrm{Pu}$ buildup at the edge of the core where there is a sharp flux gradient. The downtime per refueling is estimated at about ten days.

The sodium heat-transfer system consists of three heattransfer circuits operating in paralle1. Each circuit consists of a radioactive primary sodium loop which flows through the core in series with a non-radioactive secondary sodium loop. The primary and secondary loops are connected by means of an intermediate heat exchanger. The secondary sodium transports the thermal energy to the steam generator banks where it is transferred to the steam system. The operating pressure in the secondary-sodium side of the intermediate heat exchangers is maintained at a higher 
pressure than the primary sodium side so that a leak in the intermediate heat exchangers will not lead to radioactive contamination of the unshielded secondary system .

The combined primary loop sodium flow is from the lower plenum of the reactor up through the core and into the upper plenum. The flow then divides and goes through the three separate loops to a primary centrifugal pump through two intermediate heat exchangers in parallel and then back to the reactor lower pelnum where it recombines with the sodium flow from the other loops. At full power operation, $94 \times 10^{6} \mathrm{lb} / \mathrm{hr}$ of sodium enters the reactor at $760^{\circ} \mathrm{F}$ and exits at $1060^{\circ} \mathrm{F}$. Each intermediate heat exchanger has a design duty of $1425 \times 10^{6} \mathrm{BTU} / \mathrm{hr}$ and is about 70 inches diameter and 30 feet long. The overall fuel element peak-to-average power ratio at midcycle equilibrium is 1.605 . The corresponding peak linear power rating is $15.7 \mathrm{KW} / \mathrm{ft}$ with a maximum coolant flow velocity of $30 \mathrm{feet} / \mathrm{sec}$ and clad temperature of $1200^{\circ} \mathrm{F}$. 
The steam-generator system utilizes both superheaters and reheaters to produce $900^{\circ} \mathrm{F}$ steam at $2500 \mathrm{psi}$. This steam is admitted to the high pressure section of a double-flow turbine. Exhaust steam from this section at $575 \mathrm{psia}$ and $515^{\circ} \mathrm{F}$ is reheated in the sodium-steam reheats and returned to the intermediate-pressure section at $515 \mathrm{psia}$ and $575^{\circ} \mathrm{F}$. The turbine-generator is rated at 1240 Mva.

The fuel burnup calculations were performed by Atomics International with the PABUC computer program. The calculations were performed in one-dimensional geometry using neutron-diffusion theory. The PABUC code incorporates a modified version of ANISN for flux and eigenvalue ( $\left.k_{\theta}, t\right)$ calculation and the NUCY subroutine for solution of the nuclide production and depletion chain. The principal calculations were performed in cylindrical geometry. Two core enrichment regions were employed to facilitate control of the peak-to-average power ratio. Each enrichment region was subdivided into three burnup zones to provide greater detail in the calculations. Each of the burnup zones was divided into three equal-volume fuel batches to simulate the fuel-management scheme. The time history of the changes 
in isotopic composition of each batch was calculated on a cycle-by-cycle basis. At each refueling one batch from each burnup zone was discharged and replaced with fresh fuel.

The radial blanket was similarly treated with six fuel batches in the inner-ring blanket and nine fuel batches in the outer-ring blanket. A uniformly distributed tantalum poison was used in the outer-core enrichment region to simulate the control rods. Refer to Figure 5 for a horizontal section of the core. The vertical cross section is shown in Figure 27. Equilibrium operation had been achieved at the tenth refueling cycle.

The isotopic composition for the initial loading is assumed to be $60 \%{ }^{239} \mathrm{Pu}, 24 \%{ }^{240} \mathrm{Pu}, 12 \%{ }^{241} \mathrm{Pu}$, and $4 \%{ }^{242} \mathrm{Pu}$. This is felt to be representative of early LWR discharge compositions. The startup core employs three different enrichments in each of the two major enrichment zones to minimize the swing in reactivity during the approach to equilibrium. The lower-enrichment batches are replaced first to provide a smooth transition to high-burnup, high-enrichment fuel. 


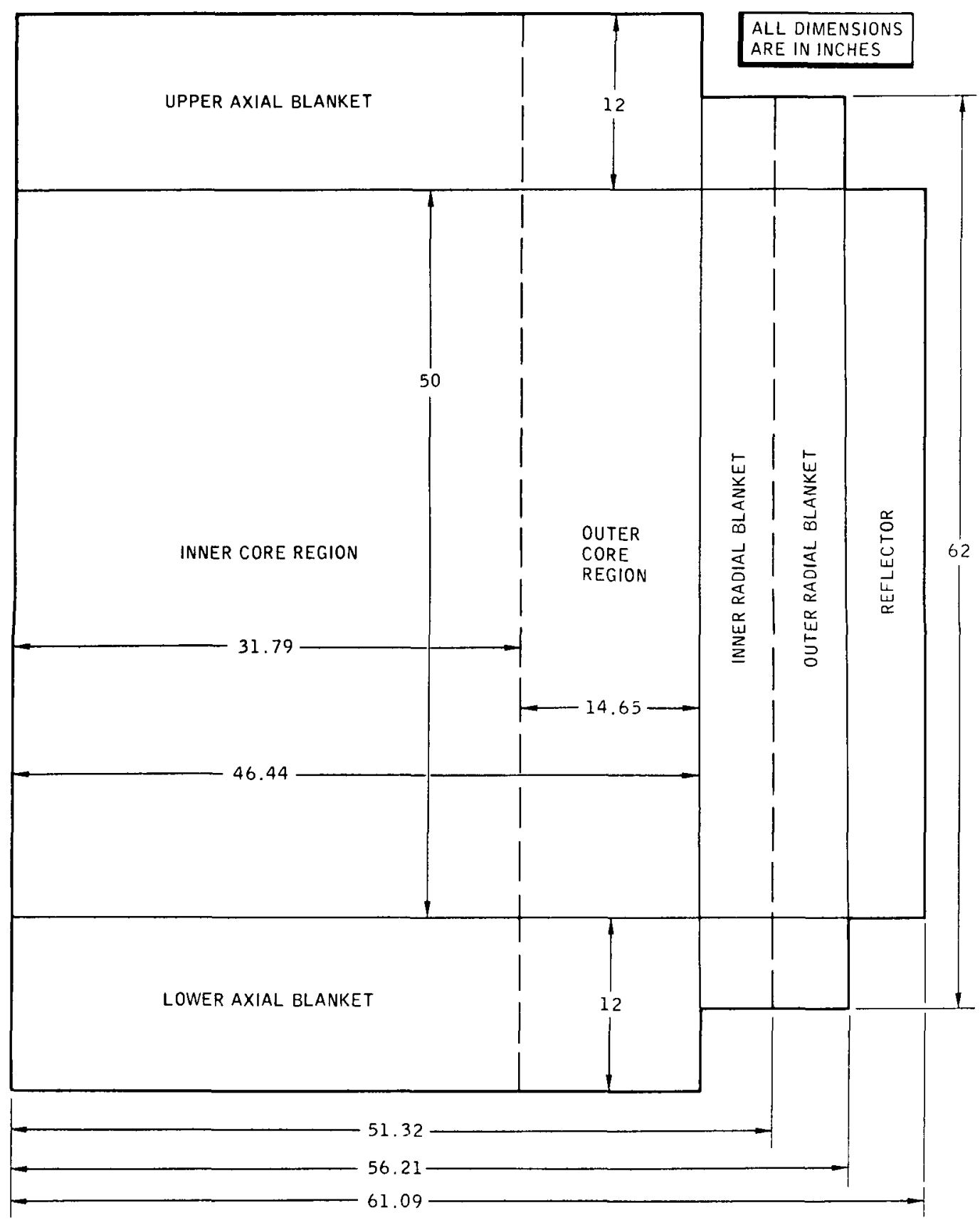

Figure 27: Vertical Cross Section of LMFBR Core Showing Fuel Regions and Dimensions (after AI-68-Memo-37, Vol. II) 
Each cycle corresponds to 144 days of full power (1000 Mwe) operation. During equilibrium operation, $610 \mathrm{~kg}$ of fissile plutonium are charged to the reactor and $721 \mathrm{~kg}$ are discharged at each refueling shutdown. AI calculates a total breeding ratio of 1.29 and with their assumption of the excore fuel inventory of $797 \mathrm{~kg}$ and $1 \%$ losses they conclude the simple doubling time (cf. Equation 2) is 8.7 years. 
APPENDIX III

\author{
Listing \\ of
}

Computer Program

MIN-E-COST 
FOKTRAN IV G LEVEL IO

MAI V

DATE $=71158$

$32,51 / 17$

C

C

C
MIN-E-COST - A PRCGRAM TO GALCILATE THL HSTLST WNWTH RATH TH FAST RKEEUER KEACTOKS II YIELE MINI MUM VIICLEAN UENERATING CLDTS
0001

0002

$\mathrm{CCC}_{3}$

0004

OCO5

OCC6

$00 \cup 7$

UcC 8

OCCS

$U C 10$

CCII

J012

4013

CC 14

(C) 1 )

0010

$\mathrm{CO} 17$

CLI8

co19

0020

CC 21

OC 22

0023

0024

0025

$\mathrm{CU} 26$

0027

C 028

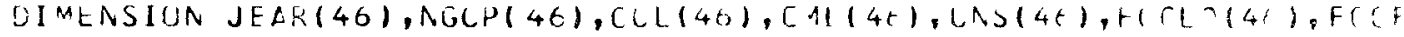

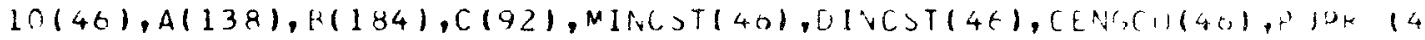

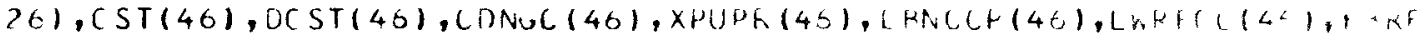
3C.C(46), UNCL LFF (40), UNCFBR $(46)$

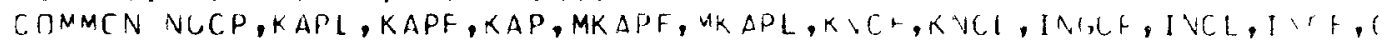

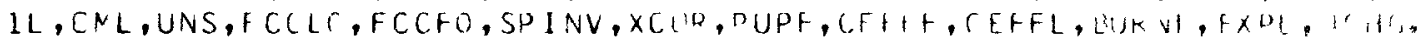
ZAVLWR, AVFBK, PUPK, FA 3LOS, KEPLCS, PISFAT, A, PUF, L, FPHPY, TVGR, CH ", WY 3AR, PUSL, PUKF, PUSF, TINV, ACFBR, ACLMR, PWF, PLWF, OFPR, EPLW, , IFt, A OC, 4PUINV, AUCCST, IINGC, EANGC, OLNGC, F, MINGST,LINCST, CHNGCO, PUPI, WI, TCS $5 \mathrm{~T}, \mathrm{C}) \mathrm{NGC}, \times$ PLPF, COENCC, LWH FCC, FLRTCC, UNCL, R, I R.LFRK, XC PF

C JNMCA/CNE/M

KEAL IVGCP,CQNUCP, KAPL,KAPR,KAP, AK APR, MKAPL, KNCF, KVCL, INCP, I UL, IN ICF, MINCST, LWFFLC

C INITIALIZL CASE CLUNTER

$$
L=0
$$

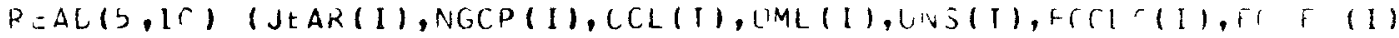

$1, I=1,46 I$

$1^{\cap}$ FLRMAT (I4,E1C.4,SF $\left.1 \mathrm{C} .3,10 \times\right)$

WRITE $(6,12)$

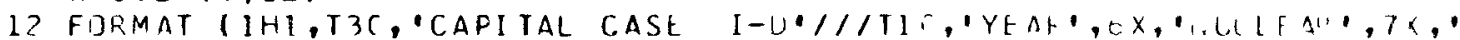

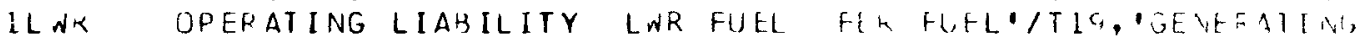

? APITAL E NAINT. INSURANCE COSTS $\triangle T$ CLSTS AT'/T2R, 'RAPAI ITY'," $3 \times,{ }^{\prime}$ CUSTS COSTS COSTS PUPR $=$ PIDK $=0 \%, 1, \cdots(M, L), 6 \times$ $4,1(N F K H H)$ (MPKWH) (MPKWH) ("HKWH) (MPKNH) $/ 1 /$ )

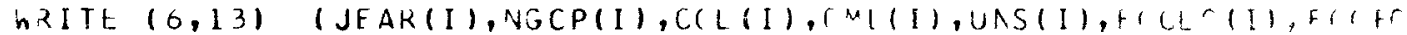
$1(I), I=1,46)$

13 FCRMAT (TIC, I 4,F15.2,5FIO.5) KEAO $15,15 \quad$ I SPINV,XCOR, PUPF, CEFH, CFFFL, , IKML, EXHL, UCHU, AVI IWR, AVFBR, XCFF, FABLOS, REPLCIS, DISRAT, F

15 FURNAT $(1+15.5 .65 X)$

15 'NRITE $(6,18)$

le f JRMAT (1+l, Tle, "INFUT UATA'///)

NRITE $(5,2 C)$

2) FURMAT $(\cdot,, F 15.5)$

WPITE $(6,22)$ SPINV

22 F JRMAT (T1C.'SPINV = , F 15.5 )

R.RIE $(t, 2 C)$

WITE $(6,24) \times C, C R$

24 F JRMAI (T1C, $X C O K=1, F 15.5)$

WRITE $(6,20)$

WIITE $(6,2$ E) PUPF

26 FORMAT (TIR, 'PUPF = ,F15.5)

WRITE $(6,20)$

WNITE $(0,28)$ CEFFF

28 FURMAT (T1C, 'LEFFF $=1, F 15.5$ ) 


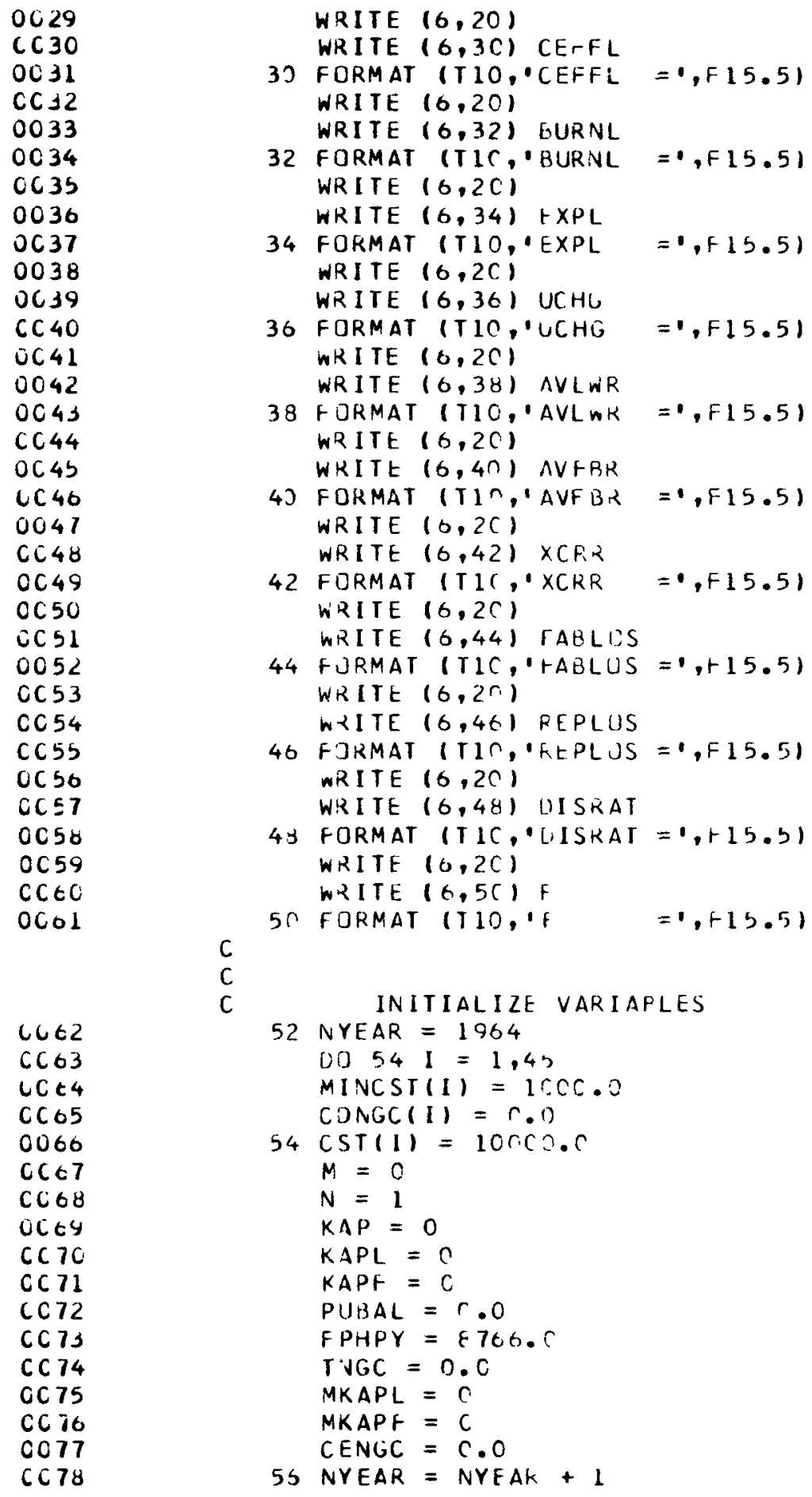


FUKTRAN IV G LEVEL 19

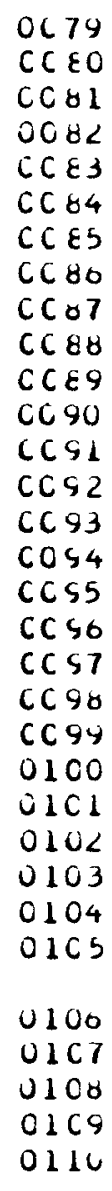

0111

0112

Cl13

0114

Clib

0110

0117

0118

0119

$01<0$

0121

C $1<2$

0123

0124

$I N G C P=N G C P(N)-K A P$

NUMB = NYEAK - $197 \%$

IF (NUMB. NE. O) GU TC SC

I.VCF $=1$ ICON.C

GO TC $7 \mathrm{C}$

60 NUMO = NYEAK - 1482

If (NUMB. NE. O) GL TC 62

INCF $=1$ CrR. O

GO TL $7 C$

62 CCATINUE

$6 O T C$ TR

04 NUME = NYEAK - 1985

It I NUMB . CE. OI GL TO BE

45 I NCF $=C$

GU TL $7 C$

66 TINV $=$ SPINV $* \times C G F$

IF (IINV .LE. I.O) GO T) 5 I

UIVCF = PUEAL, TINV

51 IF ITINV . GT. C.OO) GC TO 68

MRITE $(6,53)$ IINV

53 F CRNAT (T30,. TINV $=$, F15.5)

GS CINTINUE

NVLF $=$ UNCF

INCF $=1 \mathrm{COO} *$ VNCF

IF (INCF .LT. INGCP) GO TC 70

$I N L F=I N G C P$

70 INCL $=$ INGCF-INCF

C

$$
\text { CIMPUTE ANO PHINT PLUTONIUM DALANCE }
$$

CALL PUBA

CUNT I NUE

IF IN G G . II GO TU 74

WRITE $(6,72)$

72 FCKMAT (1H1, 'YEAR NUCLEAR

LWH', OX, 'LWK', SX, L LKK', SX, 'fKR', , X,

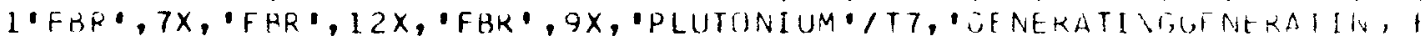
2KAC- PLUTCNIUY EENERATING FHAC - PLUTRNIUM",OX, "FLI, YIUM. $37 X, \cdot$ BALANCE / T8, 'CAPACITY CAPACITY TICN PKLCUCTIUN TAPALI

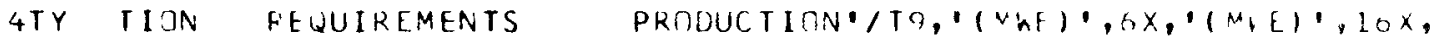

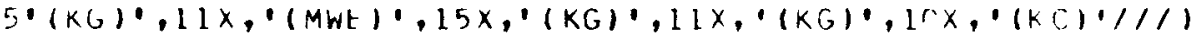

74 WRITE (6, I ( ) AYFAR, NGCP(N), KAPL, PLWK, PLSL, KAPF, FF BR, PLRF, HUSH, DUJAA

8) FJKMAT (I5, 2FIC. 3, F7.3,F $15.4, F 1 C .0,57.3,3 F 15.4)$

$K A P=\Lambda G C P(N)$

$N=N+1$

IF ( N.LE. 40) GC TC 56

C REINUEX INITIAL CCNDITICNS CF VARIAPLES

31 PUPF $=0.0$

WRI I 16,104$)$ PUPR

$82 N=1$

$K A P=0$

NYEAK $=1964$

$K A P L=0$

$K A P F=C$

PUKAL $=C \cdot O$

TVGC $=\mathrm{C} . \mathrm{O}$ 
FOK TRAN IV G LEVEL 19

MAIN

CATE $=71158$

$22 / 51 / 17$

0125
0126
0127
0128
0129
0130
0111
0132
0133
0134
0135
0136
0137
0138
0139
0140
0141
0142
0143
0144
0145
0146
0147
0148
01149
0150
0151
013

0152

0153

0154

0155

C 156

0157

C158

0159

C 160

C 161

C 162

C 163

0164

MKAPL $=0$

MKAPF $=n$

CENGC $=8.0$

COONGC $=0.0 \mathrm{C}$

CCENGC $=0.0$

C REINCREMENT YEAR, REOETERMINE INCREMENTALS CF CAPACITY

84 NYEAF $=$ NYEAR + 1

$I N G C P=N G C P(N)-K A P$

NUMB = NYEAR - 1978

IF ( $A U M B$. NE. O) GO TO 85

INCF $=10 \mathrm{CO} \cdot 0$

GO TO 92

85 NUMB = NYEAR - 1982

IF (NUMB. NE. O) GO TO 86

INCF $=1 \mathrm{CCO} .0$

GO TO 92

86 CIJNTINUE

G.] TC 92

88 NUMH = NYEAR -1985

IF (NUMB . CEE. O) GO TC 9C

INCF $=C$

GO TO 92

90 UNCF = PUBAL, TINV

NVCF $=$ UNCF

INCF $=1$ IOOO * NNCF

IF (INCF IT, INGCP) GO TO 92

$I N C F=I N G C F$

92 INCL $=$ INGCP - INCF

C

RECCMPUTE PLUTONIUM BALANCE

CALL PURA

CIJNTINUE

C CCMPUTE FNERGY CCSTS

CALL ENRGCT

CONT INUE

C

COMPUTE ECUNDMIC IDEAL

CALL ECNIDL

CCNT INUE

$A D C O S T=$ TNGC - CENGCO(N)

$M=M+N$

IF (M.LE. 67r22)GO TO 103

PRINT ECCNOMIC RESULTS

IF (A.GT. 1) GO TO 100

WRITE $(6,96)$

96 FORMAT 1 I YEAR ANNUAL PLUTONIUM PRESENT DISCOUNTED CUM IULATIVE ECON ECON ANN OISCOUNTED CUMULATIVE ADOITICNALITT 29.' NUCLEAR INVENTORY WORTH NUCLEAR NUCLEAR LWR FBR 3 NUCLEAR ECONCMIC ECONOMIC NUCLEAR'/T6, "GENERATING', 13X' 4FACTOR GENEFATING GENERATINGFRAC- FRAC- GENERATING GENERATING

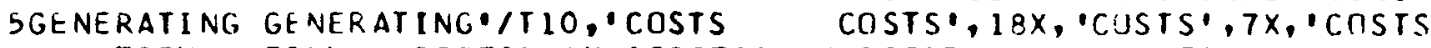

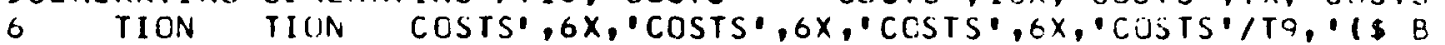
$7 I L)$ (\$ BIL), 16X,'(5BIL) (\$BIL), 16X, (\$ BIL) (\$BIL) 8 (\$BIL) (\$BIL) $1 / / 1)$

100 WRITE $(6,102)(N Y E A R, A N G C$, PUINV, PWF, DNGC, TNGC, EPLWR, EPFBR, EANGC, DEN 
FURTRAN IV G LEVEL 19

MAIN

$D A T E=71158$

$22 / 51 / 17$

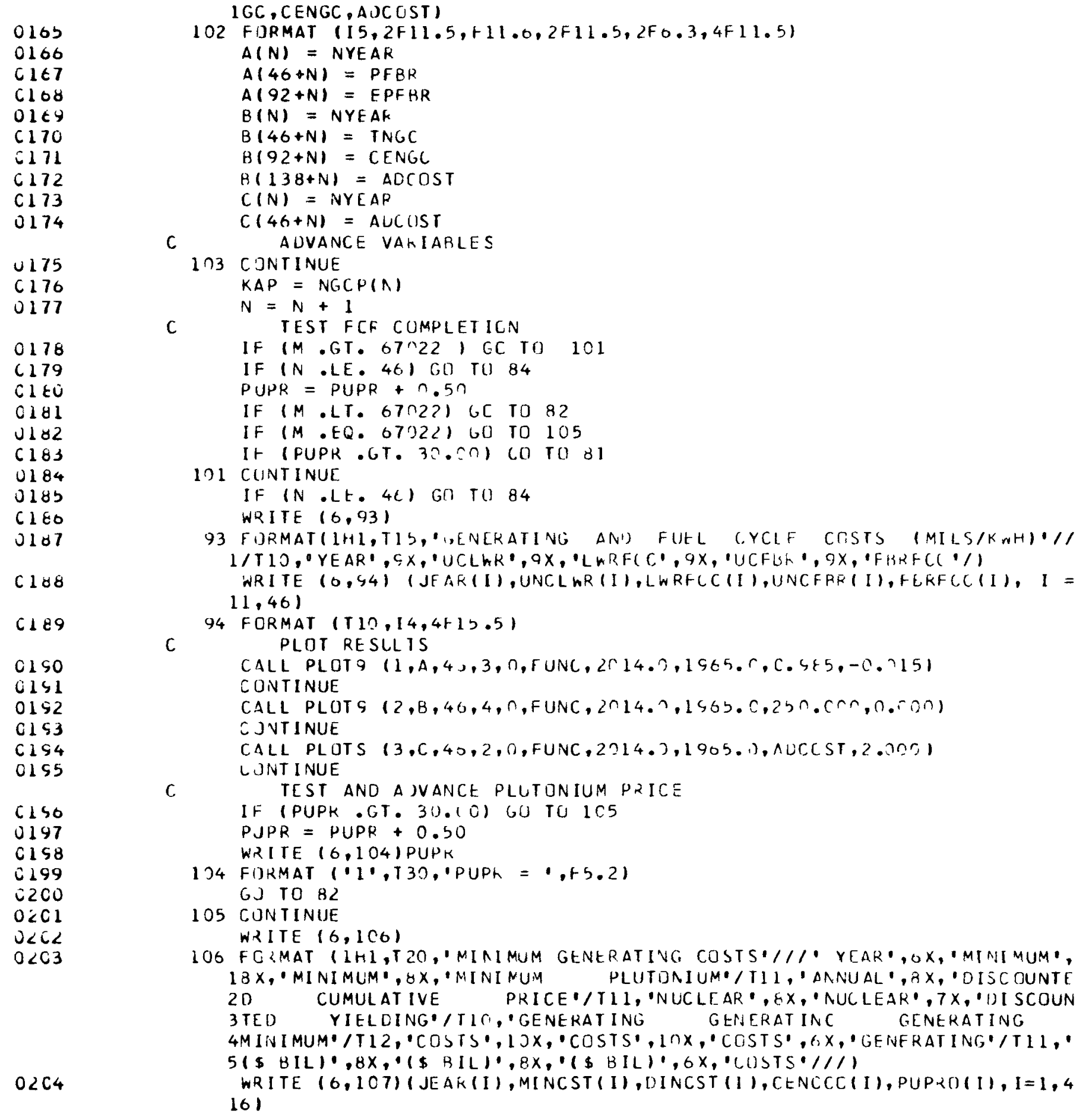




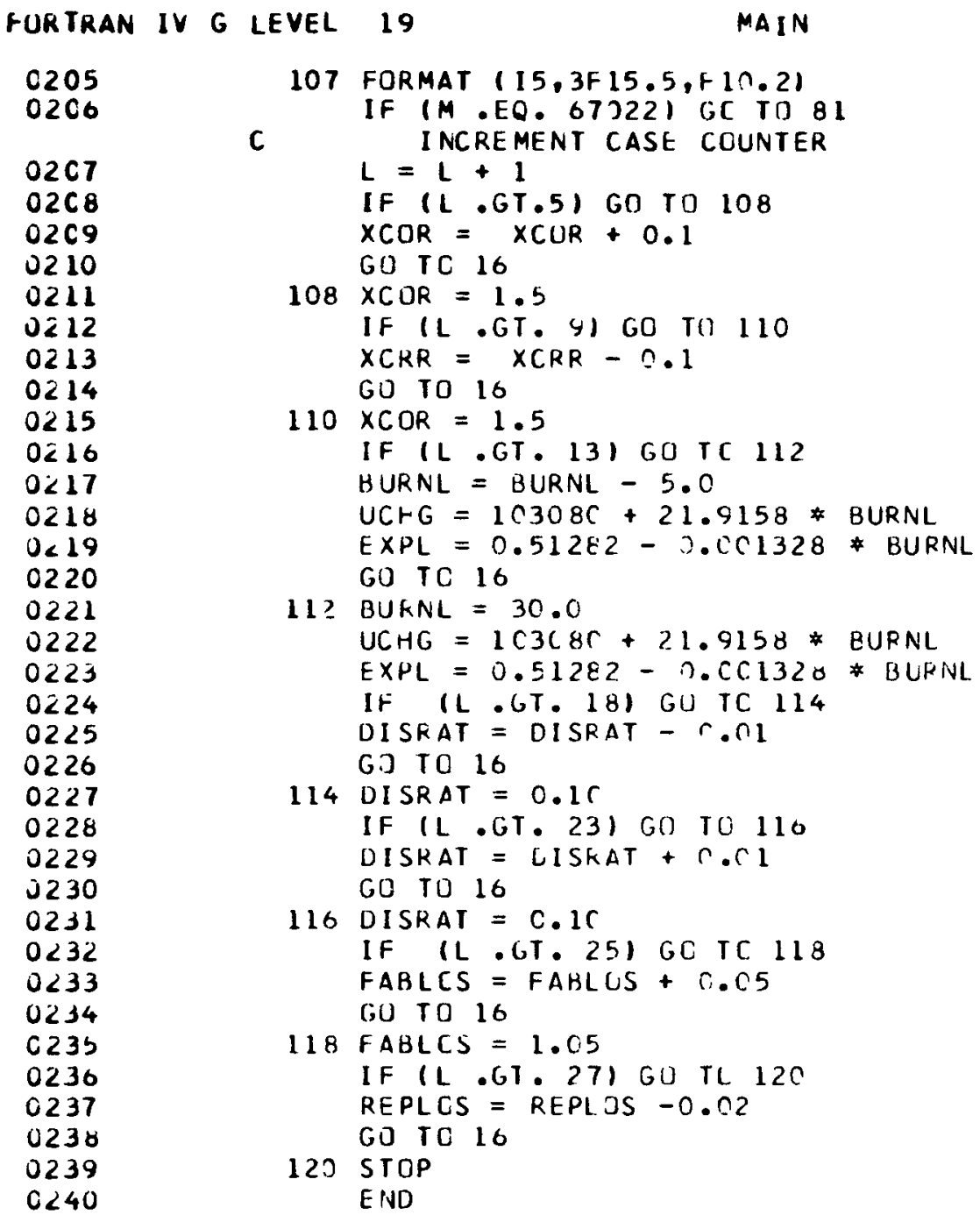




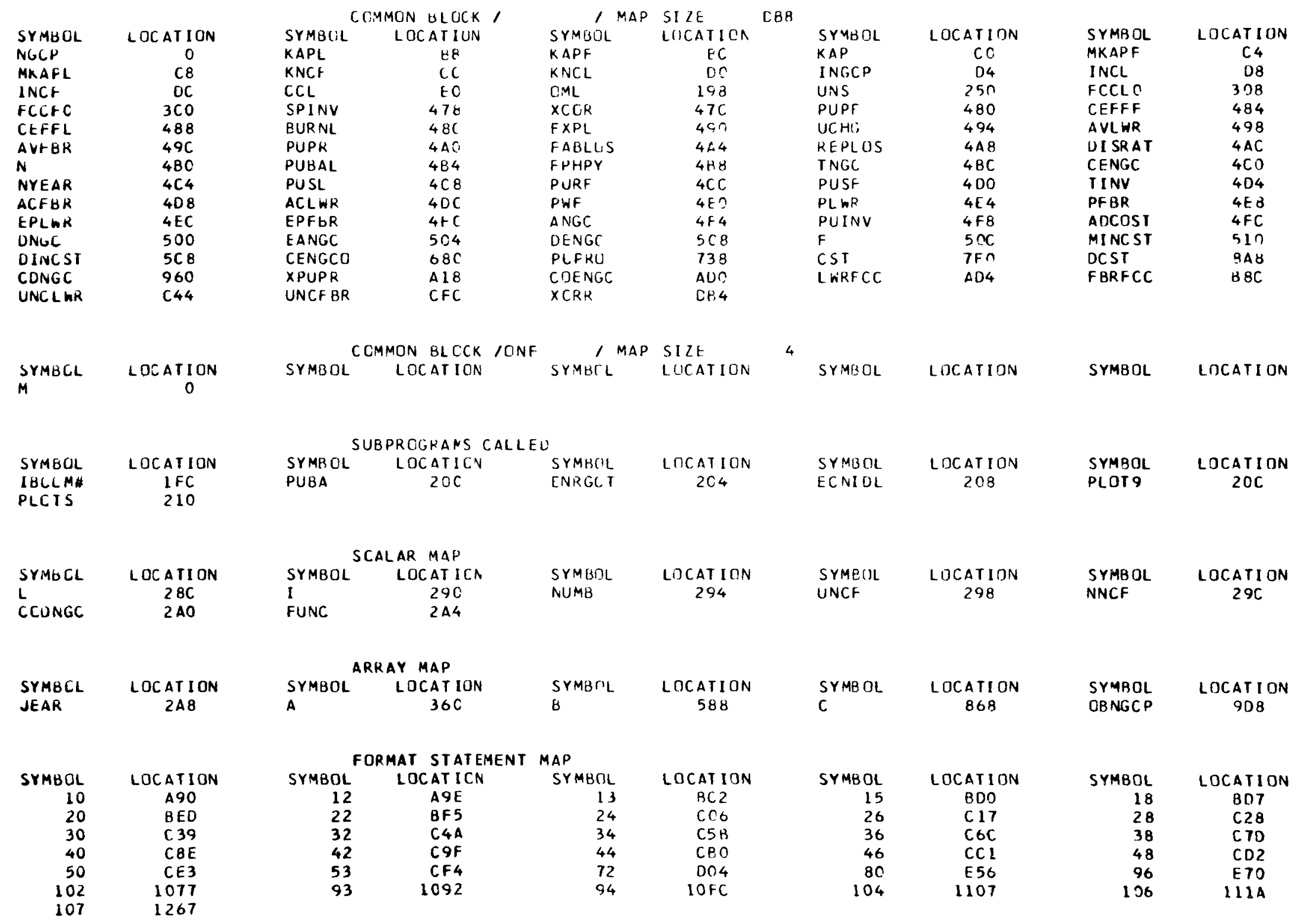


0002

0002

0003

0004

0005

0006

0007

0008

C009

0010

0011

0012

0013

0014

0015

0016

0017

C018

$\mathrm{CO} 19$

0020

0021

0022

0023

0024

0025

0026

0027

0028

OC 29

0030

0031

0032

0033

0034

0035

0036

0037

0038

0039

CO4O

0041

0042

0043

0044
SUBROUTINE PUBA

COMHCN NGCP,KAPL, KAPF, KAP, MK APF, MK APL, KNCF, KNCL, INGCP, INCL, INCF, CG 1L, OML, UNS, FCCLO, FCCFO, SP I NV, XCOR, PUPF, CEFFF, CEFFL, BURNL, EXPL, UCHG, $2 A Y L H R, A V F B R, P U P R, F A B L O S, R E P L O S, D I S R A T, N, P U B A L, F P H P Y, T N G C, C E N G C, N Y E$ 3AR, PUSL, PURF, PUSF, I INV, ACFBR, ACLWR, PWF, PLWR, PFER, EPLWR, EPFBR, ANGC, 4PUINV, ADCOST, ONGC, EANGC, DENGC, F, MINCST, D INCST, CENGCD, PUPRO, CS T, DCS $5 T$, CDNGC, XPUPR, COENGC, LWR FCC, FBRFCC, UNCLWR, UNCFBR, XCRR

DI MENSI ON JEAR(46), NGCP(46), CCL (46), CML(46), UNS(46), FCCL (4t), FCC $10(46), A(138), B(184), C(92), M I N C S T(46)$, DINCST (46), CENGCO(46), PUPRO $(4$ 26), CST (46), DCST (46), CDNGC (46), XPUPR (46), OBNGCP(46), LWRFCC (46), FBKF $3 C C(46), U N C L$ WR $(46)$, UNCFBR (46)

REAL NGCP, OBNGCP, KAPL, KAPF, KAP, MKAPF, MKAPL, KNCF, KNCL, INGCP, INCL, IN ICF, MINCST, LWRFCC

$K=0$

PUPL $=$ (BURNL * EXPL) $*$ UCHG *0.001*0.001

PUBALI = PUBAL

IFIBURNL .LE. 0.00$)$ GO TO 202

PUPL = IBURNL * EXPLI*UCHG*0.0O1

202 IFIBURNL .GT. O.DO) GC TO 226

WRITE $(6,204)$ BURNL

234 FORMAT (T2C.'BURNL $=1,115.5$ )

206 CONTINUE

PUSL $=$ PUPL $* K A P L * 0.001 *$ REPLOS

PUSF $=$ PUPF * KAPF $* 0.001$ *REPLUS

PURL $=0.0$

PURF $=(I N C F * C . C O I * S P I N Y * X C U R+K A P F * C . C O 1 * X C K R * S P I N V / 2.0) *$ FABLOS

PUBAL = PUBALI+PUSL + PUSF - PURF - PURL

IF (PUBAL . GE . 0.0 ) GO TO 208

INCF $=$ INCF -1 IOO .C

$I N C L=I N G C P-I N C F$

GO TO 206

208 CONT I NUE

NUMB $=$ NYEAR -1985

IF INUMB .LT. OI GO TU 210

IF $(\mathrm{K} . \mathrm{EQ} .1 \mathrm{OC}) \mathrm{GO}$ TC 210

If (INCF. EQ. INGCP) GO TO 210

IF (PUBAL.LT. 3500.0 ) GO TO 210

INCF $=$ INCF + 100 N.C

INCL $=$ INGCP - INCF

$K=K+1$

IF (INCF ILE.INGCP) GC TO 206

$I N C F=I N C F-1000 . C$

$I N C L=I N G C P-I N C F$

GO TO 206

210 CONT INUE

KAPL $=$ KAPL + INCL

KAPF $=$ KAPF + INCF

$P L W R=K A P L / N G C P(N)$

$P F B R=$ KAPF / NGCP(N)

PUBAL $=(F *$ PUBAL $+(1.0-F) *$ PUEAL * EXP(-0.0479)

CONT INUE

RETURN

END 


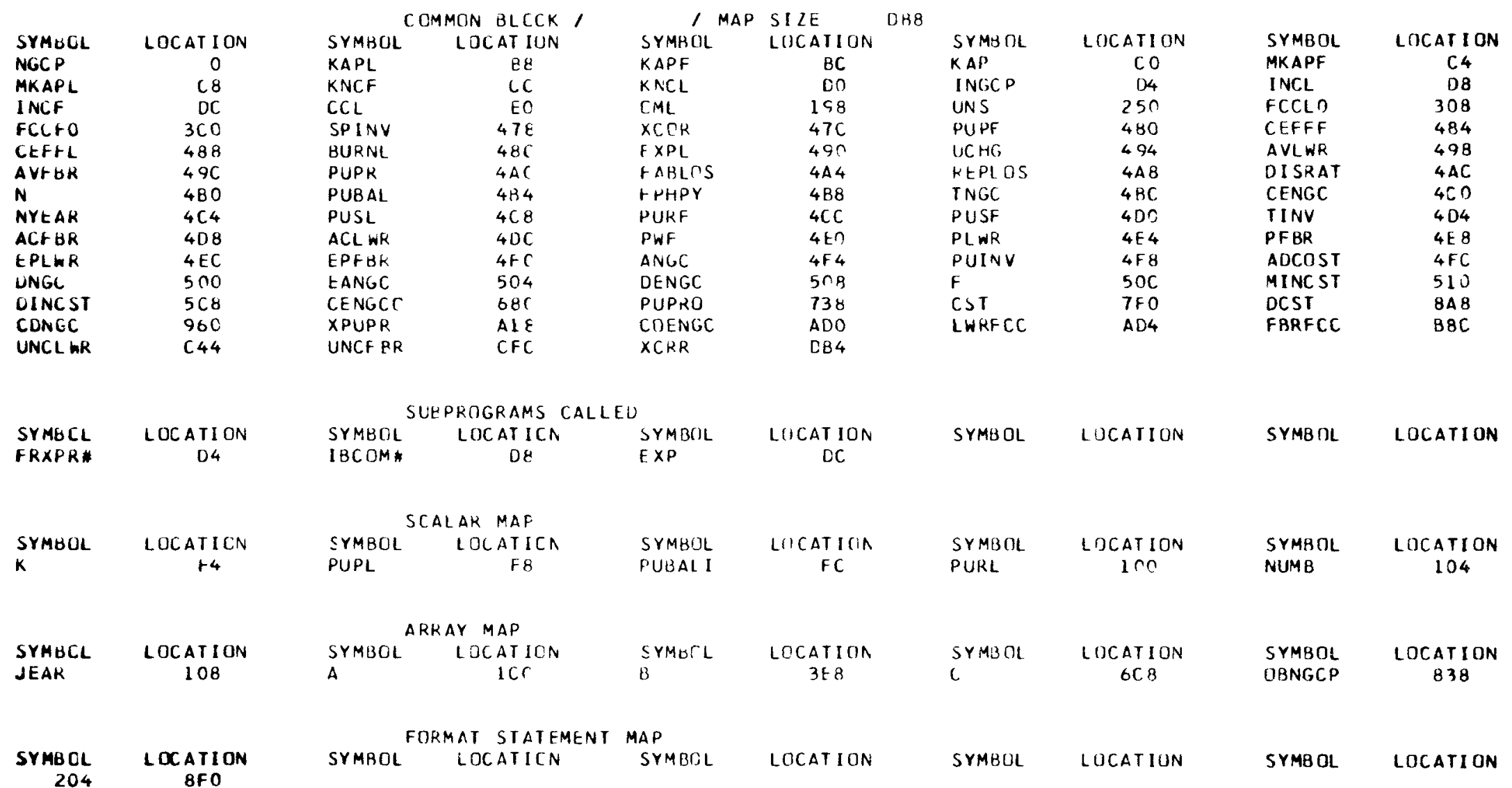


0001

$00 \mathrm{C2}$

0003

0004

0005

CCC6

0007

0008

CCC9

0010

0011

0012

0013

0014

CO 15

0016

0017

0018

0019

0020

0021

0022

0023

0024

0025

0026

0027

0028

0029

0630

0031

OC 32

0033

0034

0035

0036

0037
SUBROUT INE ENRGCT

CONMCN NGCP, KAPL, KAPF, KAP, MKAPF, MKAPL, KNCF, KNCL, INGCP, INCL, INCF 1L, OML, UNS,FCCLO, FCCFC, SPINV, XCOR,PUPF, CEFFF, CEFFL, RURNL, EXPL, UC 2 AVLWR, AVFBR, PUPR, FABLOS, REPLOS, DISRAT, N, PUBAL, FPHPY, TNGC, CENGC, 3AR, PUSL, PURF, PUSF, TINV, ACFBR, ACLWR, PWF, PLWR, PFBR, EPLWR, EPFBR, AN 4PUINV, ADCOST, DNGC, EANGC, DENGC, F, MINCST, DINCST, CENGCO, PUPRO, CST, 5T, CDAGC, X PUPR, COENGC, LWRFCC, FBRFCC, UNCLWR, UNCFBR, XCKR

DI MENSION JEAR (46), NGCP(46), CCL (4)), CML (46), UNS (46), FCCLO(46), F IC (46), A(138), B(184),C (92), MINCST (46), DINCST (46), CENGCO(46),PUPR 26), CST (46), DC ST (46), CDNGC (46), XPUPR (46), OBNGCP(46), LWRFCC (46),F 3CC (46), UNCL WR (46), UNCFBR (46)

REAL NGCP, OBNGCP, KAPL,KAPF, KAP, MKAPF, MKAPL, KNCF, KNCL, INGCP, INCL ICF, MINCST, LWRFCC

$C C F=C C L(N) * 1.25$

CMF $=O M L(N) * 1.25$

$U C L W R=C C L(N)+C M L(N)+U N S(N)+F C C L O(N)-(0.723 \neq$ PUPR)

UNCLWR (N) = UCLWR

$U C F B R=C C F+O M F+U N S(N)+F C C+O(N)+10.0257$ * PUPR $)$

UNCFBK $(N)=U C F B R$

$P C L W R=C C L(N)+C M L(N)+U N S(N)$

$L W R F C C(N)=U C L W R-P C L W R$

$P C F B R=C C F+O M F+U N S(N)$

FBRFCC $(N)=U C F B R-P C F B R$

$A C L W R=$ UCLLP * AVLWR * FPHPY * .001

$\triangle C F B K=$ UCFBK * $\triangle$ VFBR * FPHPY *0.001

$\triangle N G C=N G C P(N) *((P L W R * A C L W R)+(P F B R * A C F A R)) * 0 . C O O O N 1$

PUINV $=$ PUBAL *PUPR *UISKAT * 1?00.C*. $.0 C C O O 1 * 0.021$

DISFAC $=(1+$ DISRAT $) *(N-21)$

IF (DISFAC .GT. O.0C5) GO TO 234

IF (DISFAC ILT. C.OC5) GO TU 230

230 NRITE $(6,232)$ DISFAC

232 FORMAT (T3C.. OISFAC $=0, t 15.5$ )

234 CONTINUE

PWF $=1 /$ [ISFAC

DNGC $=$ PWF $*$ (ANGC + PUINV)

TNGC $=$ TNGC + DNGC

TOTCST $=$ ANGC + PUIAV

IF (TOTCST.GT. CST(N) ) CO TC 240

CST $(N)=$ TOTCST

DCST $(N)=D N C, C$

CODNGC $=$ CODNGC + DNGC

CONGC(N) $=$ CODNGC

$X P U P R(N)=P U P F$

240 CONTINUE

RETUKN

END 


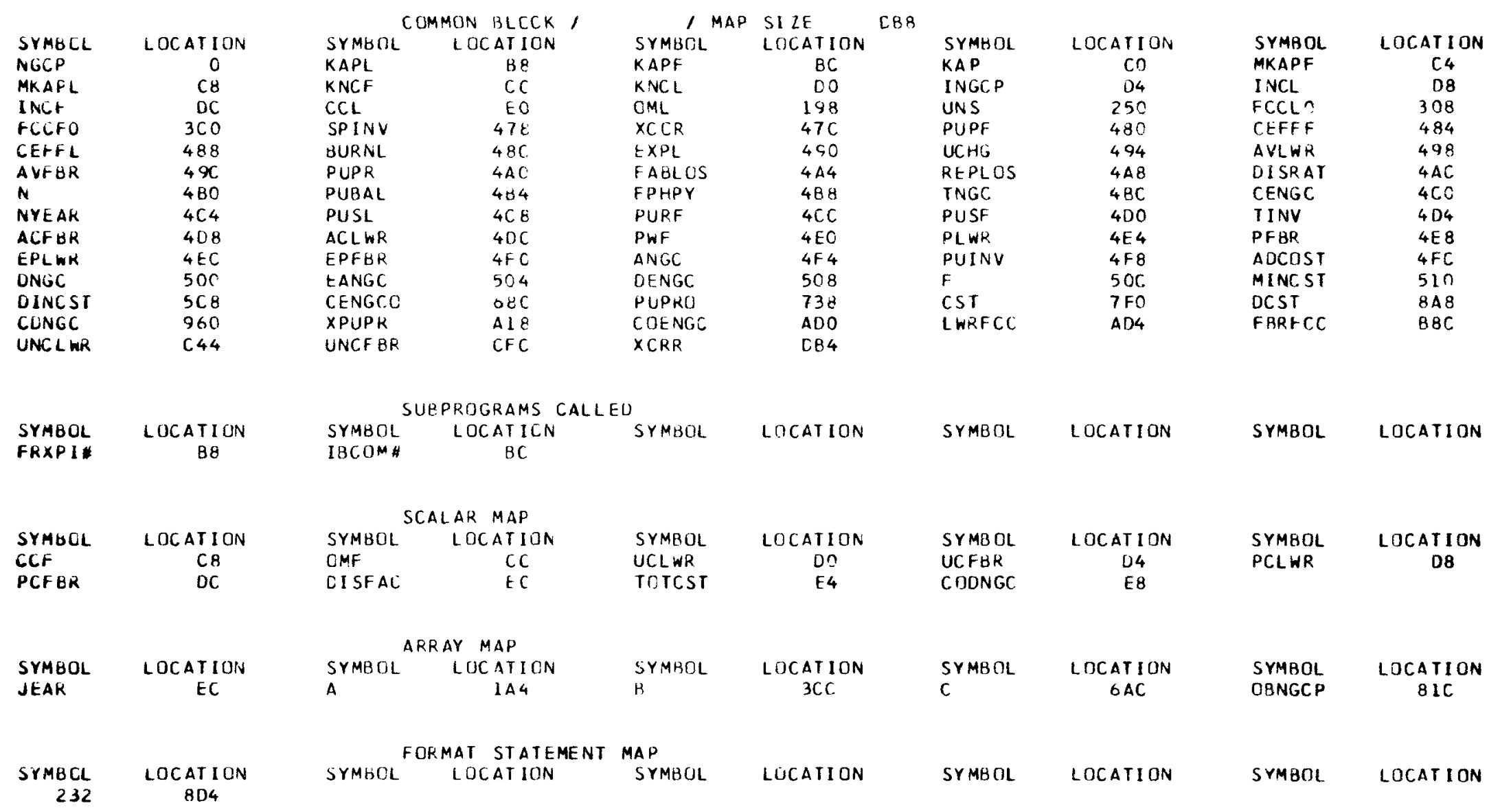


$\mathrm{COO}$

0002

0003

0004

0005

0000

OCO7

0008

0009

CO10

0011

0012

CC 13

0014

0015

0016

0017

0018

0019

0020

0021

CC 22

0023

0024

0025

0026

CO 27

$\cos 28$

0029

$\cos 30$

J0 31

0032

0033

0034

0035

0036

$0 \subset 37$

0038

C039

0040

0041

0042

0043

0044

0045

LC46

0047

OC48

CC49

0050

SUARDUTINE ECNIDL

COMMCN NGCP, KAPL, KAPF, KAP, MKAPF, MKAPL, KNCF, KNCL, INGCP, INCL, INCF, $1 L, O M L, U N S, F C C L O, F C C F O, S P I N V, X C O R, P U P F, C E F F F, C E F F L, B U R N L, E X P L, U C H C$ 2 AVLWR, AVFRR, PUPR, FABLOS, REPLCS, OI SRAT, N, PUBAL, FPHPY, TNGC, CENGC, IY $3 A R, P U S L, P U R F, P U S F, T I N V, A C F B K, A C L W R, P W F, P L W R, P F B R, E P L W R, E P F B R, A N G C$ 4PUINV, ADCOST, DNGC, $\triangle A N G C, D E N G C, F$, MINCST, DINCST, CENGCO, PUPRO, CST, LC 5T, CONGC, XPUPR, COENGC, LWRFCC,FBRFCC, UNCLWR, UNCFBR , XCRR COMMCN/ONE/M

DIMENSION JEAR(46), ACCP(46), CCL(46), CML (46), UNS (46), FCCLO(46), HCO $10(46), A(138), B(184), C(92), M I N C S T(46)$, DINCST( 46), CENGCO(46), PUPRI) 26), C ST (46), CCST (46), CCNGC (46), XPUPR(46), OBNGCP(46), LWRFC $(46), f(1):$ $3 C C(46), U N C L W R(46), U N C F B R(46)$

REAL NGCP, OBNGCP,KAPL,KAPF,KAP, MKAPF, MKAPL,KNCF, KNCL, INGCP, INCL, I ICF, MINCST, LWRFCC

$A C E C R C=A C F E R-A C L W R$

IF I ACECRC.GT. O , GO TO 252

KNCF $=$ I AGCP

$K N C L=0.0$

KYEAR = NYEAF - 1995

IF (KYEAR . LT. O) GC TO 250

$J=N-30$

ONGCP $=$ NGCP(J-1)

$N$ J $N C P=N C C P(J)$

IF (J.GT. 1) GO TO 248

ONGCP $=0 . C$

243 UBNGCP $(J)=$ VUNGCP - CNGCP

$K N C F=K N C F+O B N G C P(J)$

$K N C L=K N C L-O B N G C P(J)$

GO TO 254

$250 \mathrm{KNCL}=0$

GO TO 254

$252 \mathrm{KNCL}=I N G C P$

$K N C F=0$

254 MKAPL $=$ MKAPL $+K A C L$

IF (MKAPL .LE. 0.0) GO IO 256

MKAPF $=$ MKAPF $+K \wedge C F$

GO TG 258

256 MKAPL $=0.0$

MKAPF $=\wedge G C P(N)$

$258 \mathrm{EPLWR}=$ MKAPL / NGCP(A)

EPFBR = MKAPF / NGCP(N)

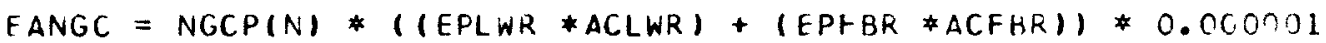

DENGC $=$ PWF $\$$ EANGC

$C E N G C=C E N G C+D E N G C$

IF (M.GT. 67,22) GC TO 262

IF (EANGC. GE. MINCST(N)) GO TO 260

$M I N C S T(N)=E A N G C$

$D I N C S T(N)=D E N G C$

COENGC = CLENGC + DENGC

PUPROINI = PUPR

IF (N.GT.1) GO TO 259

$C E N G C O(N)=C C E N G C$

GO TO 262

259 CENGCO(N) $=$ CENGCO $(\Lambda-1)+\operatorname{DINCST(N)}$

260 CONTINUE

$\operatorname{CENGCO}(N)=\operatorname{CENGCC}(\Lambda-1)+\operatorname{DINCST}(N)$

262 CONTINUE

RETURN

END 


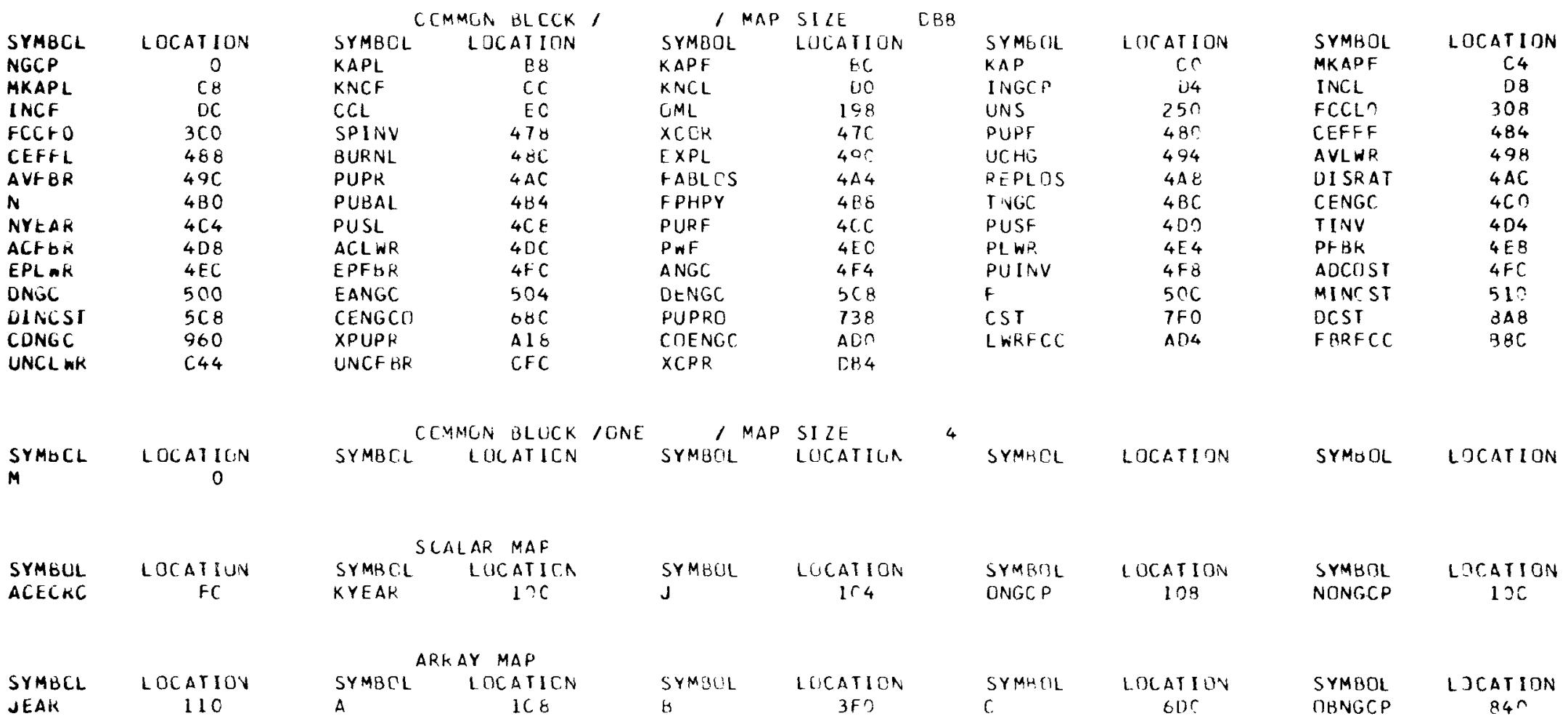


SUBROUT INE PL OT 9 (NO, A, N, M, NFUNC,FUNC, XLAX, XL I $N, Y L A X, Y L I N)$ PURPOSE - TO PLUT A CRAPH WITH ONE INDEPENCENT VAR IABLE AND UP TO 9 DEPENOENT VARIABLES, WITH THE ADDITICAAL ABILITY TO PLOT a CALCULATEC CURVE. THE INUEPENDENT VARIABLE IS PLDTTED ON A HORIZONTAL AXIS, THE LEPENDFNT UNES CN A VERTICAL AXIS. WIOTH IS 100 PRINT POSITICNS. HEIGHT IS 50. EVERY PCINT OF EACH DEPENDENT VAF I ABLE IS INDICATEO BY A NUMBER $(1-9)$, WHILE THE CALCULATED POINTS ARE UENJTED BY ASTEKISKS. PARAMETER USAGE.

NO A FIXED POINT NUMBER, UP TO 3 DIGITS, PRINTED AS THE CHART NUMBER

A A VECTOR WHOSE FIRST N POSITIONS CONTAIN THE INDEPENDENT VAKIADLE, AND wHOSE NFXT M SETS OF N POISITIONS CUNTAIN ThE DEPENDENT VARIABLES

N NUMBER OF CBSERVATIONS

$M$ NUMBER OF VARIABLES IINDF PENUENT \& DEPENDENT I

NFUNC GREATER THAN ZERO IF a CALCULATED CURVE IS TO BE PRINTEU

FUNC SUBROUTINE TO genERATE CALCULATEO CURVF. IF ONE WANTED. ELSE IS A LUMMY. PRIGRAM CALL ING PLITT MUST HAVE AN - EXItRNAL FUNC'. SUBRGUTINE CALLEU BY CALL FUNC $(x, y)$, WHERE $X$ IS GIVEN TO SURPTUTINE ANI $Y$ RETURNED.

$X L A X, X I I N, Y L A X, Y L I N$ MAXIMUM AND MINIMUM VALUES OF THE INDEPENDENT AND DEPENDENT VARIARLES TC BE USEO IN THE PLOT IF XLAX = XLIN, THE PRCGRAM CALCULATFS ITS OWN MAXINUM ANO MINIMUM FOR THE INDEPENOENT VARIABLE. SIMILARLY FCR YLAX = YLIN

0002

REQUIREU SUBRTUTINES. FUNC (IF USED), AND SCAL. DIME NSION IOUT $(101), X P K(11), A(1), C A L C(1) 2)$

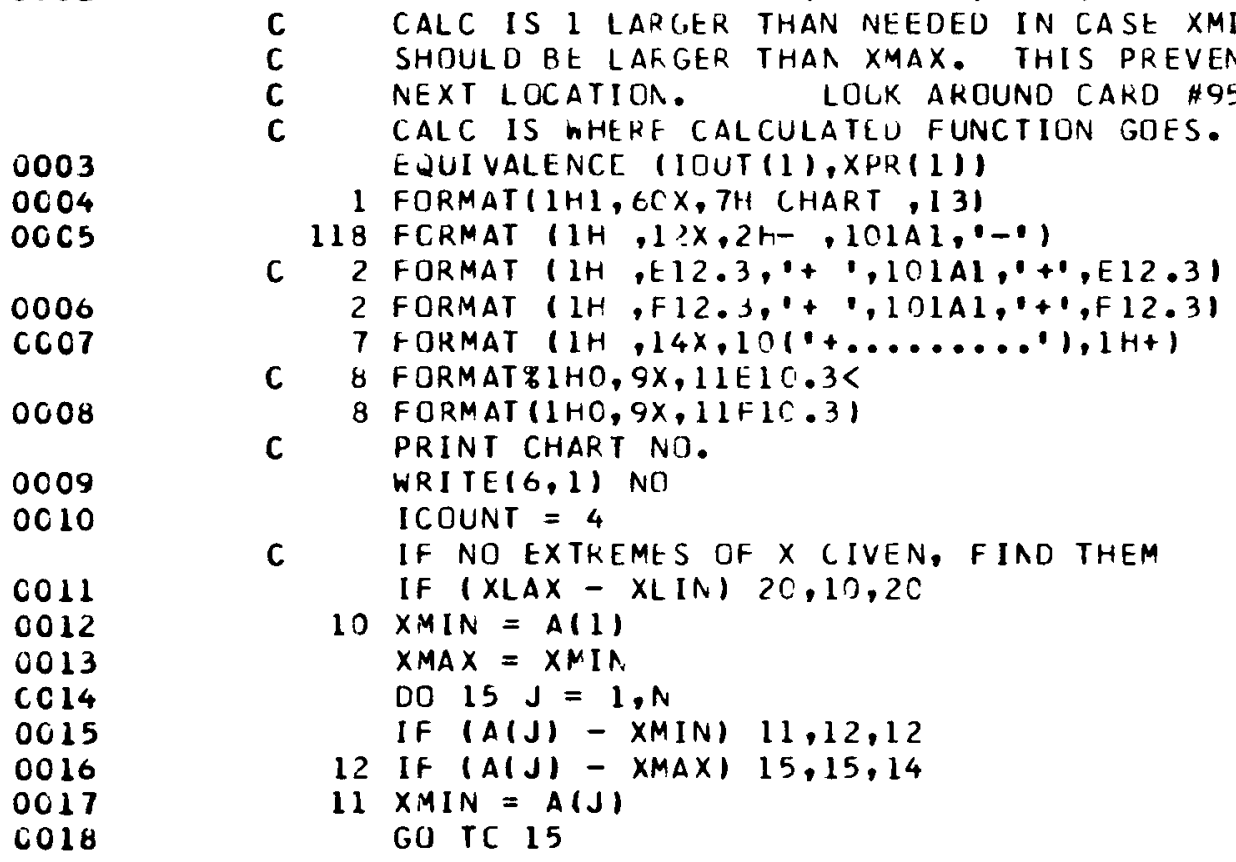


FCRTRAN IV G LEVEL 19

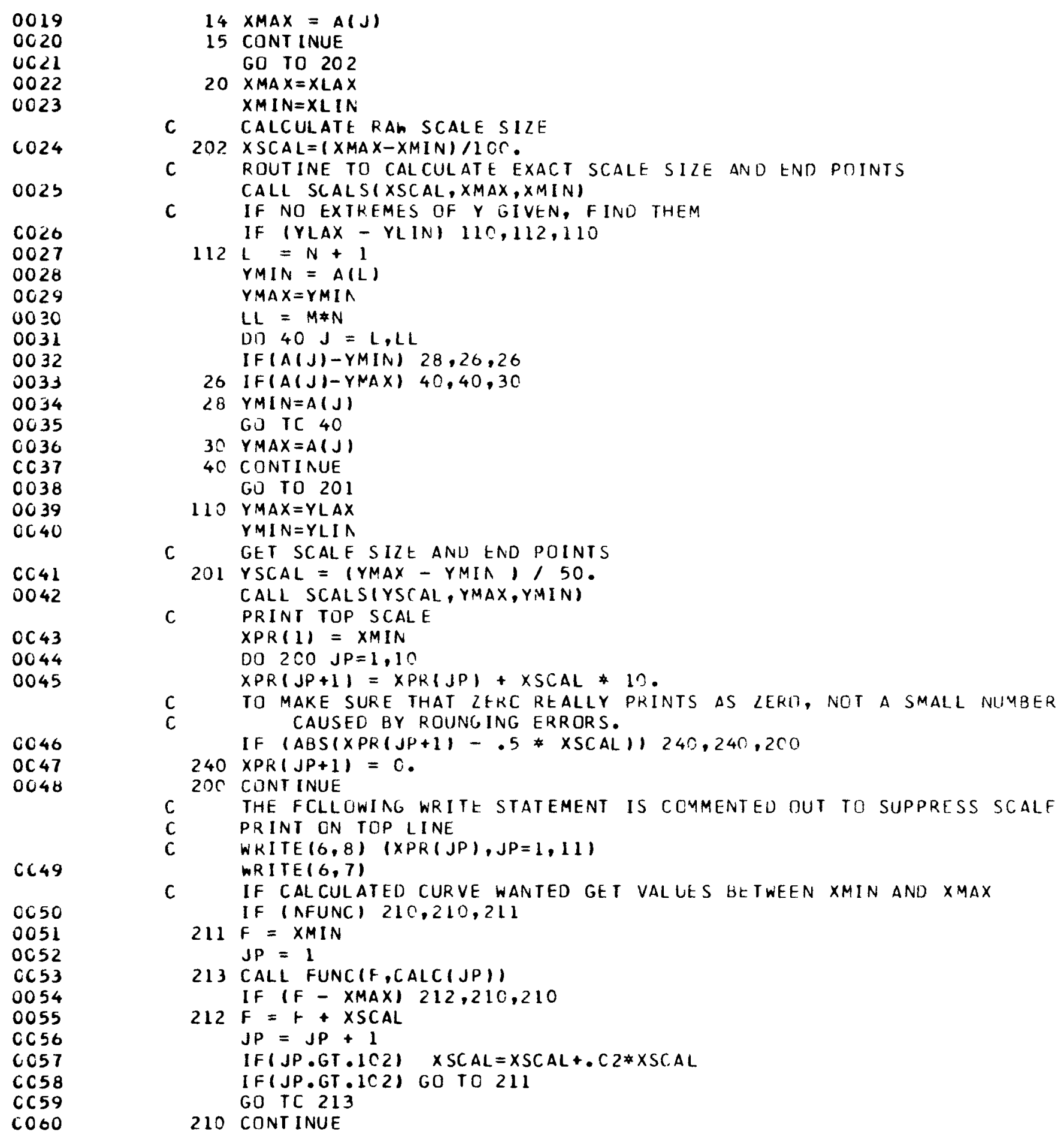




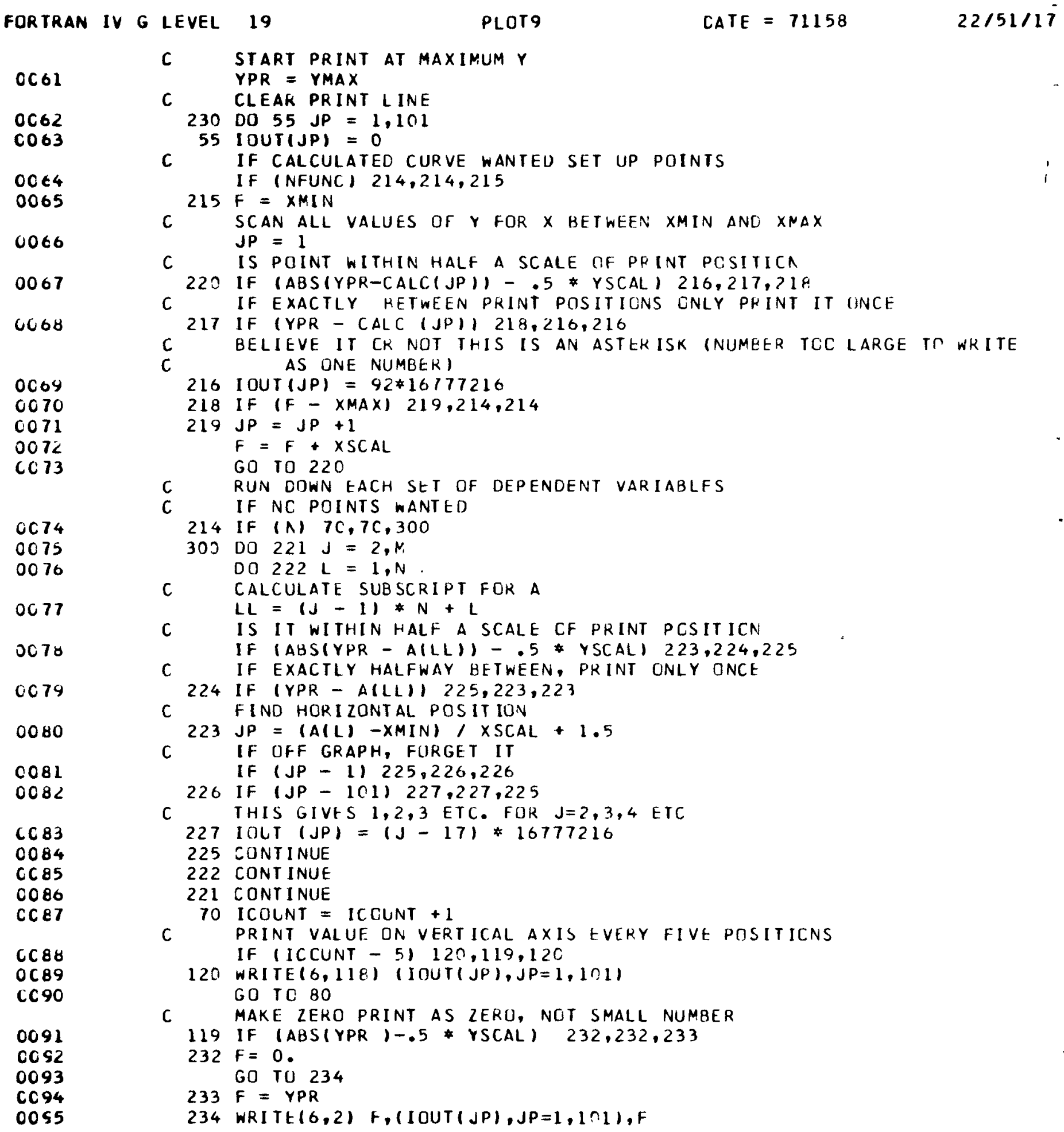


FORTRAN IV G LEVEL I9

\begin{tabular}{|c|c|c|}
\hline CC96 & C & $\begin{array}{l}\text { ICOUNT }=0 \\
\text { IF REACHEC YMIN. STCP }\end{array}$ \\
\hline CC 97 & 80 & IF (YPR - YMIN) $86,86,45$ \\
\hline & C & ELSE DECREMENT $Y$ \\
\hline $\begin{array}{l}0098 \\
\text { CC } 99 \\
0100\end{array}$ & $\begin{array}{l}45 \\
86\end{array}$ & $\begin{array}{l}Y P R=Y P R-Y S C A L \\
\text { GOTO } 230 \\
\text { WRITE } 6,7)\end{array}$ \\
\hline $\begin{array}{l}0101 \\
0102 \\
0103\end{array}$ & c & $\begin{array}{l}\text { PRINT BOTTOM SCALE } \\
X P R(1)=X M I N \\
D O 90 \mathrm{JP}=1,1 C \\
X P R(J P+1)=X P R(J P)+X S C A L * 10\end{array}$ \\
\hline $\begin{array}{l}0104 \\
01 C 5\end{array}$ & 231 & $\begin{array}{l}\text { IF }(A B S 1 X F R(J P+1)-.5 * X S C A L)) 231,211.9 n \\
X P R(J P+1)=0 .\end{array}$ \\
\hline $\begin{array}{l}0100 \\
0107 \\
0108 \\
0109\end{array}$ & 9 ? & $\begin{array}{l}\text { ZDNTINUE } \\
\text { WRITE }(6,8)(X P R(J P), J P=1,11) \\
\text { RETURN } \\
\text { END }\end{array}$ \\
\hline
\end{tabular}




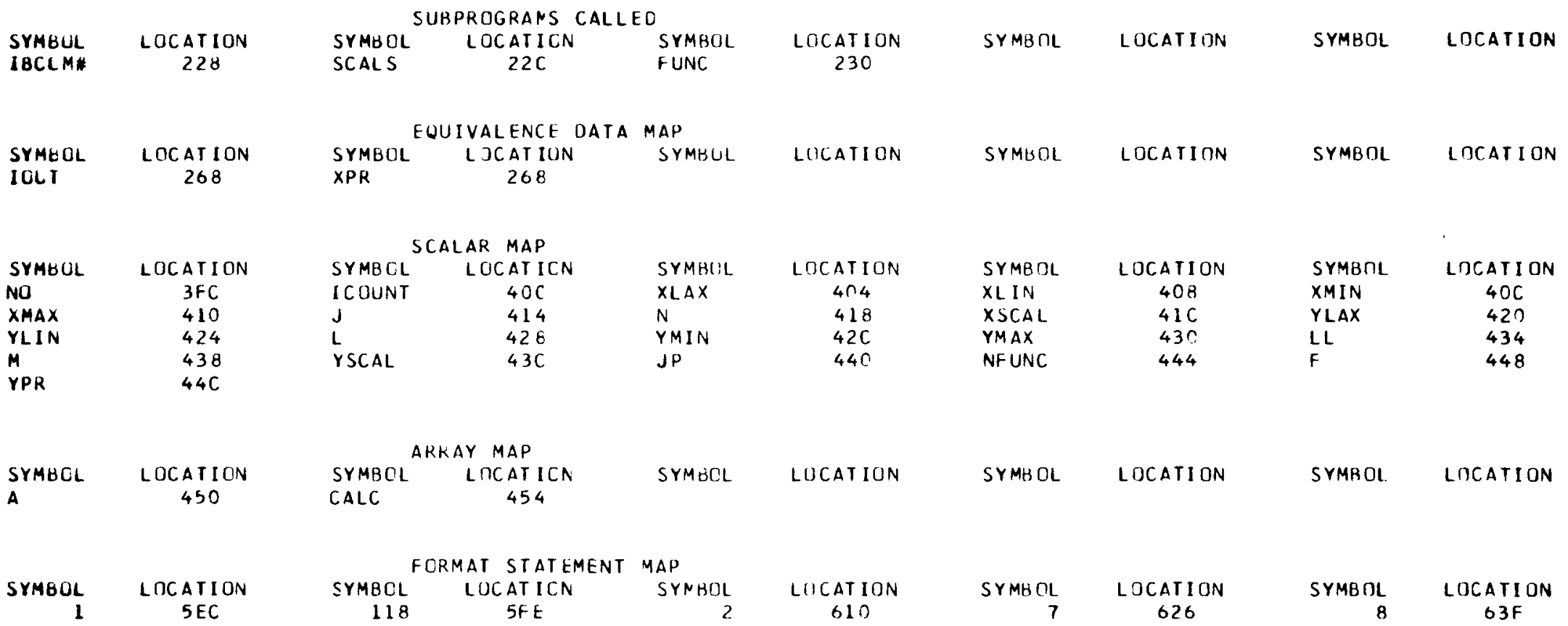


0001

SUBKOUTINE SEALSIXSCAL,XMAX, XMIN)

COO2 PUKPCSE. GIVEN KAW SCALE AND ENL POINTS, GET RCUNUFU VALUTS.

IINO NEXT LOKEST HOHER OF 10.

If (F) $1,2,2$

C It NEGATIVE, STIIP FCRTKAN FRCM ROUNDING UP

$1 \mathrm{JP}=\mathrm{F}-1$

$$
\text { SO TC } 20
$$

CuO

$\mathrm{CCCO}$

C FIND VALUE JUST LARGER IHAN IAW YSCAL, IJF FGRM $1,2,2,5,2,0 \mathrm{R}, 10$

TIMES IC TO AN INTEGKAL POWER

$2 \cap F=10 . \# \# P$

0007

$\mathrm{OCCO}$

0009

$\operatorname{col} 10$

colit

Ou 12

0011

OC 14

0015

OC 16

0017

0018

0019

0020

0021

$00<2$

0023

$00<4$

$00<5$

$\checkmark C 26$

$4 C<7$

CC 28

CC. 29

0030

OC 31

6 IF $(F-X S C A L) \quad 3,4,4$

$3 \quad F=r+t$

If $(F-X S C A L) \quad 5,4,4$

$5 f=1.25 * F$

It $(\mathrm{F}-X S C A L) \quad 7,4,4$

$7 F=F+F$

If $(F-X S C A L) \quad 3 C, 4.4$

3) $F=F+F$

GU TC 6

c StT tuUaL to SCALE

$4 \times S C A L=F$

$J P=X N A X / X S C A L$

C MAKE ENU PCINIS INTFGRAL MULTIPLES OF SCALF

$12 F=J P \# X S C A L$

If $(1-X M A X) \quad 16,11,11$

1) $J P=J P+1$

GU TO 12

$11 X M A X=F$

$J=X M I N / X S C A L$

$13+=J P * X S C A$

It $(F-X M I N) \quad 14,14,15$

$15 \quad J P=J P-1$

GU TL 13

14 XMIN $=F$

RETURN

E VI)

FORTRAN IV G LEVEL Ia

SCALS

$D A T E=71158$

$22 / 51 / 17$

PAST Cog 2

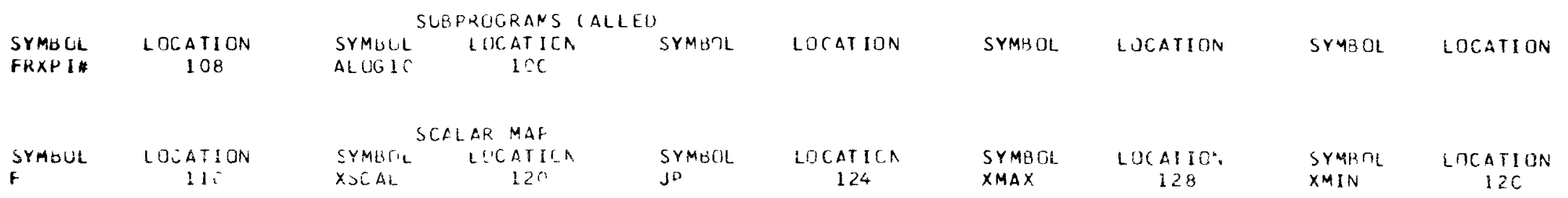




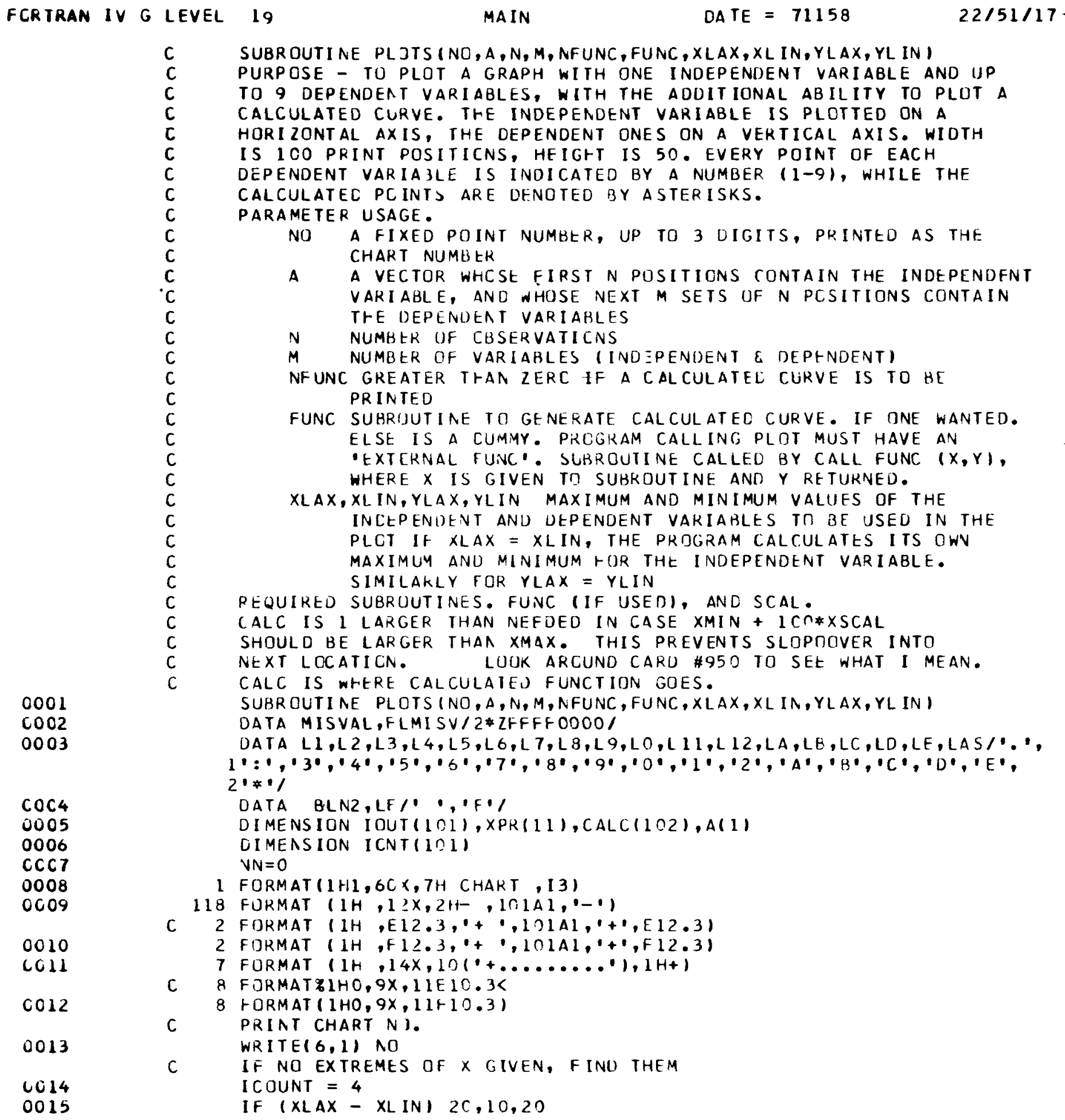

C SUBROUTINE PLJTS INO, A, N, M, NFUNC, FUNC, XLAX, XLIN, YLAX, YL IN)

C PURPOSE - TO PLOT A GRAPH WITH ONE INDEPENDENT VARIABLE AND UP

C TO 9 DEPENDEAT VARIABLES, WITH THE ADOITIONAL ABILITY TO PLOT A

C CALCULATED CURVE. THE INDEPENDENT VARIABLE IS PLOTTED ON A HORI ZONTAL AXIS, THE DEPENDENT ONES ON A VERTICAL AXIS. WIDTH IS 1 CO PRINT POSITICNS. HEIGHT IS 50. EVERY POINT OF EACH DEPENDENT VARIA3LE IS INOICATED BY A NUMBER $(1-9)$, WHILE THE CALCULATEC PCINTS ARE UENOTED BY ASTERISKS.

PARAMETER USAGE.

NO A FIXED POINT NUMBER, UP TO 3 DIGITS, PRINTEO AS THE CHART NUMBER

A A VECTOR WHCSE FIRST N POSITIONS CONTAIN THE INDEPENDFNT VARIABLE, ANO WHOSE NEXT M SETS UF N PCSITIONS CONTAIN THE DEPENDEAT VARIABLES

N NUMBER UF CBSERVATICNS

$M$ NUMBER OF VARIABLES (INDEPENUENT \& DEPENDENT)

NFUNC GREATER THAN ZERC IF A CALCULATEL CURVE IS TO BE PR INTED

FUNC SUBRIJUTINE TO GENERATE CALCULATED CURVE. IF DNE WANTED. ELSE IS A CUMMY. PRCGRAM CALLING PLDT MUST HAVE AN 'EXTERNAL FUNC!. SUBROUTINe CaLled BY CALL FUNC $(X, Y)$, HHERE $X$ IS GIVEN TO SUBROUTINE AND Y RETURNED.

$X L A X, X L I N, Y L A X, Y L I N$ MAXIMUM AND MINIMUM VALUES OF THE INCEPENUENT ANU UEPENDENT VARIABLES TO BE USED IN THE PLCT IF XLAX = XLIN, THE PRDGRAM CALCULATES ITS OWV MAXIMUM ANU MINIMUM FOR THE INDEPENDENT VARIABLE. SIMILAKLY FOR YLAX = YLIN

REQUIRED SUBRUUTINES. FUNC (IF USEDI, AND SCAL. CALC IS I LARGER THAN NEFDED IN CASE XMIN + ICN*XSCAL SHOULD BE LARGER THAA XMAX. THIS PREVENTS SLOPMOVER INTO NEXT LOCATICN. LUUK ARCUND CARU \#950 TO SEE WHAT I MEAN. CALC IS WHERE CALCULAIEJ FUNCTION GOES. SUBR QUTINE PLOTS (NO,A,N, M,NFUNC, FUNC,XLAX,XLIN,YLAX,YLIN) OATA MISVAL,FLMISV/2*ZFFFFOOOO/

DATA L1,L2,L3,L4,L5,L6,L7,L8,L9,LO,L11,L12,LA,LE,LC,LD,LE,LAS/.', 0003 $1^{\prime}: 0^{\prime} 3^{\prime}, 4^{\prime}, 5^{\prime}, 6^{\prime}, 6^{\prime} 7^{\prime}, 8^{\prime}, 9^{\prime}, 0^{\prime}, 0^{\prime}, 1^{\prime} 2^{\prime}, A^{\prime}, B^{\prime}, C^{\prime}, D^{\prime}, \mathrm{C}^{\prime}$, $2 \cdot * 1$

$\mathrm{COC} 4$ 0005 0006

CCC7

0008

0009

0010

$\operatorname{coll}$

$\mathrm{CO} 12$

0013

DATA BLN2,LF/, 'F'/

DIMENSION IOUT $(101), X P R(11), C A L C(102), A(1)$ DIMENSION ICNT(IDI) $V N=0$

1 FORMAT (1H1,6CX,7H CHART, 13)

118 FURMAT (1H, I XX,2H-, IOIA1, '-')

C 2 FORMAT $(1 \mathrm{H}, \mathrm{E} 12.3, \cdot+, 101 \mathrm{~A} 1, \cdot+\cdot, \mathrm{O} 12.3)$

2 FORMAT $\left(1 \mathrm{H}, \mathrm{F} 12.3,{ }^{\circ}+, 101 \mathrm{~A} 1,{ }^{\prime}+, \mathrm{F}_{12} .3\right)$

7 FORMAT $(1 H, 14 X, 10(+\ldots \ldots \ldots \ldots), 1 H+)$

C

G FORMAT\%IHO, $9 X, 11 E 10.3<$

8 FORMAT (1HO, 9X, 11F10.3)

C

PRINT CHART N].

1014 WRITEI 6,1) NO

C IF NO EXTREMES OF $X$ GIVEN, FINU THEM

I COUNT $=4$

0015

If $(X L A X-X L I N) 2 C, 10,20$ 


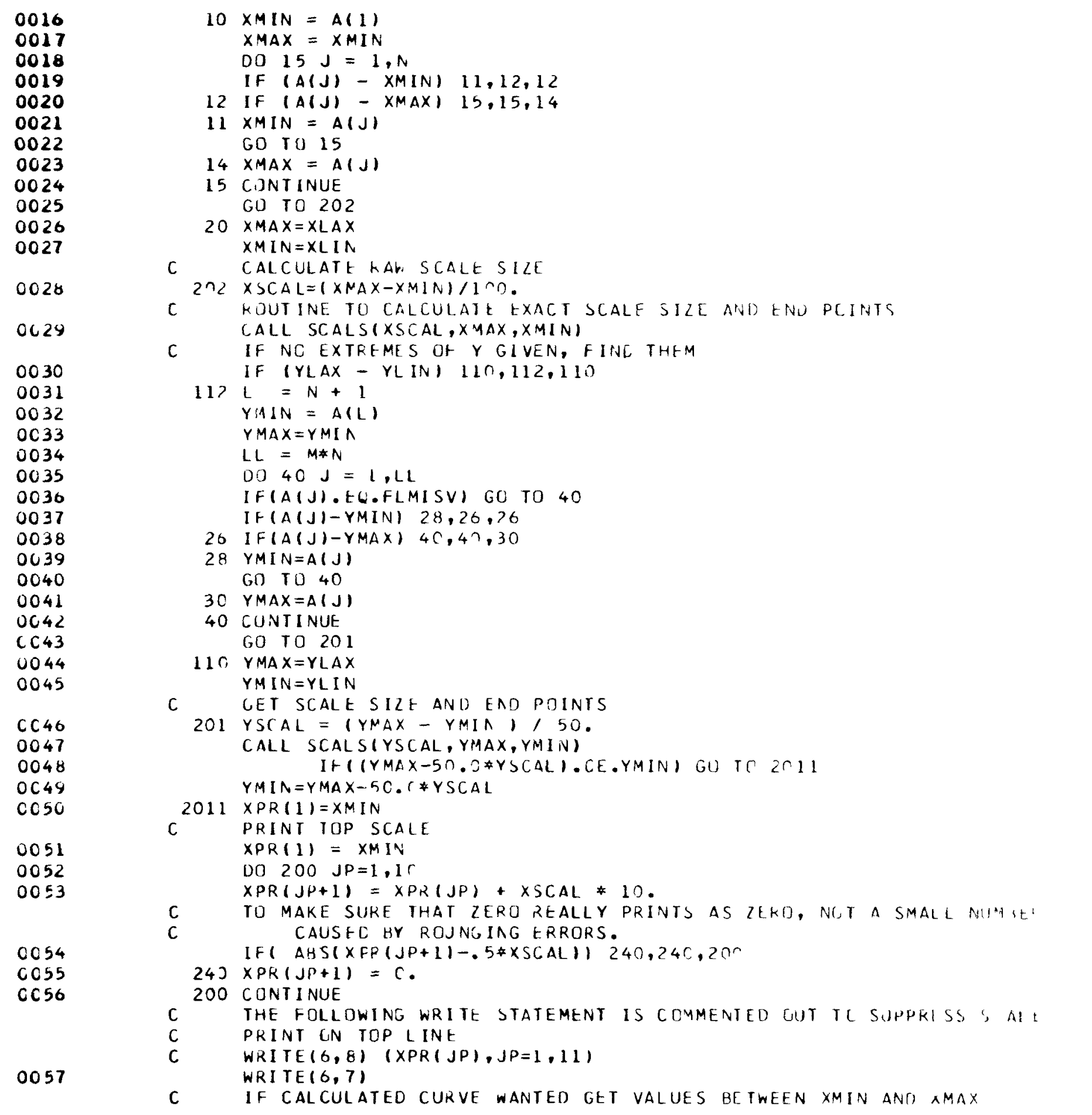




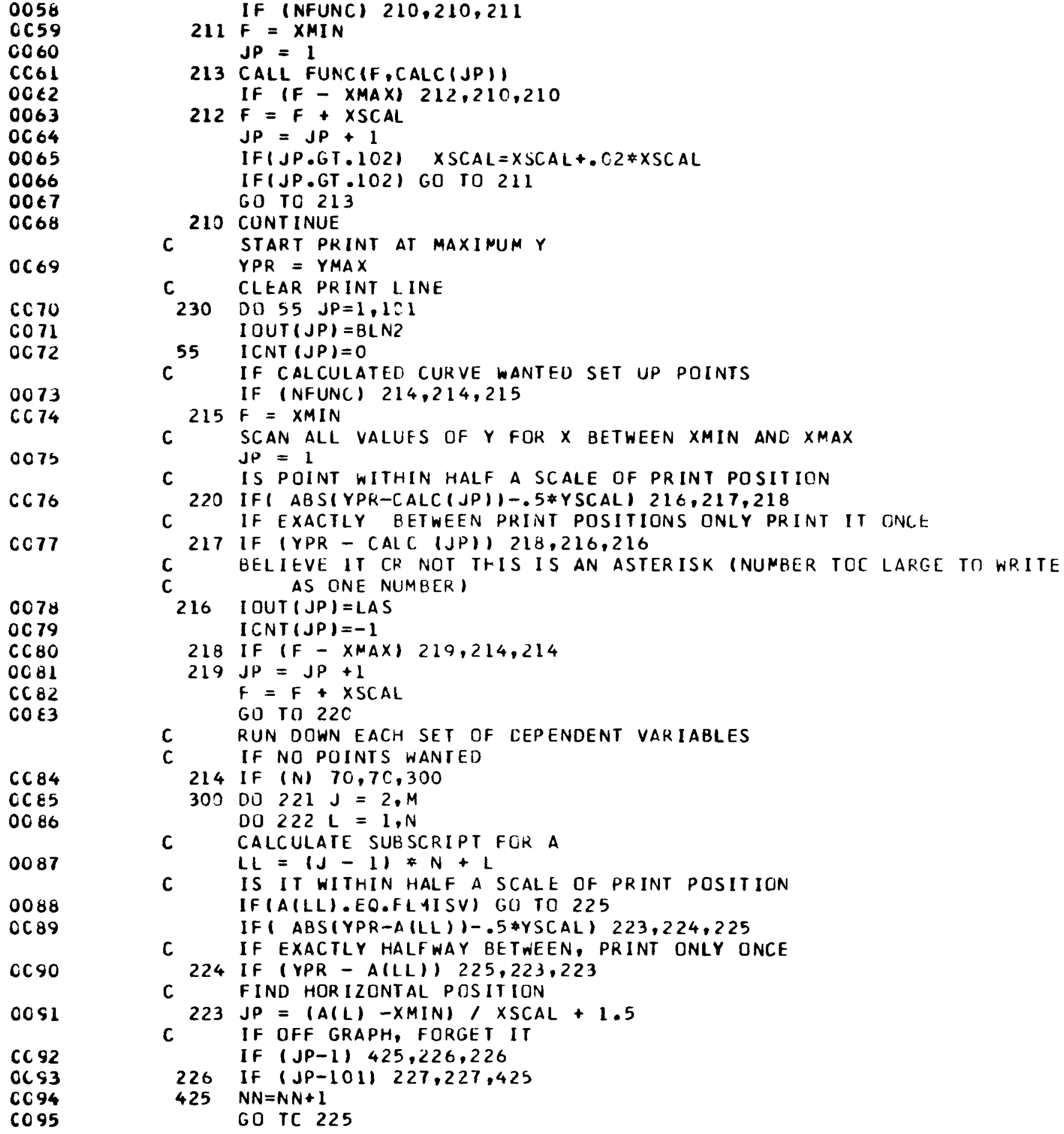


FCRTRAN IV G LEVEL 19

PLOTS

DATE $=71158$

$22 / 51 / 1 i$

C THIS GIVES $1,2,3$ EIC. FOR $J=2,3,4$ ETC

0096

$227 I C N T(J P)=I C N T(J P)+1$

IF (ICNT (JP).GT.0) GO TO 401

GO TO 225

$\cos 8$

C C99

OICO

CIC1

0102

0103

0104

0105

0106

0107

$01 \mathrm{CB}$

$01 C y$

0110

0111

0112

0113

0114

0115

0116

0117

C118

0119

0120

0121

0122

0123

C 124

0125

0126

0127

0128

0129

0130

0131

0132

0133

0134

0135

0136

0137

0138

0139

0140

0141

0142

C143

0144

0145

0146 IF (ICNT(JP).GT.1) GC TO 402 [ $D U T(J P)=L 1$

GO TC 225

402 IF (ICNT (JP).GT.2) GC TO 403

I $(J \cup T$ I JPI $=L 2$

GO TO 225

403 IF (ICNT (JP).GT.3) CU) TO 404

I OUT ( JP) $=\mathrm{L} 3$

Gu TO 225

404 IF (ICNT (JP).GT.4) GO TO 4OS

IOUT $(J P)=L 4$

GO TO 225

405 IF (ICNT(JP).CT.5) EC TO 406

I OUT (JP) $=\mathrm{L} 5$

GO TO 225

406 IF (ICNTIJPI.GT.6) GO TO 407

IOUT $(J P)=L 6$

GO TO 225

407 IF (ICNTIJP).GT.7) GO TO $4 C 8$

IOUT $(J P)=L 7$

GU TC 225

408 IF (ICNT(JP).UT.8) GC TO 409

I UUT $(J P)=L 8$

GO TC 225

409 IF (ICNTIJP).GI.9) GO TO 410

I OUT ( JP) $=19$

GO TO 225

410 IF (ICNT (JP).GT.12) GO TO $4 \mathrm{ll}$ I OUT ( JP) $=L C$

GU TO 225

411 IF (ICNTIJP).GT.11) GO TO 412 I OUT ( JPI $=\lfloor 11$

GO TO 225

412 IF (ICNTIJP).GT.12) GC TO 413

IOUT ( JP) $=\mathrm{L} 12$

GO TO 225

413 IF (ICNTIJP).GT.1O) GO TO 414 IOUT $(J P)=L A$

GO TO 225

414 IF (ICNT(JP).GT.32) GC TO 415

I OUT (JP) $=L R$

GO TO 225

415 IF (ICNT(JP).GT.64) GC TO 416

I OUT $(J P)=L C$

GO TC 225

416 IF (ICNIIJP).GT.128) GO TO 417

$\operatorname{IOUT}(J P)=L D$

GO TO 225

C147

417 IF (ICNTIJP).GT.250) GO TO 418 


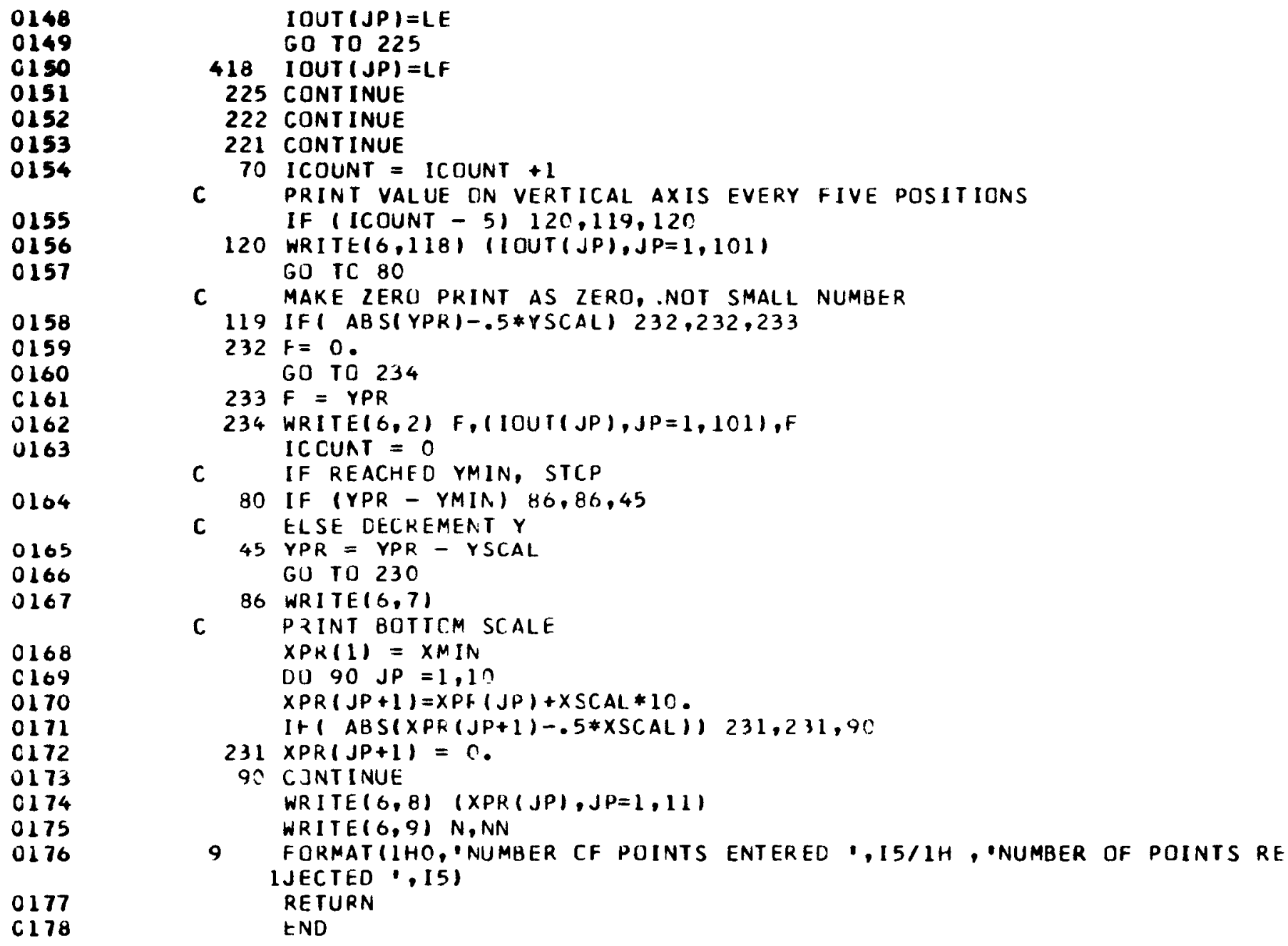

0148

0149

0150

0151

0152

0153

0154

0155

0156

0157

0158

0159

0160

C 161

0162

0163

0104

0165

0166

0167

0168

C 169

0170

0171

0172

0173

0174

0175

0176

0177

C 178

I OUT $(J P)=L E$

GO TO 225

418 I OUT (JP) =LF

225 CONT INUE

222 CONTINUE

221 CONTINUE

70 ICOUNT $=$ ICOUNT +1

C PRINT VALUE DN VERTICAL AXIS EVERY FIVE POSITIONS

IF I ICOUNT - $51120,119,120$

120 WRITE $(6,118)$ (IOUT (JP),JP=1,101)

GO TC 80

C MAKE ZERU PRINT AS ZERO, NOT SMALL NUMBER

119 IFI ABS(YPR)-.5*YSCALI $232,232,233$

$232 \mathrm{~F}=0$.

GO TO 234

$233 \mathrm{~F}=\mathrm{YPR}$

234 WRITE $(6,2) \mathrm{F},($ IOUTI JP),JP=1,101),F ICCUAT $=0$

C IF REACHED YMIN, STCP

80 IF (YPR - YMIN) $86,86,45$

C ELSE DECKEMENT $Y$

$45 Y P R=Y P R$ - YSCAL

GU TO 230

86 WRITE $(6,7)$

C PRINT BOTTCM SCALE

$X P R(1)=X M I N$

$D U 90 \mathrm{JP}=1,1$ ?

$X P R(J P+1)=X P F(J P)+X S C A L * 10$

IH ( $A B S(X P R(J P+1)-.5 * X S C A L) 231,231,90$

$231 \times P R(J P+1)=0$.

9ล CJNTINUE

WRITE $(6,8) \quad(X P R(J P), J P=1,11)$

WRITE $(6,9) \quad N, N N$

9

FORMATIIHO, 'NUMBER CF POINTS ENTERED I, I5/1H, 'NUMBER OF POINTS RE IJECTED , 151

RETURN

END 


\begin{tabular}{|c|c|c|c|c|c|c|c|c|c|}
\hline & & & PROGKANS & & & & & & \\
\hline SYMGCL & LOCA I I ON & SYMBOL & LOCAT ICN & SYMBril & LOCAT ICIN & SYMISOL & LICATIUN & SYMBOL & LNCATION \\
\hline $18\llcorner C M \#$ & $31 C$ & SCALS & 320 & FUNC. & 324 & & & & \\
\hline & & & $\angle A K M A P$ & & & & & & \\
\hline SYMBUL & LOCATION & SYMBCLL & LUCATICA & SYMBOL & LOCATICA & SYMosit & LOCAT IUN & SYMBOL & LUCATION \\
\hline MI SVAL & $35 \mathrm{C}$ & FLMISV & 360 & LI & 364 & 12 & 308 & L3 & $36 C$ \\
\hline 14 & $37 C$ & LS & 374 & Lh & 378 & $\llcorner 7$ & $37 C$ & L8 & $38 ?$ \\
\hline L9 & 384 & LO & 388 & 111 & $38 \mathrm{C}$ & 112 & 390 & LA & 394 \\
\hline LB & 398 & LC & $39 C$ & LD & $34 C$ & LE & $3 A 4$ & LAS & $3 A 8$ \\
\hline BLNZ & $3 A C$ & LF & 380 & $A N$ & $3 t .4$ & ND & 368 & I CDUNT & $3 R C$ \\
\hline$X\llcorner A X$ & $3 \mathrm{CC}$ & $X L I N$ & $3 C 4$ & $X M I V$ & 308 & $x: 1 A X$ & $3 C C$ & J & $30 n$ \\
\hline$N$ & 304 & $\times S C A L$ & $3 D E$ & YLAX & $3[C$ & YLIN & $3 E \cap$ & L & $3 E_{4}^{4}$ \\
\hline YMIN & $3 E 8$ & YMAX & $3 E C$ & $\mathrm{LL}$ & $3 F n$ & M & $3 F_{4}$ & YSCAL & $3 F 9$ \\
\hline JP & $3 F C$ & NFUNC & 400 & $r$ & $4 C .4$ & $Y P R$ & 408 & & \\
\hline & & & AY MAP & & & & & & \\
\hline SYMBCL & LOCATIUN & SYMRCIL & LOCATICN & SYMiKLL & LUCAIICN & SYMBOL & LOCATIUN & SYYHAL & LJCATION \\
\hline IOUT & $4 C C$ & $X P K$ & $5 A C$ & CALC & $5 c c$ & A & 764 & ICNT & 758 \\
\hline & & & MAT STATEI & MAP & & & & & \\
\hline SYMUCL & LOCATION & SYMBCL & LOCATICN & SYMLAOL & LUCATIGN & SYMEOL & LIJCATION & SYMHOL & LUCATION \\
\hline 1 & BFC & 118 & $9 \mathrm{Ct}$ & 2 & 920 & 7 & 936 & 8 & $94 \mathrm{~F}$ \\
\hline
\end{tabular}




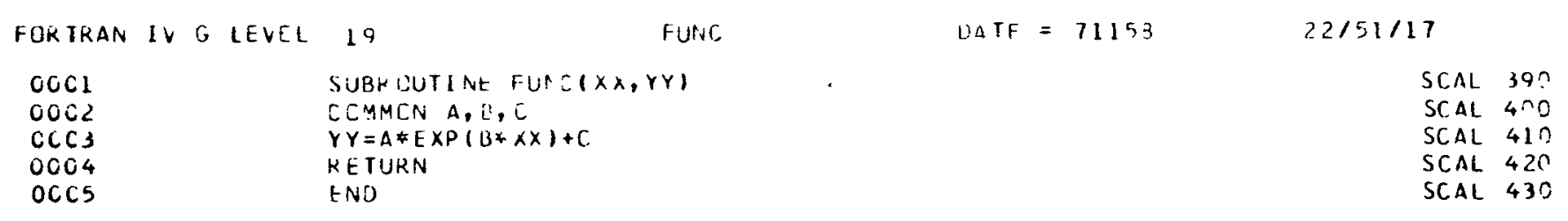

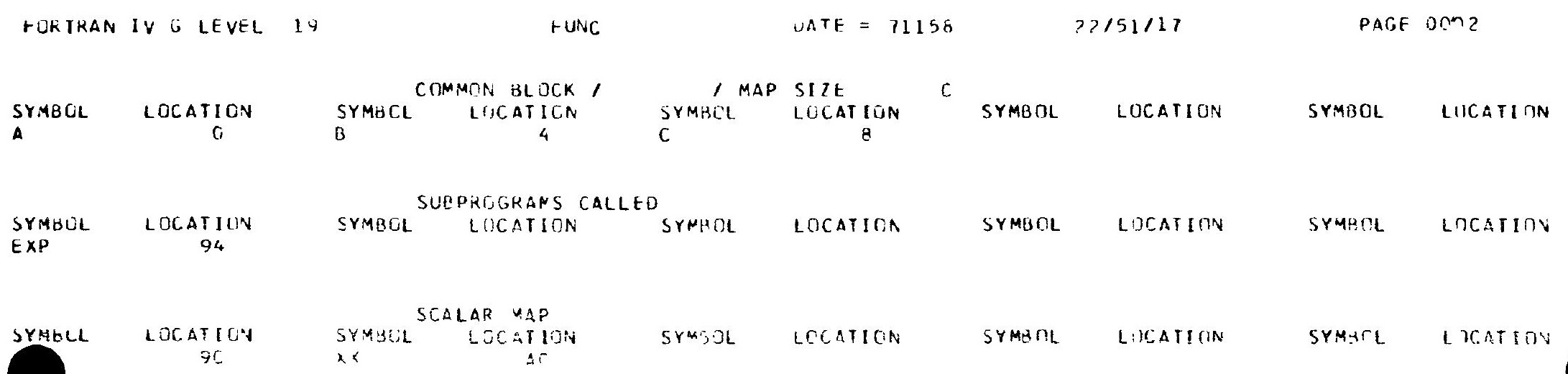




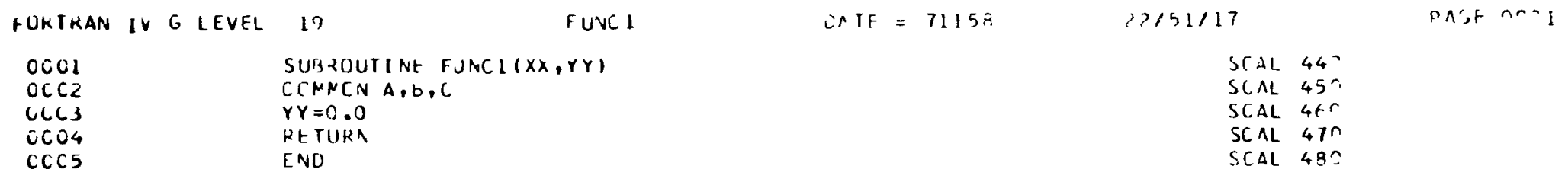

FCRTRAN IV G LEVEL IO

$\triangle A E=71158$

$22 / 51 / 17$

PACE - an?

SYMBCL

LUCATIUY

r

LYCMANN BLCCK /

SYMGOL

LULATICN

SuALAK Nib

SYMELE LERATIGH

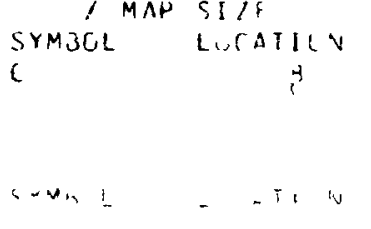

C.

$\operatorname{coc} 2 \operatorname{ton}$

SYy+-1

L BC:T I IV

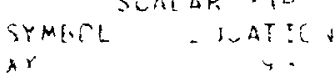


F80-LEVEL LINKAGE EDITOR UPIICAS SPECIFIEC XREF,LET,LISI

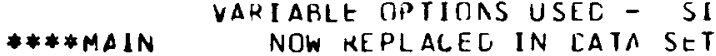

CFOSS REFERHICE TAPLF

CCATKOL SECTICN

MAME ORIGIN LENGTH

MAIN CO 2294

PLEA 2298 BEO

EIVKGLT $2 \mathrm{E} 78$ HA

ECAIUL 3 A2O CC2

$\begin{array}{lll}\text { PLCT9 } & 4628 & 144\end{array}$

$\begin{array}{llr}\text { PLCIS } & 5838 & 14 F 8\end{array}$

FUAC $\quad 6030 \quad 164$

\begin{tabular}{lll} 
FUNC1 & 6030 & 164 \\
\hline & $6 E 98$ & 136
\end{tabular}

$\begin{array}{lll}\text { IHCSLUG } & \text { 6E98 } & 136 \\ \text { IFDO } & 186\end{array}$

$\begin{array}{ll}\text { IHCSLUG * GFDO } & 186 \\ \text { IHCLUUG * } 7188 & 7 F 9\end{array}$

ItCSEXP * 7988 192

$\underset{\infty}{\infty}$

\begin{tabular}{|c|c|}
\hline IHCFKXPI & $7 \mathrm{~B} 2 \mathrm{C}$ \\
\hline IHCF RXPR* & $7 C 68$ \\
\hline IFCECLMH* & $70+0$ \\
\hline I hlCOUMHL* & 8030 \\
\hline IHCrCVIH* & 9388 \\
\hline IHCEFNTH* & $A 528$ \\
\hline IHCEFIUS* & $\triangle A 40$ \\
\hline IrCEKRM * & $B 060$ \\
\hline $\begin{array}{l}\text { IHCLATBL* } \\
\text { IHCCOPT * } \\
\text { IHCEIKCH* }\end{array}$ & $\begin{array}{l}\text { C } 320 \\
\text { C } 958 \\
\text { CC } 58\end{array}$ \\
\hline $\begin{array}{l}\text { ULAAKCOM } \\
\text { CNE }\end{array}$ & $\begin{array}{l}\text { CEEB } \\
\text { DCAO }\end{array}$ \\
\hline
\end{tabular}

ENTRY

name location name location vame lucation name location

\begin{tabular}{|c|c|c|c|c|c|c|c|}
\hline ALUGL? & ston & $\triangle L G G$ & SFE 8 & & & & \\
\hline Ct BUG & $718 d$ & & & & & & \\
\hline EXP & $7 \overline{8} 8$ & & & & & & \\
\hline$F R \times P I \#$ & $782 C$ & & & & & & \\
\hline$F K \times P K \#$ & $7 C 6 \mathrm{H}$ & & & & & & \\
\hline IECOM\# & $7 \Gamma, F O$ & to ICCSA & TE AC & INTSHTCH & BUCE & & \\
\hline SEGUASD & 9090 & & & & & & \\
\hline $\begin{array}{l}\text { AOCONA } \\
\text { FCVIOUTP }\end{array}$ & $\begin{array}{l}9388 \\
996 \mathrm{C}\end{array}$ & $\begin{array}{l}\text { FCVACUTP } \\
\text { FCVEOUTP }\end{array}$ & $\begin{array}{l}9432 \\
9 E C .2\end{array}$ & $\begin{array}{l}\text { FCVLUUIP } \\
\text { FEVCOUTP }\end{array}$ & $\begin{array}{l}94 C 2 \\
A 0 D C\end{array}$ & $\begin{array}{l}\text { FCVZOUTP } \\
\text { INT GSHCH }\end{array}$ & $\begin{array}{l}9612 \\
43 C 3\end{array}$ \\
\hline AKITH* & $A 528$ & ADJSWTCH & A894 & & & & \\
\hline rICCS* & $\triangle A 4 C$ & I IOCS SEP & $A A 46$ & & & & \\
\hline [RRMI]N & $B D 6 r$ & IHCERRE & 3078 & & & & \\
\hline IHCTRCH & $\operatorname{cc5}{ }^{\circ}$ & ERRTRA & $c r 60$ & & & & \\
\hline
\end{tabular}




\begin{tabular}{|c|c|}
\hline $\begin{array}{l}\text { EUHA } \\
\text { ECNIDL } \\
\text { PLLISS }\end{array}$ & $\begin{array}{l}\text { PUBA } \\
\text { ECNICL } \\
\text { PLCTS }\end{array}$ \\
\hline I 3 CCM M & IHCECC:AH \\
\hline IH:OUM\# & I HCECCYM \\
\hline SCALS & SCALS \\
\hline AL $\quad G 10$ & I HC SLCG, \\
\hline SCALS & SCALS \\
\hline IECCM \# & It CECOMHA \\
\hline A.)CON\# & I HCFCVTH \\
\hline f I I I S & IHCEF IJ' \\
\hline IB:CM\# & I HCE ECOMH \\
\hline I BCOM\# & I HCECCMHA \\
\hline I BCCLMA & IHCECOMH \\
\hline ALUG & I HC SLCG \\
\hline SENDASD & I HCCLNH? \\
\hline rIocs & ITCEFICS \\
\hline AJJSRTCH & IHCEFATH \\
\hline IHL USP I & IHC UOPT \\
\hline FCVL CUTP & IHCFCVTH \\
\hline ECVC UUTP & IHCFCVTH \\
\hline ECVZCUTP & I HCFCVTH \\
\hline I HCCCMHZ & IHCCCMHZ \\
\hline IHCCOMHZ & I HCCCMH? \\
\hline I HCC UMHZ & I HCCOMHZ \\
\hline I HCECOMH & IHCECCMH \\
\hline IHCERRA & I HCERR'A \\
\hline I HCECCMH & IHCECOMIA \\
\hline I HCECOMH & I HCECCMH \\
\hline IHCERRM & IHCERRM \\
\hline NTSWTCH & IHCECCMH \\
\hline HC UUP T & I HCLUPT \\
\hline$-\operatorname{InCS} \#$ & I HCEFIOS \\
\hline HCERKM & IHCERRY \\
\hline ECCCMx & $1 \mathrm{HCECCH}$ \\
\hline d:C: $4 *$ & I HCELCMH \\
\hline $10 C$ SHEP & $1 \mathrm{HC}+105$ \\
\hline WCWNE & \\
\hline
\end{tabular}

\begin{tabular}{|c|c|}
\hline$F F X P R \notin t$ & $1+x,+5 x+2$ \\
\hline$+x F$ & $1 H C$ it $x p$ \\
\hline$F F \times P I \#$ & I HEFtXXI \\
\hline CNE & UNT \\
\hline$I B C(I) M E$ & I HCESPl:ate \\
\hline$F R \times P I \#$ & InC.ttixi I \\
\hline I HCOMF & IHCFI flatit \\
\hline$(x P$ & IHC St KN \\
\hline I HCERFM & IHCTFE" \\
\hline I HCUATBL & IHCUAT L \\
\hline I or clin: & IHISECOVHA \\
\hline I HCERHM & linc. : :DA \\
\hline IHCERKM & $1+t+t+\cdots$ \\
\hline I HCEQKM & $I^{H} C+C K A$ \\
\hline$-x p$ & $1+4$ SF $\times p$ \\
\hline ADCONA & IHLSCVTH \\
\hline LRI THF & IHCTCATH: \\
\hline IHCUDPT & 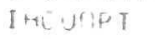 \\
\hline FCVEUTP & IHEFCVIA \\
\hline =CVIOUTH & IHE r R VTH \\
\hline FCVAOUTP & IHIT' VTH \\
\hline I HCERRE & $I+C+C_{n}$ \\
\hline HCERHM & $14 r \ldots$ \\
\hline HCC.UMH? & $I+C, A H$ \\
\hline I HR.COMHZ & I throptan \\
\hline HCECCMH & IHCF $F=1$ \\
\hline$B C \cup M=$ & It \\
\hline HCEC $\cap M H$ & 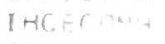 \\
\hline $\mathrm{HCCOM}$ a & $I+x+(, \ldots$. \\
\hline$n C(1)=$ & $1+46+i=$ \\
\hline NTOSACH & $I \cdot+C+:=1$ \\
\hline$\triangle O C O N A$ & IHCF, : I: \\
\hline HCERFM & I + CEF W \\
\hline HCUNYFL & 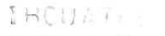 \\
\hline HEUCF'T & $1+x_{1}=1$ \\
\hline HCTREt & TACFT \\
\hline 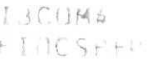 & $\int_{1-6 C+1}^{1+C}$ \\
\hline
\end{tabular}


CAPITAL CASE I-D

YEAR

1965
1966
1967
1968
1969
1970
1971
1972
1973
1974
1975
1976
1977
1978
1979
1980
1981
1982
1983
1984
1985
1986
1987
1988
1989
1990
1991
1992
1993
1994
1995
1996
1997
1998
1999
2000
2001
2002
2003
2004
2005
2006
2007
2008
2009
2010

NUCLEAR GENERATING CAPACITY (MHE)

$\begin{array}{ccc}\text { LWR } & \text { OPERATING LIABILITY } \\ \text { CAPITAL } & \text { \& MAINT. } & \text { INSURANCE } \\ \text { COSTS } & \text { COSTS } & \text { COSTS } \\ \text { (MPKWH) } & \text { (MPKWH) } & \text { (MPKWH) }\end{array}$

2000.00 2800.00 3700.00 4000.00 7000.00 14000.00 23000.00 33000.00 44000.00 56000.00 67100.00 80000.00 $950 \mathrm{C} 0.00$ $110 C 00.00$ 130000.00 $15 \mathrm{C}) \mathrm{C} 0.00$ 180000.00 220000.00 250000.00 290000.00 $32(000.00$ 360000.00 390000.00 420000.00 460000.00 500000.00 545000.00 590000.00 650000.00 705000.00 153000.00 815000.00 $88 \mathrm{COC} 0.00$ $95 \mathrm{COC} 0.00$ 1025000.00 1130000.00 1175060.00 $125 C O C 0.00$ 1345000.00 1430000.00 1540000.00 $165 \mathrm{C} 000.00$ 1730000.00 $185 \mathrm{C} 300.00$ 1990000.00 2100000.00

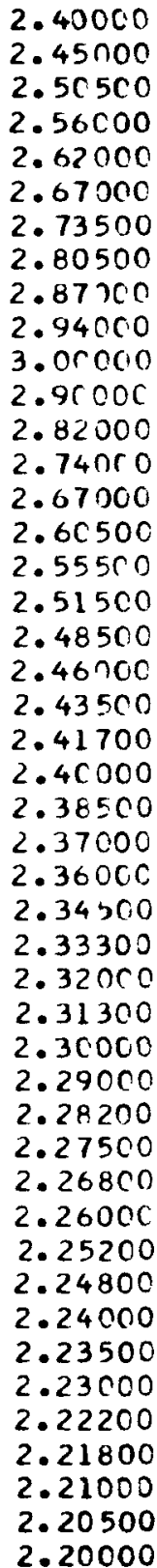

$C .187 C 0$
$C .18500$
$C .18350$
$C .18000$
$C .17800$
$C .11530$
$C .17300$
$C .171 C 0$
$C .16850$
$O .16600$
$C .16380$
$C .16150$
$C .15900$
$C .15650$
$C .15400$
$C .15200$
$C .14930$
$C .14700$
$C .14470$
$C .14250$
$C .14000$
$C .13780$
$O .13520$
$C .13300$
$C .13070$
$O .12840$
$C .12600$
$C .12360$
$C .12120$
$C .1190 C$
$C .11650$
$C .11420$
$C .11180$
$C .10950$
$C .10710$
$C .10500$
$C .10250$
$C .10000$
$C .09780$
0.09530
0.09400
$C .09080$
. $.1 C 8820$
$C .08600$
0.08360
$C .188120$

LWR FUEL COSTS AT PUPR $=C$ (MPKWH)
FBR FUEL COSTS AT PUPR $=\hat{\imath}$ (MPKWH)
0.13080

0.12920

0.12770

0.12600

0.12430

C. 12280

0.12120

0.11950

ก. 11800

0.11650

$0.115 \mathrm{cn}$

0.11320

0.11150

C. 11000

0.10850

C. 10680

c. 10500

c. 10350

0.1 r 0 on

0.18050

0.09000

0.09710

c. 09570

0.09400

0.09230

0.09380

0.08920

0.08760

$0.0860 \mathrm{C}$

$0.0844 \mathrm{C}$

0.08280

0.08130

0.07970

0.07800

0.07650

0.07500

0.07320

0.07170

0.07000

0.06850

$0.0668 \mathrm{C}$

0.06520

0.06370

0.05210

0.06050

0.05900

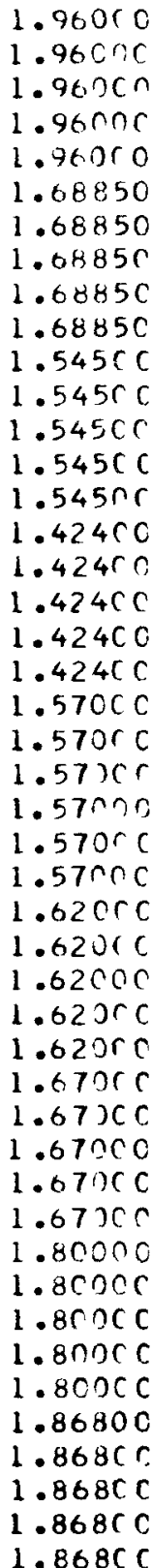

1.3500

1. 35 nif

1.3500

$1.350 \mathrm{nc}$

1. $3500^{\circ}$

1. olr gr

1. 01 nor

1.01rer

1. 7100$)$

$1.0100:$

$0.860 \mathrm{~ns}^{\circ}$

0.86000

$0.8600 \mathrm{c}$

C. $860 \mathrm{Ct}$

0.860 on

0.71 inn

0.71 nnn

0.71000

0.71 nod

$0.71 \cap \mathrm{CO}$

$0.562 r r^{\circ}$

0.56200

0.56706

$0.56<0$.

0.56200

C. 56260

$0.4080 \mathrm{r}$

$0.4080 r$

$0.4080^{\circ}$

0.40800

$0.4080 \%$

0.3650 n

0.36500

0.36500

0.36500

0.36500

ก. 30900

0.30900

$0.3090 \mathrm{C}$

0.30900

0.30900

0.28500

0.28500

0.28500

0.28500

0.28500 
INPUT DATA

$\begin{array}{lr}\text { SPINV }= & 2187.00000 \\ \text { XCOR }= & 1.50000 \\ \text { PUPF }= & 1386.22998 \\ \text { CEFFF }= & 0.40000 \\ \text { CEFFL }= & 0.33333 \\ \text { BURNL }= & 30.00000 \\ \text { EXPL }= & 0.47100 \\ \text { UCHG }= & 103814.37500 \\ \text { AVLWR }= & 0.80000 \\ \text { AVFBR }= & 0.80000 \\ \text { XCRR }= & 1.50000 \\ \text { FABLOS }= & 1.02000 \\ \text { KEPLOS }= & 0.98000 \\ \text { LISKAT = } & 0.10000 \\ \text { F }= & 0.85595\end{array}$


IEAR NUCLEAR LWR IWR LWR
GENERATINGGENERATING FRACCAPACIIY CAPACITY TION (MME)

$$
\text { (MWE) }
$$

PLUTONIUM

PRODUCT IUIY

(KG)

C. 0

$10 C 5.8035$

1413.7239

$186 \varepsilon .1362$

2019.6069

3534.3125

7068.6211

11612.7383

16661.7500

22215.6680

28274.4961

33828.4180

40392.1445

47965.6602

64627.3828

74220.5000

88862.6250

108553.8125

123196.0000

142887.1250

142887.1250

142887.1250

137838.1250

132785.1250

$13278 \% 1250$

132789.1250

132789.1250

132789.1250

132789.1250

135818.5000

159044.0625

138328.3125

214078.3125

238313.6250

263053.8125

285269.2500

305465.3125

324146.8750

352421.3125

404931.0000

434215.5000

434215.5000

446838.0000

479656.6250
521058.6250
FBR

ENERATING FRAC-

CAPACITY TION

(MWE)

PLUTONIUM

(KG)

FBR

PLUTONIUM

PRODUCTION

BAL ANCE

(KG)

(KG)

0.0

1002.9998

2400.4409

4239.8125

6217.2422

9685.0516

9685.8516

16641.5859

28063.9609

44424.3711

66191.0000

93828.9375

126797.1875

166062.8750

166062.8750

279262.8750

258880.3750

317379.6250

384700.8125

465799.4375

565597.8125

678954.8750

714411.0625

707019.8750

687181.3125

649964.2500

595485.6875

528877.1250

433602.3125

324910.2500

324910.2500

137.0702
137.000

2144.5159

931.2456

3361.3867

389.2966

1341.4631

2119.8704

1978.9514

994.2559

3376.0994

1699.4722

2711.6067

1499.8264

$\begin{array}{llllr}845000 . & 0.488 & 1505746.000 C & 1073218.0000 & 3165.5278 \\ 900000 . & 0.486 & 1597764.0000 & 1147936.0000 & 173.8209 \\ 558000 . & 0.481 & 1699821.0000 & 1222653.0000 & 2644.0649\end{array}$

$\begin{array}{llllr}845000 . & 0.488 & 1505746.000 C & 1073218.0000 & 3165.5278 \\ 900000 . & 0.486 & 1597764.0000 & 1147936.0000 & 173.8209 \\ 558000 . & 0.481 & 1699821.0000 & 1222653.0000 & 2644.0649\end{array}$

$\begin{array}{llllr}845000 . & 0.488 & 1505746.000 C & 1073218.0000 & 3165.5278 \\ 900000 . & 0.486 & 1597764.0000 & 1147936.0000 & 173.8209 \\ 558000 . & 0.481 & 1699821.0000 & 1222653.0000 & 2644.0649\end{array}$

$558000.0 .481 \quad 1699821.0000 \quad 1222653.0000$ 
MINIMUM GENERATING COSTS

YEAR

MINIMUM
MWUAL
MUCLEAR
GENERATING
COSTS
IS BILI

0.05577

0.07899

0.10573

0.11570

0.20523

0.38831

0.64779

0.94478

1.27853

1.65314

1.93689

2.25430

2.62089

2. 96991

3.44243

3.77249

4.45820

5.38133

6.05589

6.96646

7.94970

8. 88761

9. 57081

10.25136

11.16639

12.08900

13.29548

14. 32707

15. 70658

16.98219

17.97623

19.74106

21.24142

22. 85780

24.58403

$26: 29338$

28.07784

29.68028

31.68475

33.46822

35.83360

37.05651

39.45132

41.07900

4.74463

47.05962

\author{
MINI MUM \\ DI SC OUNTEO \\ NUCLEAR \\ GENERAT ING \\ COSTS \\ (S BIL)
}

0.48308

0.58783

0.58478

0.94303

1.62204

2. 45995

3.26160

4.01253

4. 71655

5.02375

5.31548

5. 61807

5. 78749

6. $C 9845$

6. 07561

6. 52722

7. 16253

7.32762

7.66311

7. $9497 \mathrm{C}$

8. 07965

7. 90977

$7.702 \mathrm{C2}$

7.62682

7. 50635

7.50499

7. 35210

7. 32729

7.20216

6.93067

6.91919

6. 76824

6.62116

6.47382

6.29451

6. 11064

5.87217

5.69887

5. 47241

5.32653

5.11566

4. 84653

4.67706

4. 54282

4.34351
MINIMUH

CUMULATIVE

DI SCOUNTED

GENERAT INE

COSTS

(s BIL)

$$
\begin{aligned}
& 0.37519 \\
& 0.85827 \\
& 1.44609 \\
& 2.03087 \\
& 2.97390 \\
& 4.59593 \\
& 7.05588 \\
& 10.31748 \\
& 14.33001 \\
& 19.04655 \\
& 24.07030 \\
& 29.38577 \\
& 35.00383 \\
& 40.79131 \\
& 46.88976 \\
& 52.96536 \\
& 59.49258 \\
& 66.65511 \\
& 73.98271
\end{aligned}
$$

81.64581

89.59550

97.67514

105.58490

113.28691

120.91373

128.42006

135.92505

143.27715

150.60443

157.80659

164.73726

171.65643

178.42467

185.04582

191.51964

197.81415

203.92477

209.79694

215.49580

220.96822

226.29474

231.41040

236.25693

240.93399

245.47681

249.82031
PLUTON IUM

PRICE

YIELDING

GENERAT I NG

COSTS
MIN IMUM
30.50
30.50
30.50
30.50
30.50
30.50
30.50
30.50
30.50
30.50
30.50
30.50
30.50
30.50
30.50
30.50
30.50
30.50
30.50
30.50
30.50
30.50
30.50
30.50
30.50
30.50
30.50
30.50
30.50
30.50
30.50
30.50
30.50
30.50
30.50
30.50
0.00
0.00
0.0
0.00
0.00
0.00
0.00
0.00
0.0
0.00
30 
YEAK

ANNUAL PLUTUNIUM PUPR $=0.0$ NUCLEAR INVENTORY GENERATING COSIS (\$ BIL) costs (s BIL)

$\begin{array}{lll}1963 & 0.06561 & 0.0 \\ 1960 & 0.09276 & 0.0 \\ 1967 & 0.12393 & 0.0 \\ 1960 & 0.13537 & 0.0 \\ 1969 & 0.23967 & 0.0 \\ 1970 & 0.45718 & 0.0 \\ 1971 & 0.16094 & 0.0 \\ 1972 & 1.10712 & 0.0 \\ 1973 & 1.49499 & 0.0 \\ 1974 & 1.92863 & 0.0 \\ 1975 & 2.26649 & 0.0 \\ 1976 & 2.64786 & 0.0 \\ 1971 & 3.08824 & 0.0 \\ 1978 & 3.51133 & 0.0 \\ 1979 & 4.08226 & 0.0 \\ 1980 & 4.50989 & 0.0 \\ 1981 & 5.34263 & 0.0 \\ 1982 & 6.46191 & 0.0 \\ 1983 & 7.28337 & 0.0 \\ 1984 & 8.34060 & 0.0 \\ 1985 & 9.42941 & 0.0 \\ 1986 & 10.45920 & 0.0 \\ 1987 & 11.18237 & 0.0 \\ 1988 & 11.90060 & 0.0 \\ 1989 & 12.90047 & 0.0 \\ 1990 & 13.90735 & 0.0 \\ 1991 & 14.80139 & 0.0 \\ 1992 & 15.85857 & 0.0 \\ 1993 & 17.27122 & 0.0 \\ 1994 & 18.60362 & 0.0 \\ 1995 & 19.81145 & 0.0 \\ 1996 & 21.56841 & 0.0 \\ 1997 & 23.31113 & 0.0 \\ 1998 & 25.15566 & 0.0 \\ 1999 & 27.11270 & 0.0 \\ 2000 & 29.02692 & 0.0 \\ 2001 & 31.22929 & 0.0 \\ 2002 & 13.13533 & 0.0 \\ 2003 & 35.57553 & 0.0 \\ 2004 & 37.69827 & 0.0 \\ 2005 & 40.54967 & 0.0 \\ 2006 & 43.56416 & 0.0 \\ 2007 & 45.45065 & 0.0 \\ 2008 & 48.45959 & 0.0 \\ 2009 & 52.06033 & 0.0 \\ 2010 & 54.70120 & 0.0\end{array}$

PRESENT
WORTH FAC TOR

6.727362
0.115806
5.559430
5.054397
4.594999
4.177192
3.797452
3.452232
3.138395
2.853088
2.593719
2.357929
2.143574
1.546765
1.771552
1.610503
1.464095
1.336997
1.269998
1.099999
$1.0067 C 0$
0.909391
0.826448
0.751317
0.083016
0.620924
0.564477
0.513161
0.466511
0.424101
0.385547
0.350497
0.318634
0.289668
0.263334
0.239395
0.217632
0.197848
0.179862
0.163511
0.148646
0.135133
0.122848
0.111680
0.101528
0.092298

NUCLEAR

COSIS
(S BILI)

CUMULATIVE ECON ECON
NUCLEAR LWR FBR

ANN

NUC LEAR

DISCOUNTED CUMULATIVE ADOITIONAL

ECONOMIC ECONDMIC MUCLEAR

GENEKATINGFRAC - FRAC- GENERATING GENERATING. GENERATING GENERATING COSTS TION TION COSTS COSTS GOSTS COSTS

(\$ BIL)

(S BIL)

(\$ BIL)

(S BIL)

0.44138

$0.441381 .060 \quad 0 . C$ $1.0 \mathrm{CB} 701 . \mathrm{CCO} \mathrm{C.C}$ $1.697721 .000 \mathrm{C} . \mathrm{n}$

$2.381961 .000 \quad 0.0$

$3.483221 . \mathrm{CCO} C .0$

$5.392951 .000 \quad 0.0$

$8.282571 . \mathrm{crn} \mathrm{C} . \mathrm{O}$

12.104611 .0000 .0

16.796461 .003 N.C

$22.299 n n \quad 1.0 C C 0.0$

$28.177641 .000 \quad n .0$

$34.421101 . r C O C . C$

41.040951 .000 C.O

$47.883501 .0 C 0 \quad 0.0$

$55.115431 .000 \quad 0 . C$

$62.37862 \quad 2.867 \quad \mathrm{C} .133$

$70.20073 \quad 0.722 \quad 0.278$

$78.80150 \quad .591 \quad C .409$

$87.61436 \sim .520 \quad 0.480$

$96.84335 \quad .0448 \quad C .552$

$106.27275 \quad . .4 C 6 \quad C .594$

$9.50837 \quad 115.731110 .361$ C.639

$9.24165 \quad 125.02275 \quad 0.333 \quad C .667$

$8.94127 \quad 133.96402 \quad 0.310 \quad 6.690$

$8.81122 \quad 142.77524 \quad 0.283 \quad 0.717$

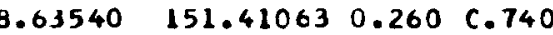

$\begin{array}{llllll}0.35504 & 159.76567 & 0.239 & 0.76\end{array}$

$8.13801 \quad 167.903670 .220 \quad .780$

$8.05721 \quad 175: 960880.260 \quad 0.800$

$\begin{array}{llllll}7.88981 & 183.85 C 68 & 0.184 & 0.816\end{array}$

$\begin{array}{lllll}7.63824 & 191.48891 & C .171 & C .829\end{array}$

$\begin{array}{lllll}7.55967 & 199.04857 & 0.156 & 0.844\end{array}$

$\begin{array}{lllll}7.42772 & 206.47629 & 0.144 & 0.856\end{array}$

$\begin{array}{llllll}7.28661 & 213.76289 & 0.133 & 0.867\end{array}$

$\begin{array}{lllll}7.13971 & 220.90259 & 0.120 \quad \text { C.680 }\end{array}$

$\begin{array}{lllll}0.94891 & 227.85149 & 0.1 C 5 & 0.895\end{array}$

$6.79650 \quad 234.647980 . C 91 \quad$ C.909

$\begin{array}{lllll}0.55574 & 241.20372 & 0.078 & 0.922\end{array}$

$6.39867 \quad 247.602390 .064 \quad 0.936$

$6.15407 \quad 253.766450 .052 \quad 0.948$

$\begin{array}{llllll}6.02755 & 259.79395 & 0.041 & 0.959\end{array}$

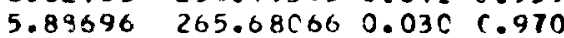

$5.58354 \quad 271.26410 \quad 0.020 \quad 0.980$

$5.41199 \quad 276.676030 .011 \quad .989$

$\begin{array}{lllll}5.28557 & 281.96143 & 0.0 & 1.000\end{array}$

5.04881

0.06551
0.09276
0.12393
0.13537
0.23967
0.45718
0.76094
1.10712
1.49499
1.92863
2.26649
2.64786
3.08824
3.51176
4.08197
4.56694
5.33040
6.43300
7.23815
8.32200
9.03858
10.06296
10.80711
11.54777
12.54340
13.54742
14.24713
15.30075
16.71002
18.31486
19.01428
20.35497
21.83626
23.43511
25.12759
26.77948
28.07784
29.68028
31.68475
33.46822
35.83360
37.85651
39.45132
41.87900
44.74463
47.05962

0.44138

0.56732

0.68903

0.68424

1.10126

1.90973

2.88962
3.82204

4.69186

5.50255

5.87865

6.24347

6.24347
6.61987

6.84201

7.23142

7.25844

7.80421

7.80421
8.56230

8.75814

8.75814
9.15419

9.03858

9.14815

8.93151

8.67603

.56734

8.41191
0.04217

0.04217
7.85186

7.79540

7.64012

7.33089

7.13436

6.95771

6.78836

6.61696

6.41088

6.11064

5.87217

5.69887

5.32653

5.32653

5.11566

4.84653

4.54282

4.34351
0.06019

.44138

0.06019

$.38196 \quad 0.35109$

$3.49322 \quad 0.50932$

1.22669

1.78713

2.46645

3.46645

3.25244

4.10735

5.03532

6.03712

7.09219

3.22568

9.41325

10.70815

10.70815

12.14639

13.63165

15.19754

16.67725

18.10597

19.43785

20.67711

21.86151

22.99057
23.84062

23.84062
26.62653

25.35645

26.04408

26.75165

27.39214

28.05162

28.71707

29.38295

30.03734

30.72321

31.40678

32.10658

32.79823

33.49921

34.27026

35.00723
35.74203

36.48462

37.18970
$1.69772 \quad 0.25163$ 


\section{GENERATING AND FUEL CYCLE COSTS (MILS/KWH)}

\begin{tabular}{|c|c|c|c|c|}
\hline YEAR & UCLWR & LWR.FCC & UCFBK & F BNFEC \\
\hline 1965 & 4.67780 & 1.96000 & 4.71455 & $1.3: 3 r c$ \\
\hline 1966 & 4.72420 & 1.90000 & 4.17295 & 1.354000 \\
\hline 1967 & 4.77620 & 1.96000 & 4.83332 & $1.3300 \%$ \\
\hline 1968 & 4.82600 & $1.960 \mathrm{co}$ & 4.90100 & 1.35000 \\
\hline 1969 & 4.88230 & 1.96000 & $4.9718 \mathrm{~B}$ & $1.3500^{\circ}$ \\
\hline 1970 & 4.65660 & 1.68850 & $4.0834 ?$ & 1. 62 \\
\hline 1971 & 4.71770 & 1.68830 & 4.750 .0 & $1.0101 \div$. \\
\hline 1972 & 4.78400 & 1.68850 & 4.84350 & 1.01005 \\
\hline 1973 & 4.84500 & 1.68850 & 4.92618 & 1.01000 \\
\hline 1974 & 4.91100 & 1.68850 & $5.0090^{\circ}$ & 1.010 .0 \\
\hline 1975 & 4.82380 & $1.545 \mathrm{Cr}$ & $4.9297 \%$ & $7.8600=$ \\
\hline 1976 & 4.71570 & 1.54500 & 4.80007 & 0.86000 \\
\hline 1977 & 4.63550 & 1.54500 & 4.69525 & $0.8600 \mathrm{r}$ \\
\hline 1978 & 4.55150 & $1.545 \mathrm{CC}$ & 4.59002 & 3.86000 \\
\hline 1979 & 4.47750 & 1.54500 & 4.49850 & $0.8600 \mathrm{C}$ \\
\hline 1980 & 4.28780 & $1.424 C 0$ & 4.26 .305 & 0.71000 \\
\hline 1981 & 4.23330 & $1.424 \mathrm{CO}$ & 4.19537 & $r .710 n$ \\
\hline 1982 & 4.18950 & 1.42400 & 4.14100 & 0.71000 \\
\hline 1983 & 4.15570 & 1.42400 & 4.09912 & 0.71000 \\
\hline 1984 & 4.12700 & 1.42400 & 4.00362 & C.71roo \\
\hline 1985 & 4.24400 & 1.57000 & 3.87975 & 0.56200 \\
\hline 1986 & 4.22190 & 1.57000 & 3.85260 & 0.56200 \\
\hline 1987 & 4.20090 & 1.57000 & 3.82670 & 0.56200 \\
\hline 1988 & 4.18200 & 1.57000 & 3.80350 & $0.582 \mathrm{cn}^{n}$ \\
\hline 1989 & 4.16300 & $1.570 \mathrm{Co}$ & 3.78017 & 0.56200 \\
\hline 1990 & 4.14920 & 1.57000 & 3.76330 & 0.54270 \\
\hline 1991 & $4.18 C 20$ & 1.62000 & 3.59595 & $0.4030 \mathrm{n}$ \\
\hline 1992 & 4.16420 & 1.62000 & 3.56635 & $0.408 \%$, \\
\hline 1993 & 4.14720 & $1.6200 \mathrm{C}$ & 3.24550 & Controt \\
\hline 1994 & 4.13640 & 1.6 .000 & $3.54+i$ & $\therefore 40$ \\
\hline 1995 & 4.11930 & $1.620 \mathrm{CC}$ & 3.51142 & 0.40000 \\
\hline 1996 & 4.15550 & 1.67000 & 3.45155 & 0.30500 \\
\hline 1997 & 4.14350 & 1.67000 & 3.43695 & 0.36500 \\
\hline 1998 & 4.13250 & 1.67000 & 3.42362 & 0.36500 \\
\hline 1999 & 4.12160 & 1.67000 & 3.41037 & $0.3650 ?$ \\
\hline 2000 & 4.11000 & 1.67000 & 3.39625 & 0.3650 \\
\hline 2001 & 4.22770 & 1.80000 & 3.32532 & 0.30900 \\
\hline 2002 & 4.21970 & 1.80000 & 3.31570 & 0.30500 \\
\hline 2003 & 4.20780 & $1.800 \mathrm{CC}$ & 3.30125 & 0.30900 \\
\hline 2004 & 4.19880 & 1.80000 & 3.29937 & 0.30900 \\
\hline 2005 & 4.19080 & $1.8 \mathrm{CCCO}$ & 3.28080 & 0.30900 \\
\hline 2006 & 4.24600 & 1.86800 & 3.24120 & 0.28500 \\
\hline 2007 & 4.23790 & 1.86800 & 3.23145 & 0.28520 \\
\hline 2008 & 4.22610 & $1.868 \mathrm{CC}$ & 3.21710 & 0.28500 \\
\hline 2009 & 4.21710 & 1.86800 & 3.20625 & 0.28500 \\
\hline 2010 & 4.20820 & 1.86800 & $3.1955 \mathrm{C}$ & 0.28500 \\
\hline
\end{tabular}




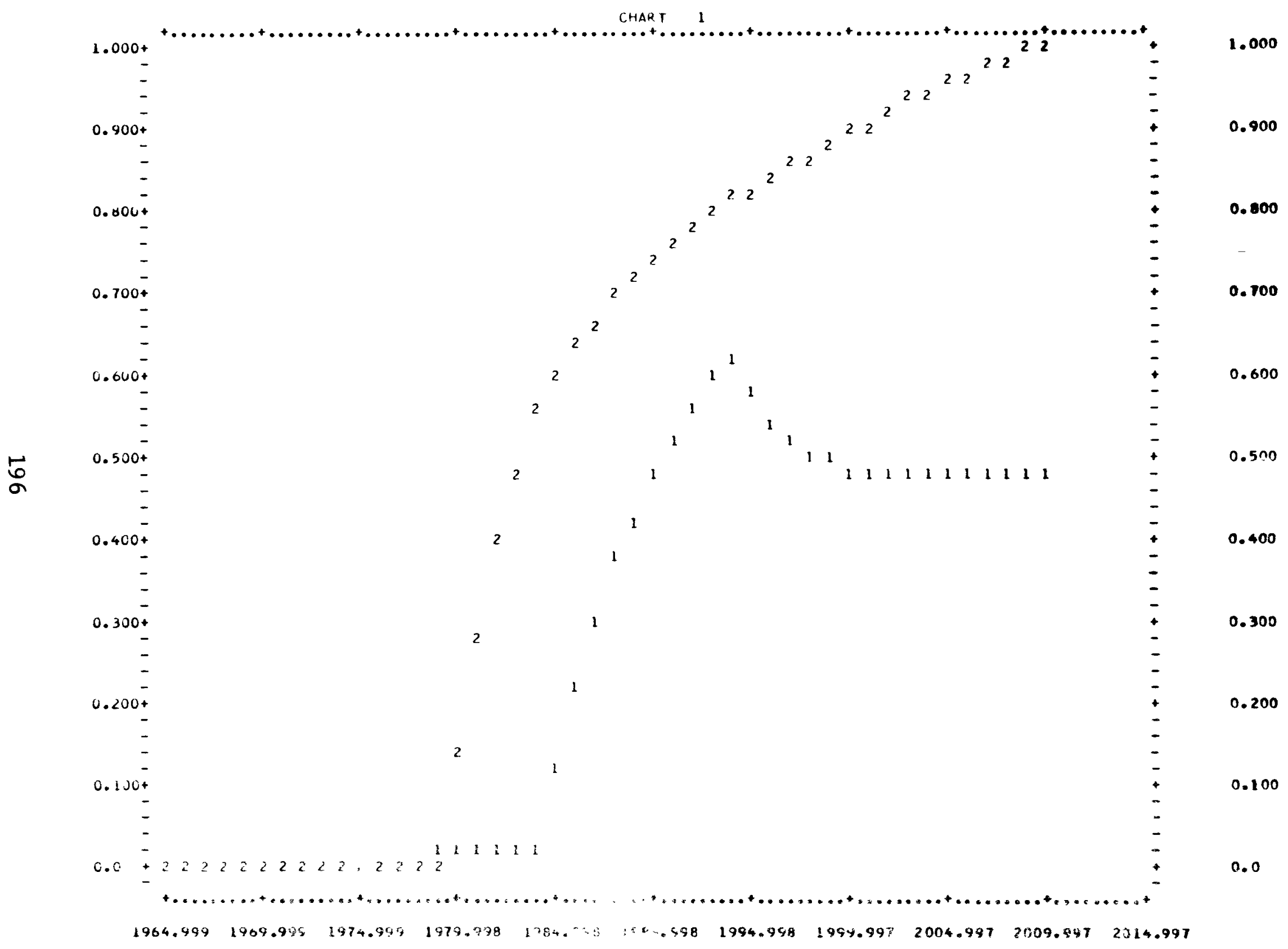




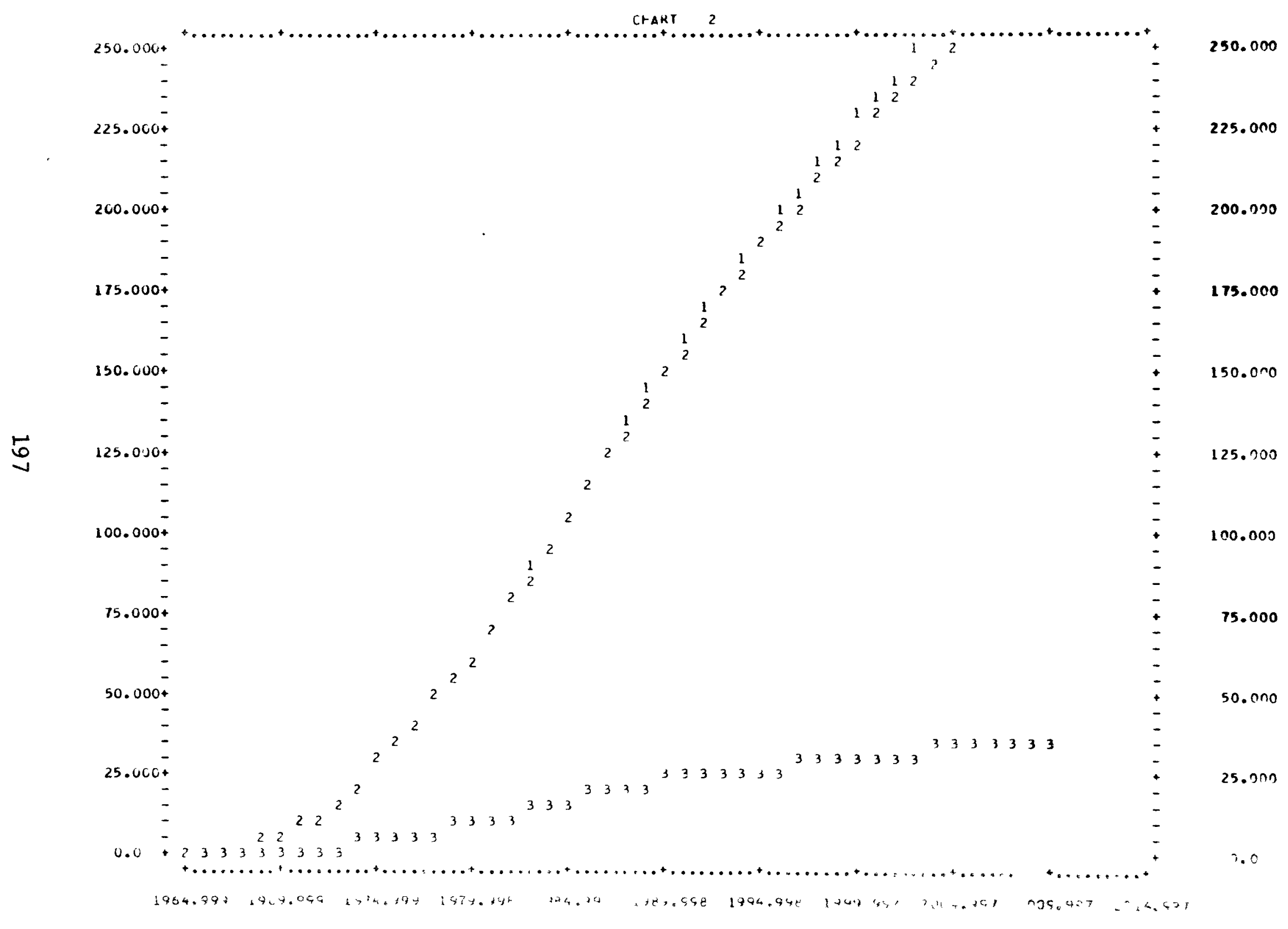




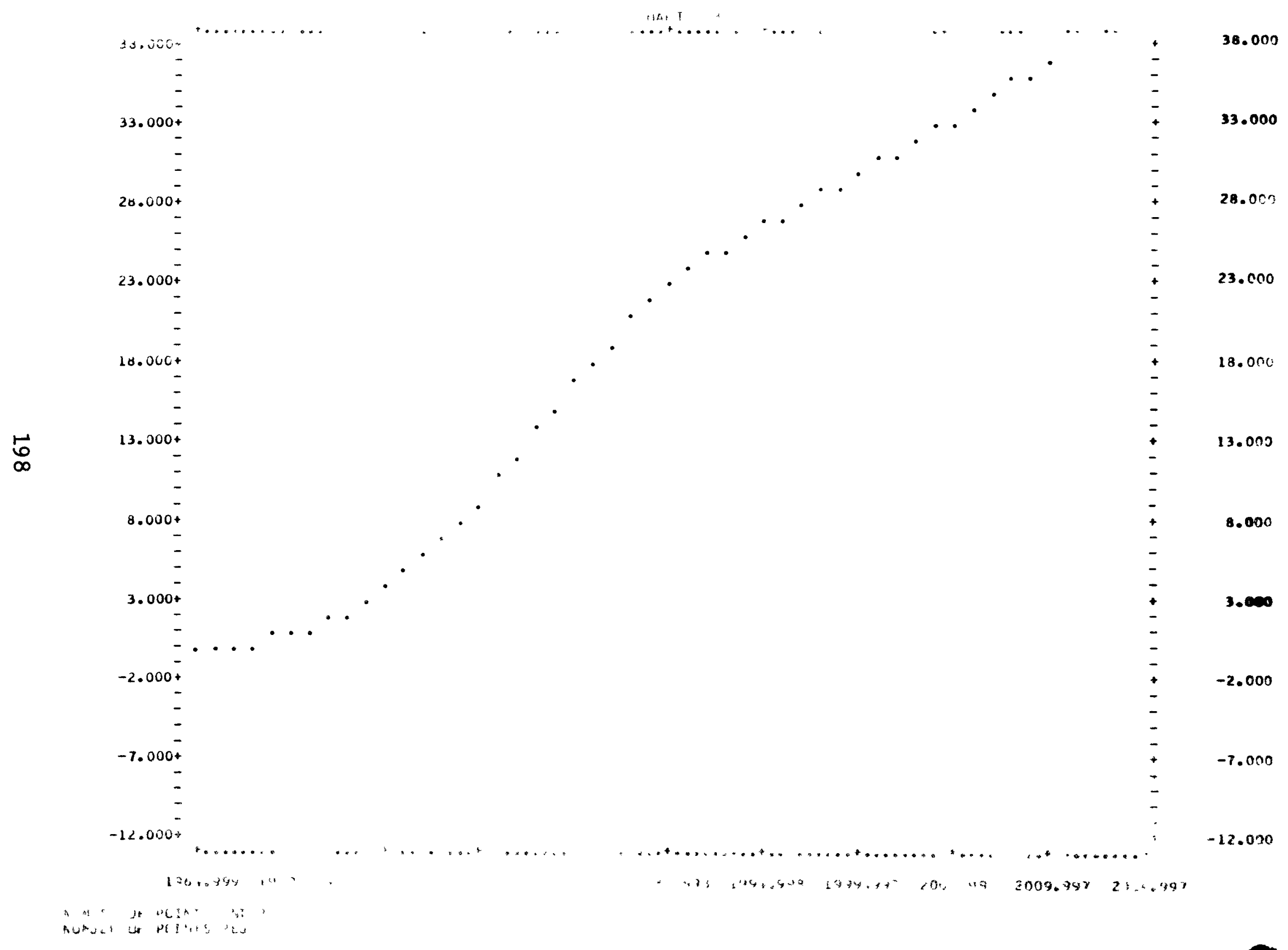

